DOI: $10.24275 /$ uama.5812.7539

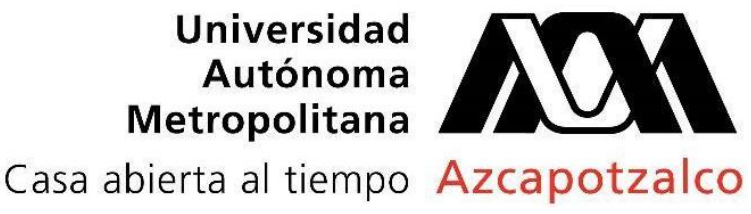

DIVISIÓN DE CIENCIAS Y ARTES PARA EL DISEÑO

Especialización, Maestría y Doctorado en Diseño

\title{
DIRECTRICES PARA EL DESARROLLO DE LA INTERFAZ GRÁFICA DE UN SISTEMA E-HEALTH QUE FACILITE LA VISUALIZACIÓN E INTERPRETACIÓN DE LOS DATOS RELATIVOS A LOS PRÓDROMOS DE EPISODIOS EN PACIENTES CON ALZHEIMER
}

\section{Mónica Yazmín López López}

Tesis para optar por el grado de Maestra en Diseño Posgrado en Diseño y Visualización de la Información

Miembros del Jurado:

Dra. Marcela Esperanza Buitrón de la Torre Directora de la tesis

Dr. Edwing Antonio Almeida Calderón Co-director de la tesis

Dra. Yadira Alatriste Martínez Dra. Andrea Perinetti Mtro. Jonathan Adán Ríos Flores 


\section{ASESORES DE LA TESIS}

Dra. en Ingeniería Multimedia Yadira Alatriste Martínez - Universitat Politèctina de Cataluya, España.

Dr. en Desarrollo de Productos Edwing Antonio Almeida Calderón - UAM Azcapotzalco, México.

Dra. en Diseño larene Argelia Tovar Romero - UAM Azcapotzalco, México.

Mtro. en Creatividad para el Diseño Jonathan Adán Ríos Flores - UNAM, México.

DCG. Pamela Coronel Tovar - UAM Azcapotzalco, México.

DCG. Omar Antonio Sánchez Rumbo - UAM Azcapotzalco, México.

DCG. Diana Marina Pérez Peña - UAM Azcapotzalco, México.

DCG. Francisco Javier Chávez Barrios - UAM Azcapotzalco, México.

Mtra. en Epidemiología General Andrea Perinetti - Fundação Oswaldo Cruz, Brasil.

Esp. en Psiquiatría y Psicología Médica León Darío Torres - Universidad Nacional de Mar del Plata, Argentina.

Médico Cirujano César Rubén Pérez López - Universidad de Guanajuato, México.

Médico General Alfredo Rafael Fuentes Castellanos - Universidade Federal da integração Latinoamérica Foz do Iguaçu, Brasil.

Lic. en Enfermería y Obstetricia Flor Minea Zainos Díaz - UNAM, México.

Lic. en Ciencias de la Ocupación Humana Ana Belén Lazo Poveda - Universidad de Playa Ancha, Chile.

Psc. Clínico David Daniel Castro Nieto - Universidad Latinoamericana, México. 


\section{DEDICATORIA}

Quisiera dedicar esta tesis en orden de importancia:

Primeramente, quiero dedicar y agradecer a mi Dios ya que a Él le debo todo lo que tengo y todo lo que soy.

A mis padres -Adolfo y Martha- y a mi hermano -Edgar-, quienes con su amor, apoyo y paciencia infinita e incondicional me han guiado y me han alentado a cumplir mis sueños.

A mis amigos quienes siempre han creído en mí y han estado ahí para enseñarme a ver todo el potencial que hay en mí.

A todos ustedes, todos mis logros también les pertenecen.

Cuando pareciera que las palabras faltan es porque la gratitud infinita no debería ser limitada a estas. Gracias por tanto, perdón por tan poco. 


\section{AGRADECIMIENTOS}

Esta tesis es un producto de colaboración de muchas personas e instancias a las cuales quiero agradecer ya que sin su apoyo no hubiera podido ser:

A mi directora Marcela Buitrón, porque esta tesis es de ambas, es esfuerzo y colaboración en conjunto, gracias a ti que lograbas entenderme cuando ni yo misma lo hacía, por motivarme una y otra vez así como por enseñarme a poner los pies sobre la Tierra sin dejar de soñar.

A mi co-director Edwing Almeida, gracias por compartirme de tu conocimiento y de tu amor al mundo del Internet de las Cosas, así como por insertarme en este maravilloso universo del e-Health, pero por encima de todo, gracias por siempre ver potencial en mí.

A mi asesora Yadira Alatriste, porque me has dado conocimientos muy valiosos como profesional y sobre todo como persona, eres en mi vida un gran ejemplo y motivación.

A mi asesor Adán Ríos por guiarme y compartirme de tu sabiduría, pero principalmente por rescatarme de las múltiples crisis y por enseñarme a ver más allá de la obviedad de las cosas y dotarlas de un significado diferente y más profundo.

A mi asesora Andrea Perinetti, porque se interesó desde el principio en mi proyecto, no dudó en brindarme su apoyo y orientación para que esta tesis fuera un mejor resultado, asimismo agradezco por sus hermosas palabras que me llegaron al corazón justo cuando más lo necesitaba y me permitieron recuperar un poco de la confianza perdida en mí.

A mis colegas y amigos que también sería correcto llamarlos mis alentadores constantes, larene Tovar, Pamela Coronel, Diana Pérez, Antonio Sánchez y Javier Chávez, gracias por colaborar en este proyecto, por compartir sus conocimientos en el ámbito del diseño, por darme sus observaciones y sus comentarios siempre objetivos, los cuales me han permitido crecer en mi papel profesional, así mismo quiero agradecer por incitarme a seguir cuando estaba con la creatividad en cero y a punto de no poder más.

A mis amigos Flor Zaínos, César Pérez, Alfredo Fuentes y Belén Lazo quienes me guiaron en el ámbito médico, sin importar sus apretadas agendas y a pesar de su poco tiempo libre, siempre dedicaron tiempo para mí, gracias, sus conocimientos resultaron fundamentales para esta tesis. 
A todos los cuidadores de pacientes de Alzheimer, quienes me abrieron su corazón, para compartir conmigo sus experiencias acerca de su hermosa labor, los admiro y respeto en gran manera, gracias por enriquecer este proyecto.

A la Fundación Alzheimer Alguien con quien contar I.A.P. ya que me abrieron las puertas y me brindaron conocimientos esenciales para esta investigación.

Al Área de Investigación de Nuevas Tecnologías y a sus miembros, porque más que compañeros de trabajo, hemos desarrollado una amistad significativa.

A la UAM-Azcapotzalco por ser mi amada alma mater, a la cual le agradezco por haberme brindado tanto conocimiento, experiencias y sobre todo personas maravillosas.

A todos gracias, por acompañarme y por ser parte de este proyecto. 


\section{RESUMEN}

La enfermedad de Alzheimer es una enfermedad neurodegenerativa, en constante aumento, que aqueja a millones de personas en México. Esta enfermedad no tiene cura y aquellos que la padecen requieren de cuidados especializados que, debido a la insuficiente cantidad de personal capacitado así como de instituciones de salud enfocadas a su detección y tratamiento, son proporcionados habitualmente por sus familiares y desde sus hogares, no contando con la infraestructura ni los conocimientos necesarios para ello, derivando en un inadecuado manejo y control de los pródromos que preceden a los episodios que caracterizan a esta demencia.

Actualmente, existen tratamientos que, apoyados por la tecnología, ayudan a retrasar la aparición y control de los síntomas en quienes la padecen, mejorando la calidad de vida tanto del paciente como la de sus cuidadores. Así, puede hablarse de los sistemas e-Health, los cuales hacen posible un cuidado y monitoreo eficiente de los pacientes desde su lugar de residencia y por las personas que son sus responsables.

Dicha situación da cabida a la presente investigación, la cual -basada en la definición de directrices de diseño y visualización de la información, como parte de una estrategia de diseñovalidó la hipótesis que refiere a su aplicación en el diseño de interfaces gráficas para sistemas eHealth, de manera que éstas faciliten la visualización e interpretación de datos relativos a los pródromos en pacientes con Alzheimer. El presente documento hace referencia al desarrollo del proyecto. 


\section{ÍNDICE}



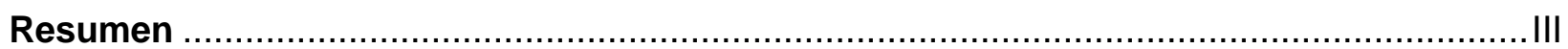



\section{Capítulo 1. El Alzheimer}

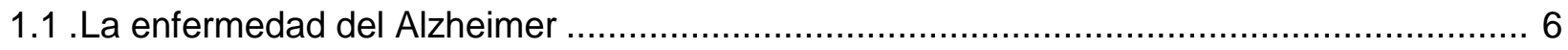

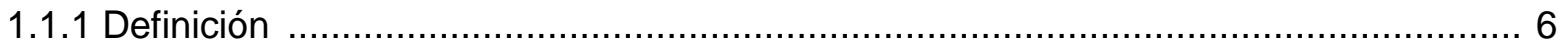

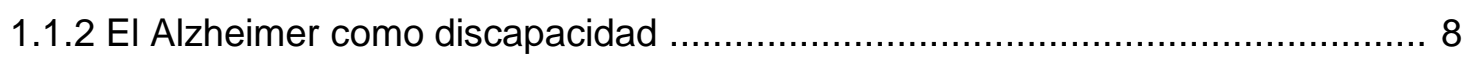

1.1.3 El Alzheimer a nivel mundial ............................................................ 9

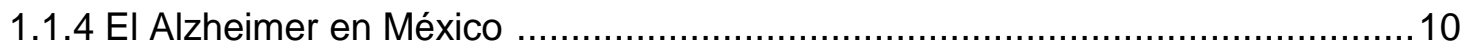

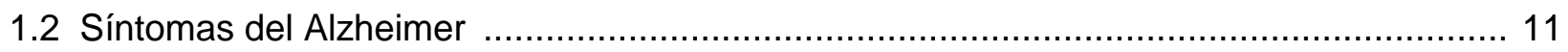

1.2.1 Clasificación y manifestaciones ……………................................................. 11

1.2.2 Pródromos de episodios de Alzheimer .............................................................. 14

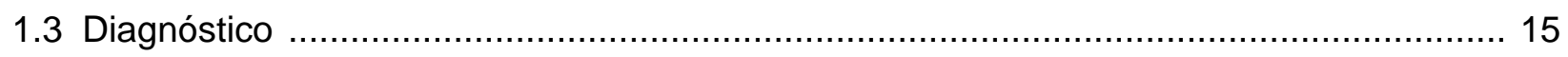

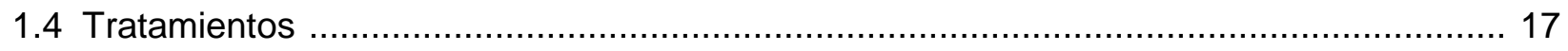

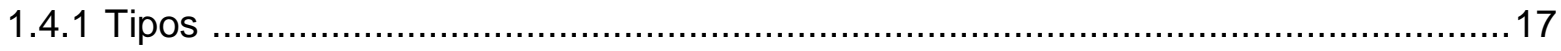

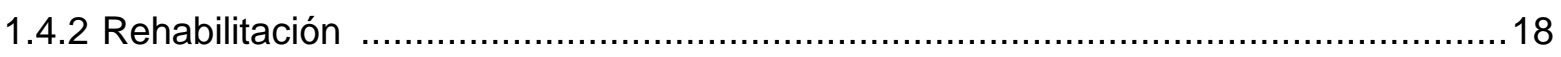

1.4.3 El papel de los médicos y cuidadores en el tratamiento de la EA …...................... 19

1.5 La influencia de la tecnología en el tratamiento de la enfermedad del Alzheimer .............. 21

Capítulo 2. El Internet de las Cosas y su impacto en el tratamiento del Alzheimer

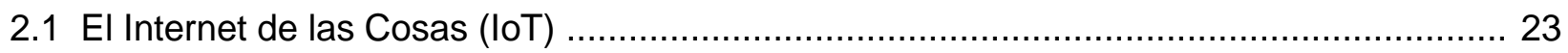

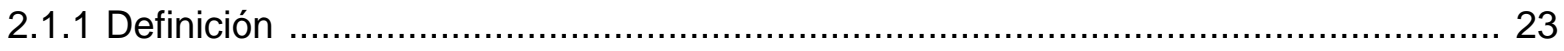




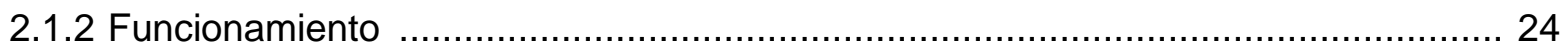

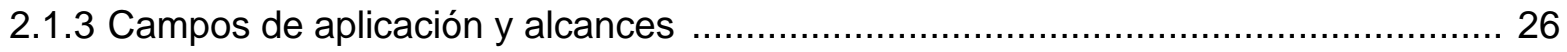



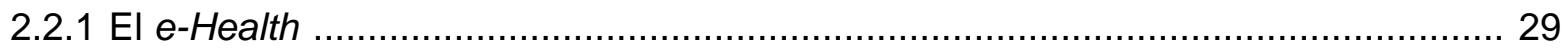

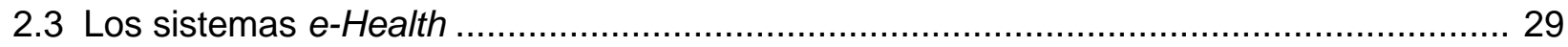



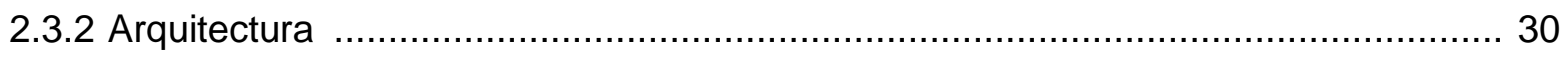

2.3.3 Los sistemas e-Health bajo la conciencia del contexto ........................................ 32

2.4 El impacto de los sistemas e-Health en el manejo de la enfermedad del Alzheimer ......... 32

\section{Capítulo 3. Diseño y visualización de la información en interfaces gráficas}

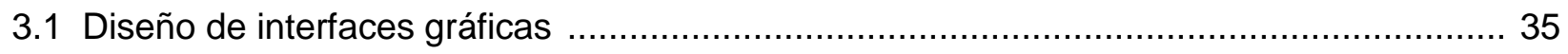

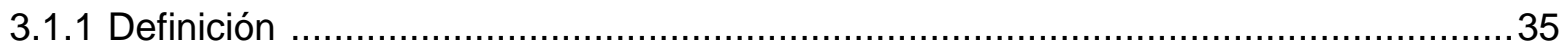

3.1.2 Consideraciones para el diseño de interfaces gráficas ……................................. 36

3.2 Fundamentos sobre diseño y visualización de la información para diseñar interfaces gráficas ……..................................................................... 39

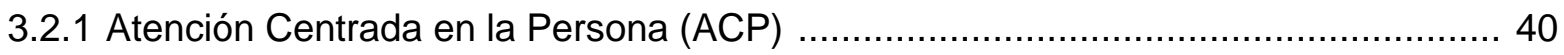

3.2.2 Modelo de Diseño Centrado en el Usuario (DCU) ..............................................40

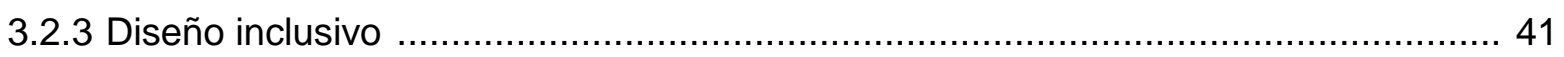

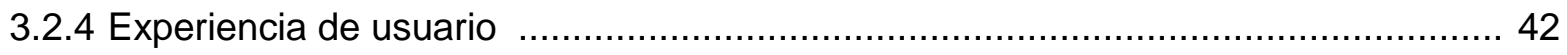

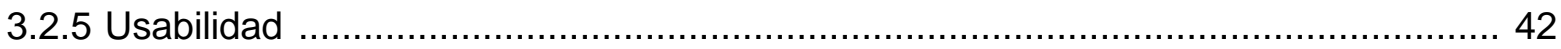

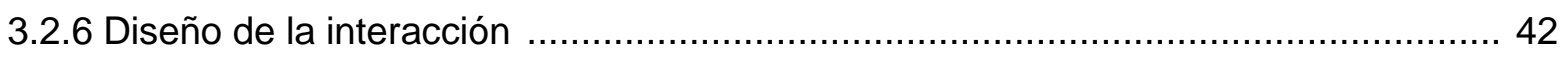

3.2.7 Diseño de la comunicación gráfica ................................................................ 43

3.3 Diseño de interfaces gráficas para un sistema e-Health ..............................................4 


\section{Capítulo 4. Directrices para el desarrollo de la interfaz gráfica de un sistema e-Health.}

Un caso de estudio.

4.1 Estrategia para el diseño de la interfaz gráfica del sistema e-Health .............................. 46

4.2 Directrices para el diseño de una interfaz gráfica para sistemas e-Health ........................ 46

Capítulo 5: Metodología de investigación

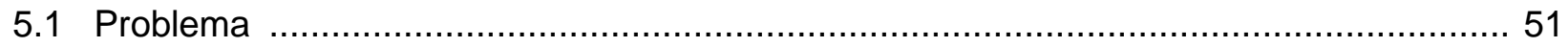

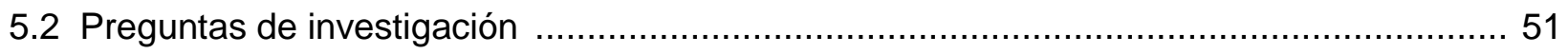



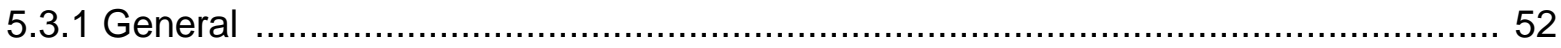

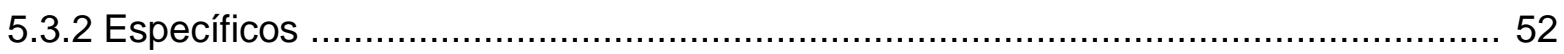

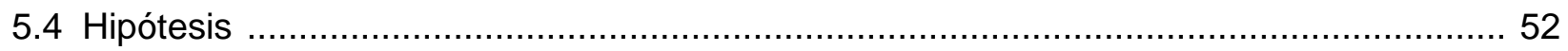

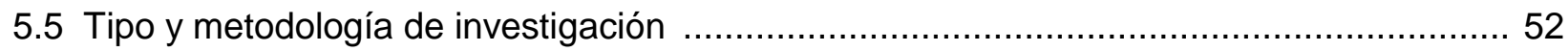

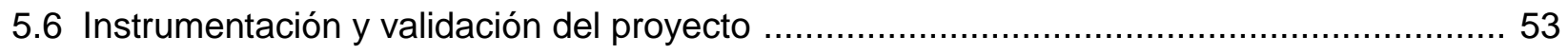

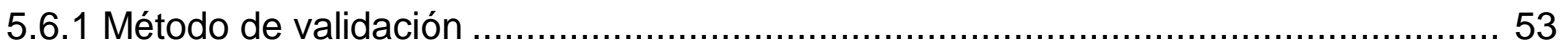

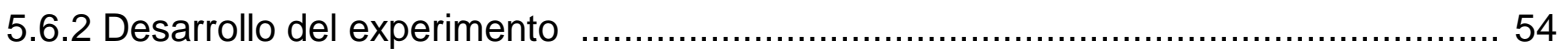

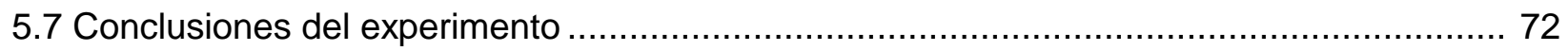

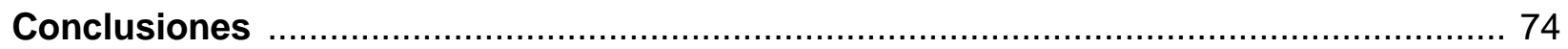

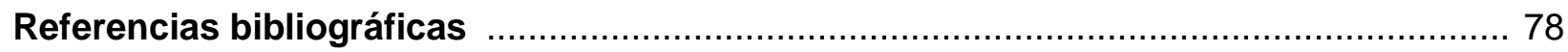

\section{Anexos}

Anexo I. Encuesta del estudio exploratorio inicial de la investigación .................................. 90

Anexo II. Diseño y desarrollo del prototipo de la interfaz gráfica de la CENTINEL App ........... 93

Anexo III. Análisis de datos obtenidos de la aplicación de los instrumentos de validación ..... 100

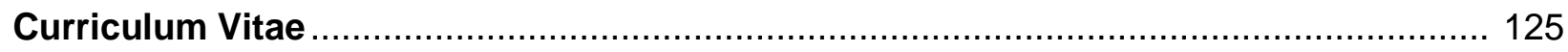




\section{ÍNDICE DE TABLAS Y FIGURAS}

\section{Capítulo 1. El Alzheimer}

Tabla 1.1 Instrumento de medición del estadio en el Alzheimer

a partir de la vigilancia que el paciente requiere

\section{Capítulo 2. El Internet de las Cosas y su impacto en el tratamiento del Alzheimer}

Figura 2.1 Paradigma del Internet de las Cosas como resultado

de la convergencia de diferentes visiones

Tabla 2.1 Arquitectura loT de cuatro capas

Figura 2.2 Ámbitos que conforman un sistema e-Health

Figura 2.3 Pertenencia de cada capa al ámbito de un sistema e-Health

Capítulo 4. Directrices para el desarrollo de la interfaz gráfica de un sistema e-Health. Un caso de estudio

Figura 4.1 Estrategias para el desarrollo de un sistema e-Health

Figura 4.2 Directrices que conforman la estrategia de diseño de interfaz gráfica

para un sistema e-Health

Figura 4.3 Prototipo de interfaz gráfica para el sistema e-Health CENTINEL App

\section{Capítulo 5. Metodología de investigación}

Figura 5.1 Etapas de un análisis Delphi en el estudio de los intangibles

Figura 5.2 Cuestionario (R.1)

Figura 5.3 Envío de correo electrónico a expertos (R.1) 63

Tabla 5.1 Tabla de resultados (R.1) 64

Tabla 5.2 Valores para la codificación de datos 65 
Figura 5.4 Análisis e interpretación de los datos obtenidos

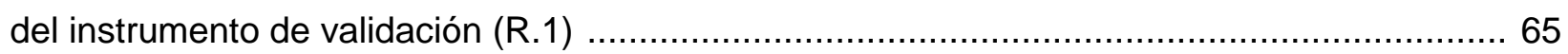



Figura 5.6 Correo electrónico para el Cuestionario (R.2) ...................................................6

Figura 5.7 Feedback de los resultados del análisis de las respuestas

del instrumento previo y justificación de la segunda validación ............................................69

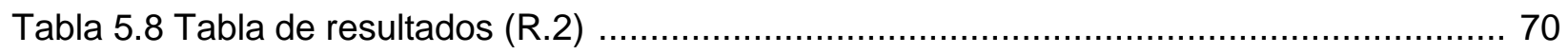

Figura 5.8 Análisis e interpretación de los datos obtenidos

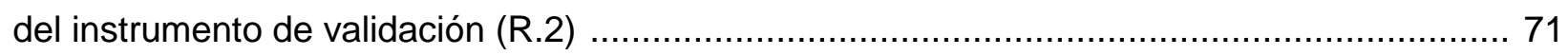

Anexos

Anexo I. Encuesta del estudio exploratorio inicial de la investigación

Figura Al.1 Encuesta semiestructurada ..................................................................... 90

Anexo II. Diseño y desarrollo del prototipo de la interfaz gráfica de la CENTINEL App

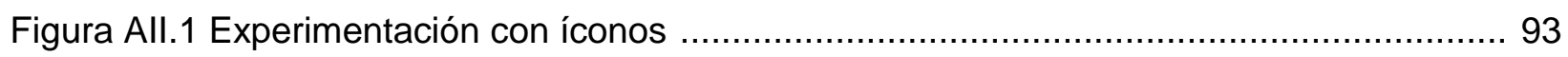

Figura All.2 Experimentación con fuentes e íconos ..................................................... 93

Figura All.3 Matices y variaciones lumínicas ………........................................................ 94

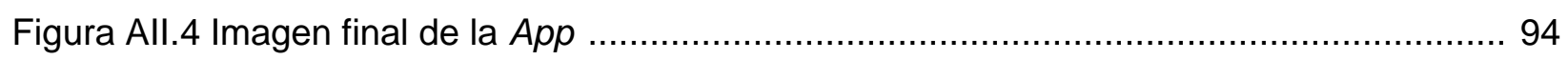

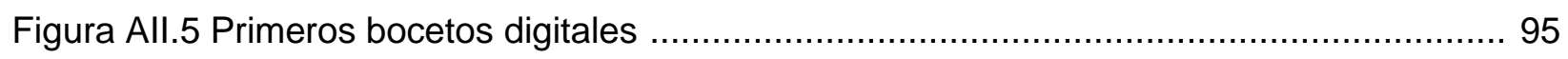

Figura All.6 Pantallas que conforman la interfaz gráfica de la App ...................................... 96

Figura All.7 Prototipo de CENTINEL App en InVision ....................................................... 96

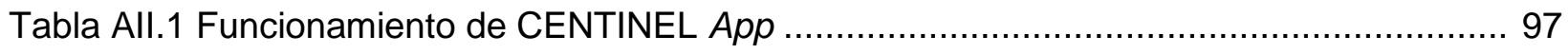




\section{INTRODUCCIÓN}

La Enfermedad del Alzheimer (EA) es una enfermedad neurodegenerativa, cada vez más común

y en constante aumento, que aqueja a millones de personas a nivel mundial. Esta enfermedad no tiene cura; sin embargo, hoy en día existen tratamientos que ayudan a retrasar la aparición y control de los síntomas en quienes la padecen.

Pese a ello, este tipo de demencia requiere de cuidados especializados, que en la mayoría de los casos, suelen ser deficientes debido a una insuficiente cantidad de personal capacitado así como de instituciones de salud enfocadas a la detección y tratamiento del padecimiento.

Esta situación ha generado que un alto porcentaje de pacientes con EA en México sean tratados desde sus hogares por sus propios familiares, quienes generalmente no cuentan con la infraestructura ni los conocimientos necesarios, derivando en un inadecuado manejo y control de los pródromos que preceden a los episodios que caracterizan a la enfermedad, entre otros síntomas del padecimiento, $y$, por ende, en la deficiente calidad de vida tanto del paciente como la de sus cuidadores.

Ante dicha problemática social, las tecnologías adquieren una importancia relevante debido a que proporcionan alternativas significativas al tratamiento y cuidado de los pacientes con EA. Así, actualmente se pueden encontrar a los llamados sistemas e-Health -conjunto de elementos interconectados entre sí y con el contexto que los rodea, gracias a la aplicación del paradigma del Internet de las Cosas-, los cuales hacen posible un cuidado y monitoreo más eficiente de los pacientes desde su lugar de residencia por parte de sus familiares y cuidadores, además de facilitar el seguimiento por parte de sus médicos.

Si bien, desde hace algún tiempo, se han implementado diversos tipos de sistemas e-Health en apoyo a pacientes con EA, aún resulta incipiente el desarrollo y aplicación de estas herramientas tecnológicas que, en su mayoría, dan respuesta a cuestiones relacionadas con la estimulación cognitiva del paciente así como con la administración de los cuidados.

En México, aún no se documenta el desarrollo de sistemas e-Health que permitan a los cuidadores monitorear, desde casa, al paciente con EA, con el objetivo de identificar los pródromos o síntomas que preceden a los episodios de la enfermedad. 
Se requiere, así, la realización de investigaciones que permitan determinar las condiciones bajo las cuales se puedan desarrollar adecuadas interfaces gráficas de dichos sistemas, en virtud de que estas serán las que le permitirán al cuidador visualizar e interpretar los datos relativos a la presencia de pródromos de episodios en pacientes con EA y, con ello, anticipar y, en el mejor de los casos, evitar la crisis.

Bajo esas consideraciones, se planteó este proyecto de investigación, con base en la definición de las siguientes interrogantes: ¿Cómo la tecnología y, en particular, el Internet de las Cosas pueden influir en el ámbito médico?, ¿De qué manera el diseño de la visualización de la información puede aportar al ámbito médico?, ¿Cuáles son las estrategias que harían posible el desarrollo de un sistema e-Health?, ¿Podría la implementación de un sistema e-Health apoyar al monitoreo y tratamiento de pacientes con Alzheimer? y, finalmente, ¿El diseño y visualización de la información influye en el desarrollo de interfaces gráficas de sistemas e-Health que posibiliten la adecuada interpretación gráfica de datos proporcionados acerca de pródromos en episodios de Alzheimer?

Para responder dichas interrogantes se estableció como hipótesis de investigación que el desarrollo de la interfaz gráfica de un sistema e-Health orientado a la enfermedad de Alzheimer basado en directrices propias del diseño y la visualización de la información y su relación con el ámbito de salud y la tecnología- permitirá al usuario visualizar y, con ello, interpretar, de manera más eficiente, los datos relativos a los pródromos de episodios de pacientes con esta enfermedad.

La validación de dicha hipótesis implicó, como objetivo de la investigación establecer una serie de directrices -propias del diseño y la visualización de la información y su relación con el ámbito de salud y la tecnología- para el desarrollo de la interfaz gráfica de un sistema e-Health conformado por un dispositivo vestible provisto de sensores y una App para su interacción-que facilitara la visualización e interpretación de datos relativos a los pródromos de episodios de pacientes con la enfermedad del Alzheimer, a través de esta.

El presente documento hace referencia al desarrollo y resultados obtenidos de la investigación, dividiéndose en 5 capítulos:

El primer capítulo, con el fin de contextualizar la investigación, hace referencia a la enfermedad del Alzheimer, definiendo su clasificación, síntomas, manifestaciones, diagnóstico y tratamiento, haciendo énfasis en la definición de los pródromos de episodios de la enfermedad y el papel relevante que tienen -en México- los familiares y cuidadores 
así como la tecnología en el cuidado y monitoreo de quienes la padecen. Además, hace mención del estudio cuali-cuantitativo que permitió incorporar las experiencias y saberes empíricos de quienes conviven con las personas con EA, a partir de las cuales se definirían los síntomas prodrómicos más frecuentes.

En el segundo capítulo se describe la importancia de la tecnología -haciendo hincapié en el paradigma del Internet de las Cosas- en el tratamiento del Alzheimer, definiendo al paradigma del loT, su funcionamiento, campos de aplicación así como la importancia de su aplicación en el ámbito médico. Además, se definen los sistemas e-Health y su impacto en el manejo de la enfermedad del Alzheimer.

El tercer capítulo contempla la definición de aspectos relativos al diseño de la interfaz gráfica de un sistema e-Health, considerando fundamentos tales como: la Atención Centrada en la Persona (ACP), el modelo de Diseño Centrado en el Usuario (DCU), el diseño inclusivo, la experiencia del usuario, la usabilidad, el diseño de la interacción así como el diseño de la comunicación gráfica, dentro del contexto tecnológico y sanitario establecido, derivando en la identificación de directrices propias para su desarrollo.

En el cuarto capítulo se establece la estrategia al igual que las directrices propias para el desarrollo de la interfaz gráfica de un sistema e-Health relativo a la EA que, como caso de estudio, permita visualizar e identificar fácilmente los datos de pródromos de episodios de la enfermedad.

El quinto capítulo plantea la metodología de investigación, a partir de la definición de la problemática así como los objetivos e hipótesis de esta, determinando el tipo de estudio así como las etapas para el desarrollo del análisis estadístico que dio cabida a la validación de la hipótesis planteada, aportando con ello resultados a la investigación.

Posteriormente, se incluye un apartado de conclusiones en torno a los resultados obtenidos, incluyendo los aportes de la investigación al campo del conocimiento así como la prospectiva de la misma.

Por último, se incluyen como anexos los instrumentos del estudio exploratorio inicial de la investigación que da sustento a la definición de los síntomas prodrómicos de la EA (Anexo I), el diseño y el desarrollo del prototipo de la interfaz gráfica -CENTINEL App- (Anexo II) 
de la misma forma que el análisis de datos obtenidos de la aplicación de los instrumentos de validación (Anexo III).

Con lo anterior, esta investigación pretende contribuir al campo del Diseño y el e-Health con la definición, por un lado, de una serie de directrices -propias del diseño y la visualización de la información y su relación con el ámbito de salud y la tecnología- que permitan desarrollar interfaces gráficas para sistemas e-Health que faciliten la visualización e interpretación de los datos, en ella, presentados y, por otro lado, de un proceso de validación de interfaces gráficas.

Con dichas acciones, esta investigación contempló la definición de una de las tres estrategias que definen el desarrollo de un sistema e-Health, pretendiendo ser un parteaguas para futuras investigaciones que consideren, en su totalidad, los ámbitos de salud y tecnología restantes, abriendo la posibilidad a nuevos proyectos con relación a la creación de sistemas e-Health.

Finalmente, cabe mencionar que, a pesar de haberse cumplido los objetivos, se buscará la adecuación de las directrices de diseño propuestas de manera que cumplan de mejor manera sus objetivos y, con ello, cubran en su totalidad las necesidades de diseño y visualización que requiere la interpretación de información, dando cabida a una expansión y/o generalización de estas para ser un paradigma en el campo del diseño y el e-Health. 
CAPÍTULO 1 El Alzheimer 


\section{CAPÍTULO 1. EL ALZHEIMER}

\subsection{La enfermedad del Alzheimer}

\subsubsection{Definición}

Los trastornos neurológicos, según la Organización Mundial de la Salud (OMS) (2016), son padecimientos del sistema nervioso central y periférico dentro de los que se encuentran las llamadas enfermedades neurodegenerativas. Estas enfermedades se caracterizan por la muerte progresiva de células del sistema nervioso central de los pacientes causando, en la mayoría de los casos, lo que se conoce como demencia.

La demencia ${ }^{1}$ es un síndrome de naturaleza crónica o progresiva caracterizado por el deterioro de la función cognitiva o capacidad para procesar el pensamiento más allá de lo que podría considerarse una consecuencia del envejecimiento normal, y de acuerdo con la OMS (2019), una de las principales causas de discapacidad y dependencia entre las personas mayores en el mundo entero.

"En toda demencia, independiente de su etiología², se afectan las habilidades cognitivas, se altera la conducta y se pierde progresivamente la funcionalidad, entendiendo por esta última aquella capacidad para cumplir o realizar determinadas acciones, actividades o tareas de diversa complejidad en la vida cotidiana." (Fuentes, P. 2008).

Muchas enfermedades pueden causar demencia, como la enfermedad del Alzheimer (EA) ${ }^{3}$, que es un padecimiento neurodegenerativo que representa casi el $70 \%$ de las demencias a nivel mundial (OMS, 2020). Cabe señalar que no todas las personas con demencia tienen Alzheimer, pero sí que todas las personas con Alzheimer terminarán desarrollando, inevitablemente, demencia. (Chappotin, 2019).

Es importante comprender que la demencia no es una enfermedad en sí, más bien es la existencia de algunos síntomas que determinan el cuadro de demencia.

2 De acuerdo con la Real Academia Española, es el estudio de las causas de las enfermedades. (2020).

3 Esta demencia tomó su nombre del neurólogo alemán Alois Alzheimer, quien -en 1906- observó cambios anormales en el tejido cerebral de una mujer que había muerto, lo cual le llevó a pensar que sufría de una enfermedad mental extraña. Estos cambios observados en el tejido cerebral corresponden a signos característicos de esta demencia. (Fraile, M., 2019). 
La enfermedad del Alzheimer ${ }^{4}$ es producida por la pérdida progresiva de las neuronas o muerte neuronal en regiones selectivas así como por la pérdida de sinapsis provocando que el sistema nervioso no pueda realizar su función con normalidad.

Se presenta principalmente en personas mayores de 60 años, teniendo factores de riesgo hereditarios (IMSS, 2015); sin embargo, es fundamental considerar que esta enfermedad no es resultado del envejecimiento normal (Falgàs, Sánchez-Valle y Barreriro, 2018) ni exclusivo de la vejez, dado que también puede afectar a personas jóvenes (Alzheimer de inicio temprano o de inicio precoz).

Su principal característica corresponde al deterioro progresivo de las funciones cognitivas procesos mentales que permiten recibir, seleccionar, almacenar, transformar, elaborar y recuperar la información del entorno que nos rodea, así como las capacidades que permiten adaptarse para dar respuestas a las exigencias de este- lo cual trae, como consecuencia, cambios en el comportamiento intelectual, además de las fallas en la orientación y la memoria, síntomas que producen que el paciente requiera de cuidados especiales. (Fraile, 2019).

Los síntomas más comunes de esta enfermedad, según Brigh Focus Fundation (2017), son: pérdida de memoria, trastornos del lenguaje que impiden llamar a las cosas por su nombre (anomia), problemas de orientación y atención, bajo nivel de energía e incapacidad de resolver operaciones aritméticas sencillas, entre otras.

Cabe mencionar que el inicio de la EA se produce mucho antes de lo que se piensa, presentando, aquellos que la padecen, daños en el cerebro de 15 a 20 años antes de que los primeros síntomas aparezcan. (Reinosa, A., 2018).

De acuerdo con la Alzheimer's Association (2018), las personas diagnosticadas con la EA viven un promedio de 8 años después de que los síntomas se vuelven evidentes, aunque la

4 L. Rodríguez (2018) señala que la EA es producida por dos estructuras anormales llamadas ovillos y placas, siendo estas las principales en dañar y matar las células del sistema nervioso. Estas estructuras se generan porque las proteínas TAU -proteína que ayuda a mantener la estructura de la neurona, encargada de transportar nutrientes esenciales al interior de esta- y betaamiloide van formando acumulaciones tóxicas en el cerebro, lo cual hace que terminen dañando a las neuronas. Durante la EA, la proteína TAU sufre de un proceso anormal que hace que pierda su estructura natural y forme ovillos dentro de las células; esos ovillos, entre otras consecuencias, hacen que las neuronas no puedan obtener nutrientes fundamentales para su capacidad para trabajar, haciendo que el daño se extienda y, con ello, que esta capacidad se vaya perdiendo hasta que, finalmente, mueran. Mientras la TAU se acumula dentro de las células, la sustancia beta-amiloide lo hace afuera, generando placas, por medio del acumulamiento de esta proteína en el espacio entre las neuronas, que impiden que estas se comuniquen entre sí. Las placas y los ovillos tienden a propagarse a través de la corteza a medida que el Alzheimer avanza. 
supervivencia puede oscilar entre 4 y 20 años dependiendo de la edad del paciente, el manejo o tratamiento que se lleve de la enfermedad y de otras afecciones de salud que pueda presentar.

Este trastorno evoluciona, generalmente, a lo largo de siete fases ${ }^{5}$ de acuerdo con la Escala de Deterioro Global de Reisberg (GDS) (Reisberg, B. y Franssen, E., 1999), dando por consecuencia un deterioro gradual en todas las funciones intelectuales reflejadas en la autonomía e independencia del paciente.

La EA es una enfermedad que no tiene cura. Aun así, existen medicamentos enfocados en detener la muerte de las células cerebrales y aliviar los síntomas de la enfermedad, además de los tratamientos paliativos que permitan mejorar la calidad de vida de los pacientes.

Sin embargo, dado el inexorable curso de la enfermedad, el rol de los familiares y cuidadores es un factor decisivo en el largo proceso que deben transcurrir tanto las personas con EA como sus convivientes. Esto es debido a que, cuando el apoyo y cuidado son adecuados y sostenidos en el tiempo, facilitan la autonomía personal, la participación social y actúan como facilitadores de casi la totalidad de situaciones cotidianas que influyen decisivamente en la salud física así como en la salud psíquica de quienes padecen esta enfermedad. (Gay, et al., s.f.).

\subsubsection{El Alzheimer como discapacidad}

De acuerdo con la Fundación Alzheimer España (2015), “La Organización Mundial de la Salud llamó la atención sobre el hecho que la enfermedad de Alzheimer tenía que considerarse como una "discapacidad".

La OMS (2019) define la discapacidad ${ }^{6}$ como un término que abarca deficiencias, limitaciones de la actividad y restricciones de la participación ${ }^{7}$, por lo que la discapacidad resulta un fenómeno complejo que refleja una interacción entre las características del organismo humano y de la sociedad en la que este vive.

5 Las fases de evolución del Alzheimer, de acuerdo con Reisberg y Franssen (1999), son: Fase 1: Ausencia de alteración cognitiva (normal), Fase 2: Deterioro cognitivo muy leve o compatible con la edad, Fase 3: EA incipiente, Fase 4: EA leve, Fase 5: EA moderada, Fase 6: EA moderada-severa y Fase 7: EA severa.

6 En México, la definición de la Ley para las Personas con Discapacidad del Distrito Federal (1995) dice que la persona que padece esta corresponde a todo ser humano que padece temporal o permanentemente una disminución en sus facultades físicas, mentales o sensoriales que le impide realizar una actividad normal.

7 Las deficiencias son problemas que afectan a una estructura o función corporal, las limitaciones de la actividad son consideradas como dificultades para ejecutar acciones y tareas y las restricciones de la participación son tomadas en cuenta como problemas para participar en situaciones vitales. 
La discapacidad no corresponde a una entidad estática exclusiva de unos pocos, dado que todos los humanos pueden presentar alguna discapacidad, en algún periodo de su vida, por diversos motivos como la edad, las características consideradas distintas por los estándares o media de la población o por algún evento existencial, que puedan incapacitarlos durante un determinado tiempo para realizar algunas de sus actividades cotidianas. (García, D., 2014).

El grado de discapacidad de un individuo no sólo se encuentra dado por su déficit, sino que depende en gran medida del entorno social, cultural y de diseño en el que le ha tocado vivir. Por ello, se asevera que estos entornos pueden modificar el grado de discapacidad de las personas, es decir, puede aumentarlo o en el mejor de los casos reducirlo.

Hay una gran cantidad de clasificaciones de discapacidad, dependiendo del género, afección, edad, enfermedad, entre otras. Sin embargo, retomando lo mencionado por Herrera Lasso (2005), se puede hablar de discapacidad de origen congénito o adquirido, a su vez puede ser estable o progresiva.

Existen muchas enfermedades que pueden derivar en algún tipo de discapacidad. Pueden ser curables, controlables, crónicas o progresivas como lo es la EA. Esta patología se considera como una entidad que genera diversas deficiencias, limitación de la actividad, restricción de participación y pérdida de la autonomía, además de catalogarse como una discapacidad de origen adquirido y progresiva dado que, conforme las funciones cerebrales del paciente disminuyen, aumenta la pérdida y la afectación de las actividades diarias así como la pérdida de la función cognitiva, convirtiéndose en una secuencia inversa de lo que sucede en la infancia; es decir, lo que el individuo ha aprendido es lo primero que empieza a olvidar para posteriormente desaparecer de su mente, por lo que la adaptación de los cuidados a las facultades físicas como a las facultades mentales del paciente tendrían que estar en constante adaptación. (Gay, et al., s.f.).

\subsubsection{El Alzheimer a nivel mundial}

Actualmente, 50 millones de personas, a nivel mundial, padecen alguna demencia, correspondiendo el 70\% de estas a la enfermedad del Alzheimer (OMS, 2020), lo que equivale a unos 35 millones de personas en el mundo. Además, se considera que la carga de esta 
enfermedad ${ }^{8}$ así como su medida de los $\operatorname{AVAD}^{9}$ van en aumento ${ }^{10} \mathrm{y}$, a ese respecto, la OMS (2020) señala que "Se prevé que el número total de personas con demencia alcance los 82 millones en 2032 y 152 millones en 2050 [...]", lo cual permite inferir que para el 2032 existirá una prevalencia de la EA de 57.4 millones de personas, mientras que en el año 2050 será de 106.4 millones de personas a nivel mundial.

Ante, dicha situación, la poca literatura científica de habla hispana existente respecto a la EA ${ }^{11}$, indica que actualmente existen gobiernos e instituciones sanitarias a nivel mundial llevando a cabo esfuerzos significativos para lograr el bienestar de aquellas personas que presentan la enfermedad, siendo España y Chile ${ }^{12}$ dos de los países más comprometidos a ese respecto.

Quizá esto tenga que ver con que España corresponde al tercer país en el ranking de prevalencia de dicha enfermedad. De acuerdo con el último informe del Instituto Nacional de Estadística (INE) "Defunciones según la Causa de Muerte 2016", en este país fallecieron 14793 personas a causa de la EA. Correspondiendo al cuarto lugar entre las muertes más habituales en España.

\subsubsection{El Alzheimer en México}

Como se mencionó en el apartado anterior, el Alzheimer es una enfermedad común que aqueja en todo el mundo, y México no es la excepción.

Cruz (2019) señala que, de acuerdo con datos del Instituto Nacional de Estadística y Geografía (INEGI), en México viven aproximadamente un millón 200 mil personas con algún tipo de demencia, de las cuales 840 mil padecen la EA a nivel nacional. De acuerdo con estas cifras, existirá una prevalencia de la EA de un aproximado de 2.6 millones de personas.

8 La Organización Mundial de la Salud ha definido a la carga de la enfermedad como el "impacto de un problema de salud en un área específica medida por la mortalidad y la morbilidad." (Romero, 2014).

9 El estudio de la carga de la enfermedad ha derivado en el desarrollo del concepto de "años de vida ajustados en función de la discapacidad (AVAD) como una nueva medida de utilidad para cuantificar las pérdidas de vida sana, ya sea por mortalidad prematura o por el tiempo vivido con una salud menguada" (Salomon, 2010), en este caso, una discapacidad por la EA.

10 Uno de los aspectos relevantes de esta investigación es la presencia significativa y en aumento de la enfermedad del Alzheimer a nivel mundial.

11 En la labor de búsqueda de documentos científicos referentes al Alzheimer solamente fue posible encontrar algunos de estos en publicaciones eventuales y sin periodicidad regular, en su mayoría editados en España.

12 Esta investigación tomará como referencia a las publicaciones científicas generadas principalmente por investigadores españoles y chilenos respecto al Alzheimer, para acotar el rango de estudio a Iberoamérica. 
Pese a la gran cantidad de personas que padecen la enfermedad son muy pocas las instituciones de salud en México enfocadas en el tratamiento de la $E A^{13}$, dando como consecuencia que el $80 \%$ de los pacientes sean tratados por sus propios familiares en su entorno doméstico (Guillén, Ruíz y Suárez, 2019), situación que confiere una deficiencia tanto en la evolución del paciente como del bienestar familiar, convirtiéndose en una problemática nacional.

\subsection{Síntomas del Alzheimer}

\subsubsection{Clasificación y manifestaciones}

La sintomatología del Alzheimer puede surgir en cualquier estadio de la enfermedad, aunque se hace más presente conforme a su progreso gradual.

Los síntomas son de carácter multifactorial, con diferente patrón y diferente intensidad variando en cada individuo, debido a que depende de la zona del cerebro dañada serán los efectos reflejados en el paciente. Sin embargo, estos pueden ser predecibles si existe una adecuada observación por parte de los médicos y cuidadores.

Cabe mencionar que el bienestar del paciente como el del cuidador depende en gran medida del control de la sintomatología. El conocimiento de las causas, el desarrollo y su abordaje individual resulta fundamental en el manejo clínico del paciente.

Existen diversas clasificaciones de los síntomas del Alzheimer, siendo los síntomas más coincidentes los clínicos y los psicológico-conductuales, ambos descritos a continuación:

\section{- Síntomas Clínicos: ${ }^{14}$}

\section{Síntomas neuropsicológicos:}

- Desgaste progresivo de la memoria y del lenguaje.

- Deterioro en capacidades visoespaciales y motoras.

- Alteraciones en las funciones como la capacidad de abstracción y de juicio.

- Desorientación temporal y personal.

\footnotetext{
13 APAES (2016) señala que, hasta 2016, existían en la Ciudad de México y su Área Metropolitana menos de 10 instituciones y organizaciones de salud que apoyaban pacientes y familiares con EA.

14 Para fines de la investigación, se definen los síntomas de tipo clínico del Alzheimer con base en los planteamientos de los siguientes autores: Francisco Gay, Irene Ruiz, Miriam Guillén y Roberto Suárez (2018).
} 


\section{Síntomas psiquiátricos:}

- Acentuación de rasgos premórbidos.

- Cambios de personalidad, apatía o disminución de intereses previos.

- Depresión, alucinaciones, ansiedad, agresividad, agitación.

- Deambulación errante.

- Trastornos del sueño, del apetito y del impulso sexual.

\section{Síntomas neurológicos: ${ }^{15}$}

- Rigidez generalizada.

- Incapacidad para la marcha y la deglución -ingesta del alimento-.

- Incontinencia.

- Aparición de reflejos primitivos -prensión, succión-

- Mioclonías -contracciones musculares-

- Crisis epilépticas.

\section{- Síntomas Psicológicos y Conductuales: ${ }^{16}$}

\section{Alteraciones del humor:}

- Depresión y ansiedad.

- Apatía.

- Episodios de risa o llanto repentinos, descontrolados y fuera de lugar (labilidad emocional). ${ }^{17}$

- Agitación y agresión.

\section{Alteraciones de la actividad psicomotora:}

- Acatisia ${ }^{18}$ e inquietud.

- Vagabundeo.

15 Los síntomas neurológicos únicamente aparecen en la última fase de la EA.

16 Para fines de esta investigación, se considera la clasificación de los síntomas psicológicos y conductuales de las demencias (SPCD) propuesta por Francisco Gay (2017).

17 La labilidad emocional "se caracteriza por episodios de risa o llanto repentinos, descontrolados y fuera de lugar." Mayo Clinic (s.f.).

18 La acatisia es "un trastorno del movimiento que se caracteriza porque la persona experimenta una sensación de inquietud interna e incapacidad de permanecer quieta." (Rovira, I., s.f.). 


\section{Alteraciones de la percepción:}

- Alucinaciones y delirios.

- Alteraciones de la identificación.

\section{Alteraciones vegetativas:}

- Alteraciones del sueño.

- Alteraciones de la conducta alimentaria y sexual.

Cabe mencionar que, sin importar la clasificación de los síntomas, la etiopatogenia u origen del Alzheimer es la misma y se clasifica de acuerdo con los factores señalados por Gay (2017), enlistados a continuación:

Factores psicosociales:

- Necesidades insatisfechas

- Umbral de estrés disminuido

- Teoría del aprendizaje

- Personalidad previa

Factores Somáticos:

- Cardiovascular

- Fármacos

- Infecciones

- Dolor

Factores Biológicos:

- Neuropatología

- Alteración de circuitos cerebrales

- Neurotransmisión alterada

- Enfermedad intercurrente

- Genética 


\section{Factores ambientales:}

- $\quad$ Entorno físico

- $\quad$ Relación con el cuidador

- Relación con el familiar

- Relación con la sociedad.

\subsubsection{Pródromos de episodios de Alzheimer}

Con base en la definición aportada por la Medciclopedia (2019), se puede establecer como episodio ${ }^{19} \mathrm{o}$ crisis de la EA como un agravamiento disruptivo y transitorio de su sintomatología -de distinta duración-, alterando la vida diaria del paciente durante el curso progresivo de su enfermedad. En muchas ocasiones, el episodio suele estar precedido por uno o más síntomas que actúan como señales y que constituyen el pródromo -señal o malestar que precede a una enfermedad (RAE, 2020)- de dicho episodio y, en algunos casos, las características de los episodios podrían mostrar un patrón de la evolución de esta patología.

Un ejemplo frecuente es el que un paciente mantiene un estado pasivo o habitual durante el transcurso del día, pero la alteración de algún factor (por ejemplo, algún cambio brusco en su rutina diaria) suele manifestarse como cambios de humor, ansiedad y aceleración en el ritmo cardíaco, precediendo el desencadenamiento de un episodio en el paciente. En este caso, se puede decir que estos síntomas son reconocidos como pródromos de un episodio de la EA, ya que el paciente sale de su estado "pasivo" o habitual.

Cabe mencionar que esta investigación requirió, para la definición de los síntomas prodrómicos más frecuentes en un episodio de Alzheimer, de un estudio exploratorio inicial (cuali-cuantitativo), el cual involucró la aplicación de una encuesta semiestructurada así como de una entrevista abierta no estructurada a pacientes, familiares, cuidadores, médicos y especialistas -en total 56 personas- relacionados con la $\mathrm{EA}^{20}$, cuyos resultados proporcionaron datos significativos sobre la experiencia y saberes empíricos de los encuestados y, derivado de ello, la definición de dichos síntomas. Los datos obtenidos señalaron, por un lado, que son los familiares quienes, generalmente, se convierten en la sombra del enfermo, es decir, pasan todo el tiempo posible

\footnotetext{
19 La Medciclopedia (2019) define como episodio a un acontecimiento o hecho que sale de la rutina de la vida cotidiana o dentro del curso normal de una enfermedad.

20 Ver: Anexo I.
} 
con ellos para manejar los episodios de la EA que presenten y, por otro lado, que si el cuidador estuviera al pendiente en todo momento podría, gracias a la detección oportuna de los pródromos, en este caso manifestados a través de cambios físicos en el paciente, darse cuenta cuándo un episodio de la enfermedad se avecina. Algunos de los cambios físicos en los pacientes de la EA mencionados fueron: el movimiento ocular y la sudoración excesivos en el paciente así como, en mayor frecuencia, diversas alteraciones físicas con relación a su temperatura corporal, oxigenación sanguínea, ritmo cardíaco y presión arterial ${ }^{21}$.

Dichos cambios, considerados desde el punto de vista médico, se podrían reconocer como pródromos de episodios de Alzheimer. Sin embargo, no siempre están presentes antes de que un episodio se desencadene.

Los pródromos son muy variables entre los distintos pacientes, incluso en un mismo paciente durante el curso de la enfermedad, dependiendo de las características propias de cada persona, como sus rasgos psicológicos previos, antecedentes personales, trastornos psiquiátricos desarrollados durante el proceso de deterioro y etapa evolutiva, entre otros, y, en todos los casos, un diagnóstico temprano permite mejorar significativamente la calidad de vida del paciente.

\subsection{Diagnóstico}

De acuerdo con la Fundación Alzheimer España (2015), el concepto sobre la EA ha ido cambiando con el tiempo. Inicialmente, el Alzheimer era considerado como la evolución lógica de la edad de las personas y era sinónimo normal de su envejecimiento; más adelante, se le consideró como demencia senil ${ }^{22}$, hasta que finalmente, entre las décadas de los setenta y ochenta, se le reconoció como enfermedad con sus propios signos, evolución y criterios de diagnóstico.

En cuanto al diagnóstico del Alzheimer se refiere, es importante señalar que antes de notarse los síntomas de la enfermedad en el paciente, este ha ido paulatinamente sufriendo la muerte progresiva de neuronas así como la pérdida de conexiones entre ellas durante años previos. De

\footnotetext{
21 Cabe mencionar que las alteraciones físicas no son las únicas manifestaciones de la enfermedad. Sin embargo, para efectos de esta investigación, con base en los resultados del estudio exploratorio pudieron definirse como síntomas prodrómicos de episodios de la EA a las alteraciones de temperatura corporal, oxigenación sanguínea, ritmo cardiaco y presión arterial en los pacientes.

22 La demencia senil es considerada como la pérdida de las facultades mentales vinculada con la edad.
} 
acuerdo con la Alzheimer's Association (s.f.) este periodo de tiempo es conocido como Alzheimer preclínico.

Mayo Clinic (2020), señala que al presentar síntomas -déficit en la memoria y al menos algún deterioro en la función del lenguaje, de praxias $^{23}$, de gnosias ${ }^{24}$ y funcionamiento ejecutivo que afecta su actividad social- el paciente debe acudir a un centro de salud para someterse a un examen general de tipo físico y neurológico y, con base en los resultados, practicarse una serie de pruebas de laboratorio que permitan identificar las causas de los síntomas presentados o, en su defecto, detectar otras posibles enfermedades.

Si los síntomas de la EA son más avanzados y, en consecuencia, evidentes, se deben realizar al paciente diversas pruebas psicológicas, tales como los Test de cribado o Screening ${ }^{25}$, las cuales permitan evaluar, de manera más precisa, las funciones cognitivas del mismo ${ }^{26}$. Estas pruebas permitirán al especialista a cargo, a partir de la obtención de "un índice del estado cognitivo que [...] sugiere presencia o ausencia de patología", emitir un diagnóstico más concluyente. (Lanfranco, et al., 2012).

También existen métodos más avanzados de diagnóstico por imágenes del cerebro (neuroimagen) ${ }^{27}$-como la resonancia magnética, la tomografía computarizada, la morfometría basada en voxel (VBM) y la tomografía por emisión de positrones (PET), entre otras- que no por ello son totalmente confiables, pues llegan a diagnosticar otras enfermedades que comparten sintomatología con la EA.

Pese a la variedad de métodos de diagnóstico existentes, un diagnóstico de EA definitivo sólo puede corroborarse hasta que el paciente muere, a través de la autopsia de su cerebro con el fin

23 "Se definen como la función cognitiva encargada de los movimientos." (Rojas, 2019).

Capacidad que tiene el cerebro para reconocer información previamente aprendida a través de los sentidos, como pueden ser objetos, personas o lugares. Cabe mencionar, que hay gnosias para cada uno de los canales sensitivos y gnosias que combinan diferentes canales. (NeuronUP, s.f.).

25 Los test de cribado en el ámbito médico, "se refieren a la realización de pruebas diagnósticas a personas, en principio sanas, para distinguir aquellas que probablemente estén enfermas de las que probablemente no lo están". (Nieves, 2015). Lanfranco, et al. (2012), señala que existen diversos tipos de test de cribado que permiten realizar una evaluación más detallada de las funciones cognitivas, como lo son: test de fluencia verbal, figura Compleja de Rey-Osterrieth, test de Bender BIP, Benton Visual Retention Test, por mencionar algunos.

26 En la actualidad, el test más usado es el Mini-Mental State Examination (MMSE). Sin embargo, estudios recientes indican que el Test Your Memory (TYM) "es capaz de detectar el 93\% de los pacientes con EA, siendo mucho más sensible que el MMSE, el cual sólo detecta a $52 \%$ de los pacientes con la misma enfermedad." (Lanfranco, et al., 2012).

27 Son aquellas que se pueden obtener a través de imágenes de estructuras neuronales mediante técnicas radiológicas. (Diccionario Médico, s.f.). 
de comprobar si efectivamente este cuenta con ovillos y placas ${ }^{28}$ relacionados con los depósitos anormales de las proteínas TAU y beta-amiloide característicos de esta enfermedad.

Una vez diagnosticada la EA, existen escalas médicas -como la escala de deterioro global de Reisberg, mencionada anteriormente-, que permiten valorar y ubicar la fase o nivel de gravedad de la enfermedad en la que se sitúa el paciente así como instrumentos de medición a partir de la vigilancia que el paciente requiere. (Ver: Tabla 1.1).

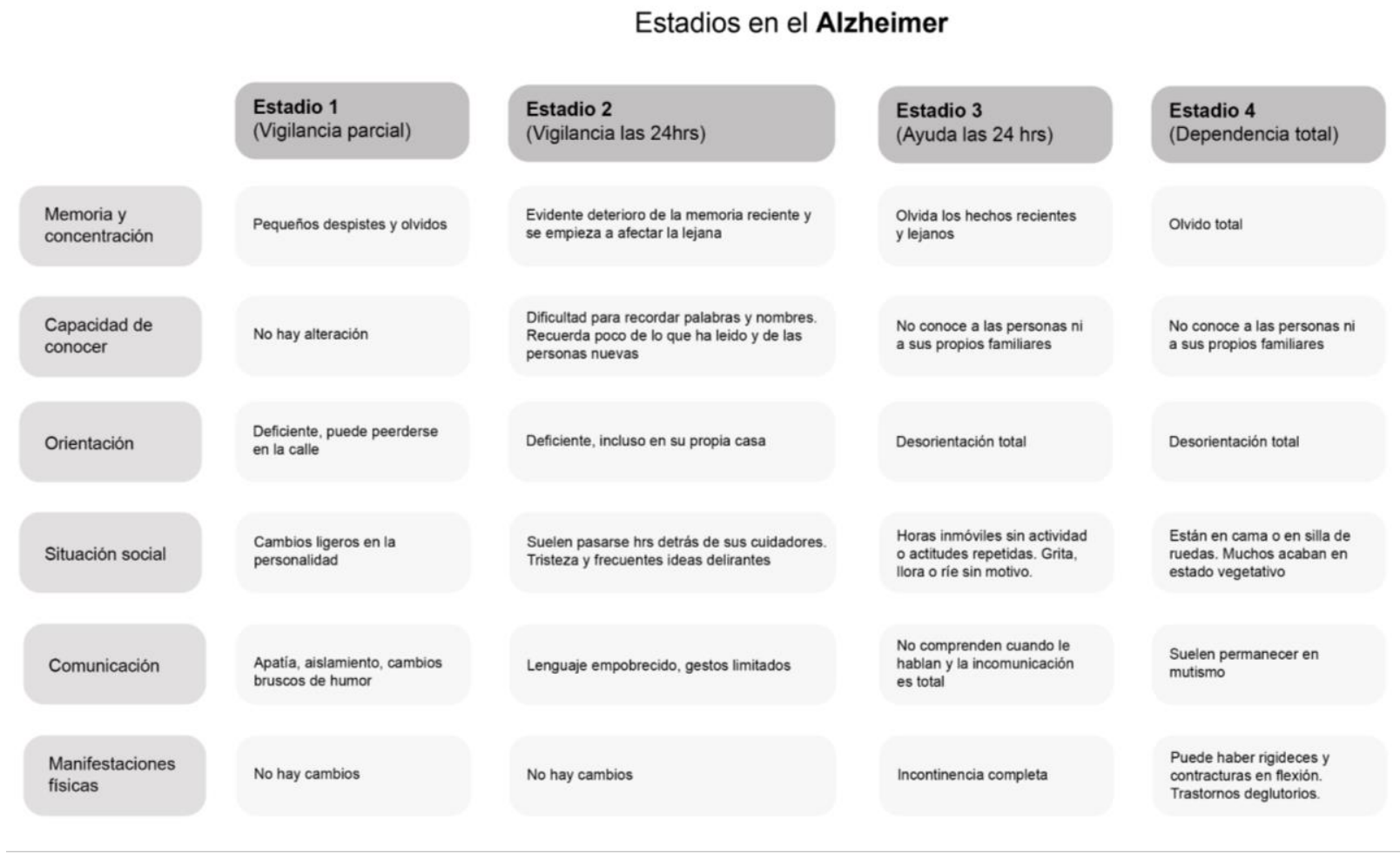

Tabla 1. Instrumento de medición del estadio en el Alzheimer a partir de la vigilancia que el paciente requiere. Retomada de Jesús T. J. (2011).

\subsection{Tratamientos}

\subsubsection{Tipos}

Cómo se mencionó anteriormente, la EA es una enfermedad que no tiene cura, pero existen tratamientos que permiten evitar y controlar los síntomas en quienes la padecen.

28 De acuerdo con Suárez (2019), los ovillos son característicos de la demencia, mientras que las placas se ven en ancianos normales. 
Si bien los tratamientos actuales para el Alzheimer no pueden detener el avance de la enfermedad, si pueden ayudar a retrasar la aparición así como a controlar los síntomas de la enfermedad, mejorando con ello la calidad de vida de los pacientes y, en consecuencia, de sus cuidadores.

Existen dos tipos de tratamiento para la enfermedad de Alzheimer: los farmacológicos -tratamientos apoyados por medicamentos para controlar y, en su caso mejorar, por tiempo limitado, algunos síntomas de la enfermedad- y los no farmacológicos ${ }^{29}$-tratamientos teóricamente sustentados, focalizados y replicables que no implican la intervención de algún químico para obtener un beneficio relevante en la enfermedad-.

Los tratamientos no farmacológicos pueden clasificarse en: psicoestimulación cognitiva -llevada a cabo a través de talleres (de memoria, de reconocimiento, de expresión oral y psicoexpresión con musicoterapia y danzoterapia, ocupacionales así como de integración social), de juegos de activación física y mental así como de estimulación sensorial y relajación- y psicoterapia, mediante grupos de apoyo y reuniones de información, dirigida a la integración familiar durante el proceso de la enfermedad.

De acuerdo con la severidad de los síntomas, regularmente se recomienda, en primera instancia, llevar a cabo un tratamiento de tipo no farmacológico y sólo en caso de que este no funcione, complementar dicho tratamiento con uno de tipo farmacológico.

\subsubsection{Rehabilitación}

El término de rehabilitación corresponde al proceso del tratamiento dirigido a las personas con discapacidad, principalmente física, a emplear al máximo sus capacidades residuales y permitirles obtener la máxima satisfacción y utilidad en lo que se refiere a sí mismos, a su familia y a su entorno (DISCAPNET, s.f.). En algunos casos, los fines de la rehabilitación pueden suponer la mejor adaptación del paciente a una vida independiente.

En cuanto a la EA se refiere, la rehabilitación de los pacientes es un tanto subjetiva, porque difícilmente logran restablecer sus capacidades. Sin embargo, la rehabilitación sí puede evitar el avance de su deterioro con mayor rapidez.

29 De acuerdo con Olazarán, et al. (2010), citados por la Asociación de Familiares de Personas con Alzheimer y otras demencias de Huelva (s.f.). 
El tratamiento de rehabilitación para pacientes con Alzheimer depende, en gran medida, de los síntomas y la progresión de la enfermedad, tomando en cuenta que el paciente deberá, de acuerdo con DISCAPNET (s.f.):

- Realizar ejercicio físico y actividades sociales diariamente.

- Llevar un mantenimiento adecuado de nutrición y estado de salud general.

- Realizar nuevas actividades, en función de sus capacidades.

- Mantener sus actividades familiares.

- Llevar a cabo todas las actividades que pueda realizar por sí mismo.

\subsubsection{El papel de los médicos y cuidadores en el tratamiento de la EA}

Las personas que padecen la EA requieren cuidados especializados así como una vigilancia constante por parte de un cuidador, quien debería ser una persona con los conocimientos específicos para atender y cubrir, de manera adecuada, sus necesidades.

Sin embargo, como se ha comentado anteriormente, frente a la problemática que supone la falta de un número suficiente de instituciones y organizaciones de salud enfocadas a la detección, tratamiento y cuidado de pacientes con la EA, los pacientes son atendidos por sus familiares, en su entorno doméstico, quienes generalmente no cuentan con los conocimientos necesarios para llevar a cabo las acciones requeridas cuando un episodio de Alzheimer sobreviene, dando lugar a una asistencia de tipo informal cuyas principales características son:

- Tiene un carácter no institucional.

- Es un trabajo no remunerado.

- Se presta en y desde el ámbito doméstico.

- Se regula mediante relaciones no explícitas, de modo que pasan a ser invisibles y no reconocidas.

- Se mueve en el terreno de lo privado y se asienta sobre las relaciones personales.

- Se aplica gracias a la relación de parentesco, en la que existen lazos de afectividad y un carácter de compromiso duradero entre sus miembros.

De acuerdo con la OMS (2019), la mayoría de los cuidadores son familiares, resultando un $88 \%$ del tiempo empleado en el cuidado de la salud como asistencia informal frente al $12 \%$ del tiempo que dedica el sistema formal, sea público o privado (Tirado, López-Saez, Capilla, Correa y Geidel, 
2011) como consecuencia de la evidente falta de centros de salud capaces de atender a pacientes con Alzheimer.

El proceso de cuidar pacientes con Alzheimer puede ser una práctica gratificante al descubrirse la satisfacción por ser útil a los familiares próximos y necesitados. Sin embargo, a la par puede resultar una actividad muy compleja, con poco o, incluso, soporte nulo y una sobrecarga de actividades, que exige una reorganización en la vida familiar, laboral y social del cuidador (Pérez, Ma. J. 2005), esto sumado a la necesidad de tener una formación adecuada en cuanto a los cuidados de salud requeridos para el manejo de la enfermedad.

Toda esta práctica puede ser causa de estrés, agotamiento, ansiedad o depresión en los cuidadores, quienes llegan a sufrir enfermedades ${ }^{30}$, tanto físicas como psicológicas, deteriorando significativamente su calidad de vida lo cual es conocido como el Síndrome del Cuidador ${ }^{31}$, derivando en la modificación de los umbrales de percepción del sufrimiento y dolor del enfermo a su cuidado. Este síndrome se diagnosticó por primera vez en Estados Unidos en 1974 (Guillén, 2019). El cuidador que lo padece es considerado por algunos autores como un paciente oculto o desconocido, que precisaría de una intervención inmediata antes de que el deterioro sea difícilmente reversible. (Lara, Díaz, Herrera y Silveira, 2001).

Para un adecuado manejo de este síndrome, se recomienda contar con una excelente relación entre los especialistas involucrados en la EA y la familia del paciente, con ayuda de un tratamiento psicoterapéutico así como de una instrucción en mecanismos de salud que favorezcan la relación paciente-cuidador-familia. Además, es necesario que exista una orientación con un enfoque biopsicosocial, que involucre cuestiones biológicas, psicológicas y sociales, por parte de los especialistas hacia la familia y el paciente con la finalidad de reorganizar las funciones en los miembros de la familia. (Dueñas, Martínez, Morales, Muñoz, Viáfara y Herrera, 2014).

Lo anterior evidencia el que no debe centrarse la atención únicamente en el paciente con Alzheimer sino también en el cuidador y en su entorno familiar, los cuales son también partícipes

30 De acuerdo con el Informe Mundial sobre el Alzheimer 2019 (Alzheimer's Disease International, 2019), más del 50\% de los cuidadores de todo el mundo aseveran que su salud ha sufrido como resultado de sus responsabilidades de cuidado, inclusive aun cuando estos expresan sentimientos positivos sobre su papel.

31 El cuidador que padece de este síndrome presenta, como consecuencia, una repercusión física/biológica, psicológica, social y familiar. (Guillén, M., 2019). 
de la enfermedad con la finalidad de obtener una visión integradora en el proceso de cuidar y, con ello, lograr una adecuada calidad de vida para el paciente. (Lara, et al., 2001).

\subsection{La influencia de la tecnología en el tratamiento del Alzheimer}

Derivado de la constante evolución tecnológica, se ha ido definiendo una gran cantidad de alternativas significativas a las problemáticas que plantean los ámbitos de salud en las sociedades actuales.

En ese sentido, de acuerdo con Chui et al. (citados en Almeida, 2017), incluir la tecnología en el cuidado de la salud "ofrece posibilidades para vigilar el comportamiento y los síntomas de un paciente en tiempo real, o cercano al tiempo real y con un costo relativamente bajo, lo que permite a los médicos diagnosticar mejor la enfermedad a distancia y prescribir tratamiento a medida. Los pacientes [...] pueden ser monitoreados en sus actividades que realizan cotidianamente con una serie de sensores diminutos, casi imperceptibles para el paciente.".

Además, la tecnología permite dar seguimiento domiciliario a los pacientes aumentando, con ello, el control de la enfermedad, situación que favorece la aplicación de los tratamientos sin la necesidad de una asistencia frecuente de los pacientes a los centros de salud (García, S., 2019), lo cual resulta altamente beneficioso para la EA considerando la insuficiente cantidad de instituciones enfocadas a la detección y tratamiento de esta. Sin embargo, su aplicación directa sobre esta enfermedad sigue siendo poco explorada, generando un área de oportunidad para el tratamiento del Alzheimer.

Si bien ha existido la inquietud por generar herramientas tecnológicas que permitan apoyar el tratamiento del Alzheimer, aún no se han desarrollado las herramientas tecnológicas necesarias para diluir las problemáticas derivadas de inadecuados procesos de detección y tratamiento del Alzheimer, tanto en México como en el mundo. 


\section{CAPÍTULO 2 El Internet de las Cosas y su impacto en el tratamiento del Alzheimer}




\section{CAPÍTULO 2. EL INTERNET DE LAS COSAS Y SU IMPACTO EN EL TRATAMIENTO DEL ALZHEIMER}

\subsection{El Internet de las Cosas}

\subsubsection{Definición}

El Internet se ha convertido en un elemento clave para el desarrollo de la humanidad (González, 2013), al hacer posible una conexión -remota y en tiempo real- entre las personas, disminuyendo las barreras de tiempo y espacio.

Desde su creación, en la década de los sesenta, el Internet ha ido evolucionado de una manera vertiginosa hasta nuestros días en los que la incorporación de nuevos sistemas, así como de diversos dispositivos está ofreciendo nuevas posibilidades a la interconexión, no sólo entre personas sino también entre objetos y personas con objetos.

Así, surge el paradigma del Internet de las Cosas o Internet of Things (IoT), término acuñado por Kevin Ashton en el año 2000 (Weber, 2010), el cual "refiere a una evolución del Internet que permite la interacción entre personas, entre objetos y entre personas con objetos, planteando una era de ubicuidad $[\ldots]^{32}$ en donde se dan nuevas formas de comunicación en situaciones cotidianas" (Almeida, 2017), evolución que ha permitido añadir un tipo de conectividad más extensa, una mejor recepción y percepción de la información, así como una diversidad de bienes y servicios inteligentes más completos.

El loT se reconoce como la nueva etapa del Internet, la cual está generando nuevas posibilidades en la capacidad para reunir, analizar y distribuir datos que se pueden convertir en información, conocimiento, posteriormente en sabiduría. Este avance, combinado con la gran capacidad de comunicar y compartir información que la interconexión de los objetos vía Internet hará posible que las personas mejoren significativamente su vida cotidiana.

En otras palabras, el loT es una red de objetos físicos o cosas, frecuentemente equipadas con algún tipo de inteligencia, que utilizan sensores y $\mathrm{API}^{33}$ para conectarse, recibir e intercambiar datos por Internet, con una mínima intervención humana. (Evans, 2011).

32 Cualidad de ubicuo, que está en todas partes. (RAE, 2005).

33 Una API (Application Programming Interface) es un conjunto de definiciones y protocolos que se utiliza para desarrollar e integrar el software de las aplicaciones. (RedHat, s.f.). 
Giusto, lera, Morabito y Atzori (2010), señalan que la idea básica de este paradigma es la omnipresencia, en nuestro alrededor, de una gran variedad de objetos que pueden interactuar y cooperar entre sí para alcanzar objetivos en común, convergiendo para ello diferentes visiones como son las relativas a la visión de los objetos, del Internet y de la semántica. (Ver: Figura 2.1).

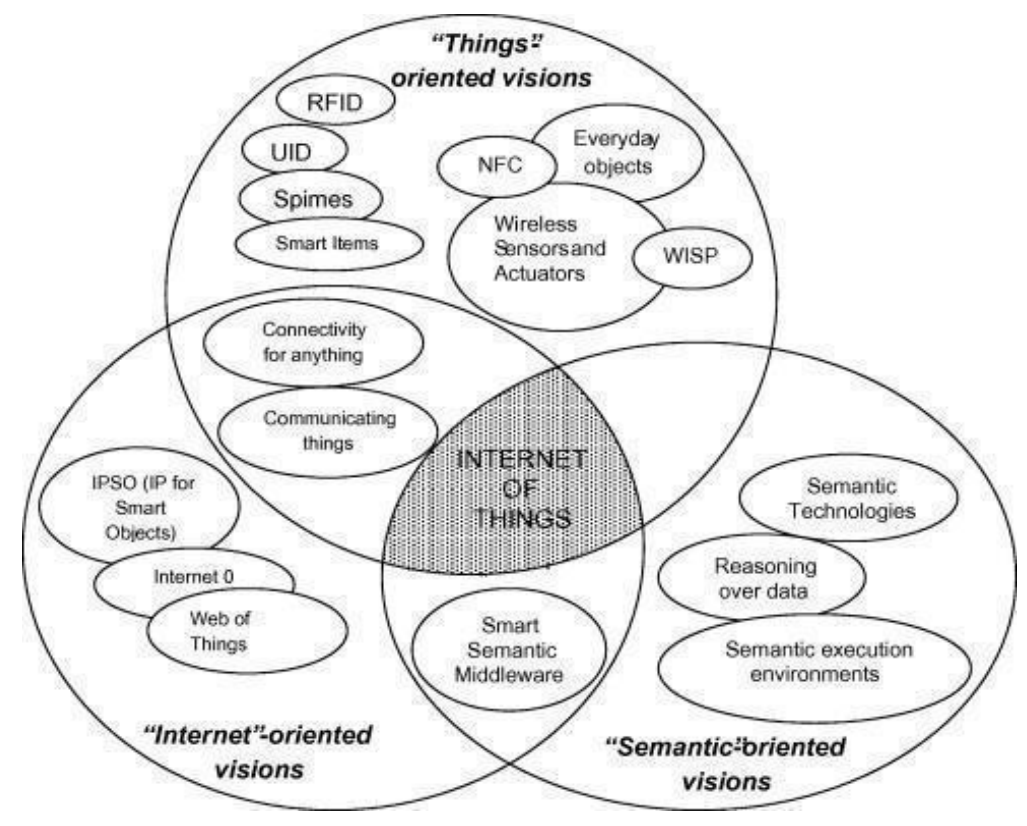

Figura 2.1. Paradigma del Internet de las Cosas como resultado de la convergencia de diferentes visiones. (Giusto, lera, Morabito y Atzori, 2010).

Es conveniente acotar que hoy en día, el loT se considera un paradigma muy importante y relevante para el desarrollo de las sociedades actuales, que potencializa las diferentes actividades humanas como la manera en que se comunican, se desenvuelven, aprenden, trabajan y se entretienen, entre otras.

\subsubsection{Funcionamiento}

En esta perspectiva el loT implica hablar de una red de objetos físicos -que pueden llevar sensores integrados-, software y otras tecnologías, cuyo objetivo no sólo es conectar dispositivos y sistemas sino también intercambiar datos por medio del servicio de Internet entre estos, con una mínima operación del usuario dando cabida a un mundo físico capaz de combinarse con un mundo digital. (Oracle, s.f.). 
En este punto surge el cuestionamiento sobre ¿qué es lo que hace posible el funcionamiento del Internet de las Cosas?, De acuerdo con SAP (s.f.), el funcionamiento del loT depende de una serie integral de tecnologías como lo son: las API que conectan los dispositivos a Internet, los sensores $^{34}$ y actuadores ${ }^{35}$-conectados a un controlador lógico programable ${ }^{36}$ - en los objetos, sumados a estos las herramientas de gestión del Big Data ${ }^{37}$, las analíticas predictivas ${ }^{38}$, la Inteligencia Artificial $(\mathrm{Al})^{39}$, el Machine Learning $(\mathrm{ML})^{40}$, la Cloud Computing $(\mathrm{CC})^{41}$ y la identificación por radiofrecuencia (RFID) ${ }^{42}$.

Gracias a estas tecnologías los objetos pueden conectarse para recibir e intercambiar datos a través de las redes inalámbricas, en un ciclo de retroalimentación (RedHat, s.f.), siempre bajo la consideración de la conciencia del contexto $(C A)^{43}$ en la que se encuentran inmersos, es decir, de la extracción de la información del entorno -mediante los objetos provistos de sensores- para

34 Unidades que emiten una señal analógica, permitiendo dotar de sentidos a los objetos (Tecnología para los negocios, s.f.), con la finalidad de medir una amplia gama de variables físicas o fenómenos y, posteriormente, transmitir los datos obtenidos. (Salazar y Silvestre, 2016).

35 Un actuador es un dispositivo capaz de transformar energía en una acción con la finalidad de automatizar un proceso. (Tecnología para los negocios, s.f.).

36 Un controlador lógico programable o PLC es el encargado de monitorizar los valores de los mismos y, dependiendo del valor obtenido, actuar de una forma u otra según hayan sido programados. (Tecnología para los negocios, s.f.).

37 Término en el que se agrupan toda clase de técnicas de tratamiento y análisis masivo de datos, englobando ideas y aproximaciones con el objetivo de extraer información de valor de los datos. (Instituto de Ingeniería del Conocimiento, s.f.).

38 "[...] uso de datos, algoritmos estadísticos y técnicas de machine learning para identificar la probabilidad de resultados futuros basados en datos históricos." (Sas, s.f.).

39 Término acuñado por John McCarthy, en 1956, quien consideraba a la Al como "la ciencia y la ingeniería de crear máquinas inteligentes, especialmente programadas por computación inteligente", desarrollada por medio de una serie de algoritmos que le proporcionan la capacidad de interpretación, decisión y resolución de problemas de forma autónoma ante las señales que recibe. (Revista de Robots, 2020).

40 Es la capacidad de un hardware o software "para aprender mediante la adaptación de ciertos algoritmos de su programación respecto a cierta entrada de datos en su sistema." (APD, 2019).

41 Conocida como computación en la nube, refiere "a una situación en la cual la computación se hace en un sitio remoto (en la nube), en lugar de hacerlo en un computador de escritorio o en un portátil, usando para ello Internet." (Rueda, F., 2009). Al respecto, la nube no es una entidad física sino una red global de servidores remotos, diseñados para almacenar y administrar datos, ejecutar aplicaciones o entregar contenido o servicios, conectados para funcionar como un único ecosistema. (Microsoft Azure, s.f.).

42 Radio Frecuency Identification (RFID) es "una tecnología de transferencia de información por ondas electromagnéticas que permite el intercambio de datos a distancia entre sistemas emisor-receptor. (lonos, 2020).

43 La conciencia del contexto (Context Awareness) o computación sensible al contexto es un término acuñado por Schilit and Theimer (Barrientos, A., Calderón, J. y Mujica, S., 2020), el cual refiere -de acuerdo con Almeida (2017)- a la adquisición y uso "de la información acerca del contexto de un dispositivo para proporcionar servicios adecuados a la configuración particular, refiriéndose a la situación física y social en la que están integrados los dispositivos computacionales ". 
posteriormente interpretarla ${ }^{44}$ y utilizarla para cumplir un propósito con relación a la mejora de los ambientes en que se desenvuelve el usuario.

\subsubsection{Campos de aplicación y alcances}

Evidentemente, el Internet de las Cosas tiene la capacidad de mejorar la calidad de vida de las personas al reducir el grado de dificultad que presenten las actividades -sociales, recreativas, económicas, empresariales, educativas y médicas, por mencionar algunas- que desarrollan cotidianamente, a través de objetos con capacidades inteligentes ${ }^{45}$-como la monitorización, el control así como la optimización, la autonomía y el proceso de toma eficiente de decisiones-, los cuales se pretende que, en un futuro, resulten imperceptibles para sus usuarios.

En ese sentido, puede hablarse de la creación de una Inteligencia ambiental o Ambient intelligence $(A m l)^{46}$, -con base en una acción recíproca, ubicua e inteligente- hace posible la interacción transparente ${ }^{47}$ a través de dispositivos u objetos cotidianos, omnipresentes y no intrusivos. Como lo señala Mark Weiser (Barrientos, Calderón y Mujica, 2020), "las tecnologías más profundas son las que desaparecen de modo que deben relacionarse con la vida cotidiana al punto que no se puedan distinguir de ella", es decir, que las tecnologías se impregnan de tal manera del contexto del usuario que logran desaparecer, no de una manera física sino psicológica, permitiéndole interactuar de forma cómoda e imperceptible con ellas con el fin de facilitar sus actividades (InnoWiki, 2014) y, con ello, promover una mejora en los diversos aspectos que involucra su vida cotidiana.

\subsection{El loT en el ámbito médico}

El paradigma del loT ha favorecido el desarrollo de los diversos ámbitos que conforman a las sociedades contemporáneas, propiciando, particularmente, el desarrollo de una gran cantidad de

44 Acción que se conoce como el procesamiento inteligente del contexto, que implica "la recolección y manipulación de elementos de información para producir data significativa que pueda ser utilizada para algún fin determinado". (Barrientos, A., Calderón, J. y Mujica, S., 2020).

45 Capacidades que van cada vez en mayor incremento (Salazar y Silvestre, 2016).

46 Término, acuñado por Mark Weiser (InnoWiki, 2014), que hace referencia a "una inteligencia omnipresente y transparente en un entorno vigilado que soporta las actividades e interacciones de los usuarios" (Ribera, J., s.f.).

47 La Am/ busca una interacción transparente, es decir, que las personas no reconocerán como tal a los dispositivos con los que interactúen, pero estos sí reconocerán la presencia del usuario para adaptarse a él. 
herramientas de apoyo a la asistencia médica y la estimulación cognitiva ${ }^{48}$, las cuales han permitido mejorar y agilizar el desarrollo de procesos centrados en una medicina personalizada que beneficie tanto a los pacientes como a las personas involucradas con sus padecimientos.

Así, puede apreciarse como, hoy en día, el loT tiene una fuerte presencia en el ámbito médico, dando lugar a servicios y sistemas que, "a través de dispositivos y herramientas tecnológicas [...]" inteligentes "[...] con una gran variedad funcional, sensorial, de formas de comunicación, entre otras" (García, 2019), permiten "conocer mejor a los usuarios, cubrir sus necesidades y ofrecerles un mejor servicio personalizado y efectivo, garantizando en todo momento su seguridad" (Rodríguez , 2019) de manera inmediata.

Entre los objetivos más importantes del uso del loT en este ámbito, de acuerdo con Tomé (2019), se pueden destacar los siguientes:

- Promover el mayor grado de autonomía e independencia de las personas.

- Maximizar la seguridad y la confianza de las personas, proporcionando una intervención, así como una atención rápida y eficaz.

- Favorecer la permanencia y la integración del paciente en el medio habitual en que desarrollan su vida.

- Apoyar a los familiares y cuidadores.

Si bien, el apoyo principal que el loT aporta a la medicina tiene que ver directamente con el diagnóstico y manejo de enfermedades, desde el punto de vista del paciente y el médico tratante. Este apoyo también se ve reflejado en los responsables, familiares y cuidadores de personas enfermas ${ }^{49}$, quienes reciben apoyo y asesoramiento -rápido y sencillo- por parte de los especialistas. Así, las personas implicadas en el cuidado de un paciente adquieren cierto protagonismo al convertirse en los destinatarios de estos servicios.

Por un lado, un ejemplo de la implementación del loT en el ámbito médico, desde el punto de vista del paciente, es Timeless, aplicación que permite -a través del reconocimiento facial mediante inteligencia artificial- que los pacientes con demencias recuerden eventos y reconozcan e interactúen con amigos y familiares. (Timeless, s.f.). Por otro lado, como

48 Retomando de AFAGI (s.f.), de Medeiros (2016) y Bitbrain (2018), la estimulación cognitiva es un conjunto de técnicas y estrategias enfocadas al estímulo y mantenimiento de las capacidades cognitivas de los pacientes, como son la atención, la memoria y el lenguaje, entre otros procesos mentales residuales, mejorando con ello su calidad de vida.

49 Esta investigación se centrará en la aplicación del loT en sistemas médicos dirigidos a los cuidadores, sean familiares o expertos en el cuidado de pacientes. 
ejemplo de una aplicación para especialistas en la salud se puede mencionar a Avizor, sistema de gestión que notifica en tiempo real al Observatorio para la Seguridad del Paciente de la Agencia de Calidad Sanitaria de Andalucía (ACSA) sobre incidentes, en curso o a punto de ocurrir, que presenten los pacientes de manera que pueda proporcionarles a tiempo la asistencia requerida. (FIDISP, 2018). Y, finalmente, un ejemplo de aplicación desde el punto de vista de los familiares y cuidadores, en general, es la llamada Joyners que ofrece el servicio de contacto directo con el cuidador, indicándole las tareas a realizar, los horarios de suministros de medicamentos, entre otras actividades necesarias para el paciente. (Joyners, s.f.).

Sin embargo el uso de sensores también ha cobrado importancia en el ámbito médico, dando lugar a las Redes de Área de Cuerpo o Corporal (Wireless Body Area Network (WBAN)) "cuentan con sensores inteligentes (biosensores) que capturan los parámetros biofisiológicos de las personas y pueden ofrecer de una manera más fácil la recolección de datos [...]" para las aplicaciones de monitoreo de pacientes, permitiendo mayor flexibilidad para el personal médico y la movilidad de los pacientes (Khan, et al. y Vallejos de Schatz, et al., citados en Almeida, 2017). Sin embargo, es importante mencionar que las "WBAN necesitan interfaces adecuadas para el procesamiento de datos, presentación y almacenamiento con una óptima recuperación y visualización (Pereira, et al., citados en Almeida, 2017).

De tal forma, la inserción del loT en el ámbito médico ha permitido la aparición de conceptos tales como el e-Health ${ }^{50}$, el $u$-Health $h^{51}$ y el $m$-Health ${ }^{52}$ o en su caso el $i$-Health $h^{53}$, por mencionar algunos, que hacen referencia a diferentes modalidades de la medicina apoyada y soportada por las tecnologías como lo son la teleconsulta, telediagnóstico, telemonitorización, teleasistencia, telecirugía, teleformación y telerehabilitación (Cabo, J., 2020), todas ellas enfocadas a la mejora en cuanto a salud se refiere.

50 Para los fines de esta investigación, se considerarán exclusivamente las condiciones que dicta el e-Health, a definirse en el siguiente apartado de este capítulo.

51 Servicio informático ubicuo, que ofrece servicios inteligentes y autónomos basados en la conciencia del contexto. Con el desarrollo de la tecnología de sensores, se centra en monitorear las condiciones de salud del paciente en tiempo real, así como de la gestión de las rutinas médicas y del bienestar del mismo. (IGI Global, s.f.).

52 Corresponde a "una variante de telemedicina realizada con el apoyo de los dispositivos móviles como: smartphones -teléfonos inteligentes-, tabletas, PDA - Personal Digital Assistant-". (Cabo, J., 2020).

53 Variante del $m$-Health, con la única diferencia de que se da a través del uso de iPhone® o iPod®. (Almeida, 2017). 


\subsubsection{El e-Health}

El e-Health, denominado también como e-Salud, telemedicina, salud 2.0 o medicina 2.0, de acuerdo con la Organización Mundial de la Salud (IntraMed, 2012), consiste "en el apoyo que la utilización eficaz y segura de las tecnologías de la información y las comunicaciones ofrece a la salud ${ }^{54}$ y a los ámbitos relacionados con ella, con inclusión de los servicios de atención de salud, la vigilancia y la documentación sanitarias, así como la educación, los conocimientos y las investigaciones en materia de salud".

Por otro lado, la publicación La Sociedad de la Información en España 2016 (2016) asevera que el e-Health se refiere a "la aplicación de las TIC en el amplio rango de aspectos que afectan el cuidado de la salud, desde el diagnóstico hasta el seguimiento de los pacientes, pasando por la gestión de las organizaciones implicadas en estas actividades."

Esta situación deja entrever como el e-Health está inmerso en la vida cotidiana de los pacientes así como de todas aquellas personas relacionadas con sus padecimientos a partir de aplicaciones móviles o $A p p^{55}$, dispositivos vestibles o wearable ${ }^{56}$, entre otros, es por eso que ha ido aumentado considerablemente posicionándolo en una nueva era tecnológica que tiene como objetivo el desarrollo de sistemas que promuevan la mejora en la calidad de vida y la autorrealización de aquellos involucrados en un padecimiento médico.

\subsection{Los sistemas e-Health}

\subsubsection{Definición}

Actualmente no hay referencias específicas respecto a lo que es un sistema e-Health. Sin embargo, a partir del significado de ambas palabras es posible llegar a su definición.

Por un lado, la palabra sistema refiere a un conjunto de elementos tangibles y/o abstractos -sean de origen natural o artificial- que se interconectan y relacionan entre sí, con el medio que los

54 De acuerdo con la OMS (s.f.), la salud "es un estado de completo bienestar físico, mental y social, y no solamente la ausencia de afecciones o enfermedades".

55 App es la abreviatura de la palabra application y hace referencia a una "aplicación de software diseñada para ejecutarse en los smartphones (teléfonos inteligentes), tabletas y otros dispositivos móviles." (Ceuta, s.f.).

56 De acuerdo con el Instituto Internacional Español de Marketing Digital (IIEMD, 2016) el término wearable hace referencia al conjunto de dispositivos electrónicos que se pueden llevar en alguna parte del cuerpo y que son capaces de obtener o mostrar información interactuando de forma continua con el usuario. (Tecnología para los negocios, s.f.), por ejemplo: aparatos de monitorización, dispositivos con GPS, prendas inteligentes -relojes, ropa, lentes, zapatos, joyas- entre otros. 
rodea, cuyo funcionamiento corresponde como un todo; si bien cada uno de los elementos que lo componen pueden funcionar de manera independiente siempre formarán parte de este. (Yirda, A., s.f.).

Un sistema ${ }^{57}$, de acuerdo con su naturaleza y su relación con el entorno, puede considerarse de tipo abierto -al tener entrada y salida de información que es procesada para generar más información- o de tipo cerrado -al tener un intercambio nulo de materia con el entorno transformando de manera poco significativa la información- (TGS01, s.f.).

Por otro lado, como se ha mencionado en apartados anteriores, el significado de e-Health alude a la aplicación y apoyo que la utilización de las tecnologías ofrece a la salud y a los ámbitos con los que esta se vincula.

Así, partiendo de las definiciones anteriores, se puede definir como sistema e-Health al conjunto de elementos -tangibles y abstractos- interconectados, de manera abierta, entre sí y con el contexto que los rodea, que hacen posible una aplicación eficaz y segura de la tecnología en el desarrollo y solución de problemáticas en el ámbito de la salud de las sociedades actuales.

\subsubsection{Arquitectura}

Considerando que el planteamiento del e-Health se deriva del paradigma del loT, a partir de la definición de la arquitectura de un sistema loT -establecida por Salazar y Silvestre (2016)-, la arquitectura de un sistema e-Health se divide en cuatro capas o etapas: 1) Detección, 2) Intercambio de datos, 3) Integración de la información y 4) Servicio de aplicación. (Ver: Tabla 2.1)

\begin{tabular}{|l|l|}
\hline \multicolumn{2}{|l|}{ Arquitectura IoT de cuatro capas. } \\
\hline Capa de detección & Sensores, los objetos físicos y la obtención de datos. \\
\hline $\begin{array}{l}\text { Capa de Intercambio de } \\
\text { Datos }\end{array}$ & $\begin{array}{l}\text { Transmisión transparente de datos a través de redes } \\
\text { de comunicación. }\end{array}$ \\
\hline $\begin{array}{l}\text { Capa de integtración de } \\
\text { la información }\end{array}$ & $\begin{array}{l}\text { El procesamiento de la información incierta } \\
\text { adquirida de las redes, filtrado de datos no deseados } \\
\text { e integración de información principal en } \\
\text { conocimiento útil para los servicios y los usuarios } \\
\text { finales. }\end{array}$ \\
\hline $\begin{array}{l}\text { Capa de servicio de } \\
\text { aplicación }\end{array}$ & Da servicios de contenido a los usuarios. \\
\hline
\end{tabular}

Tabla 2.1 Arquitectura loT de cuatro capas. (Salazar y Silvestre, 2016).

57 Esta investigación hará referencia a un sistema que involucra la interacción de elementos tanto tangibles como abstractos, como parte de un sistema de tipo abierto. 
Estas etapas responden a cada uno de los ámbitos -salud, tecnología y de diseño de interfaz gráfica- que conforman el sistema e-Health. (Ver: Figuras 2.2 y 2.3).

\section{SISTEMA E-HEALTH}

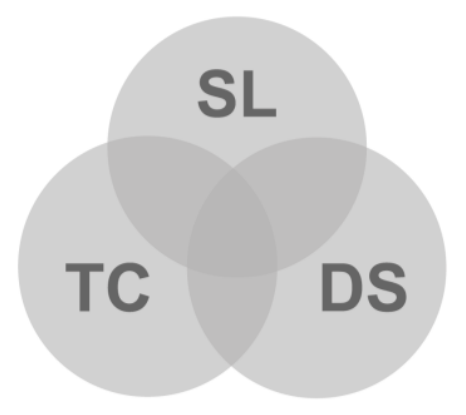

SL: Ámbito de Salud

TC: Ámbito de Tecnología

DS: Ámbito de Diseño de Interfaz Gráfica

Figura 2.2 Ámbitos que conforman un sistema e-Health.

\section{SISTEMA E-HEALTH}



SL (Ámbito de Salud)

TC (Ámbito de Tecnología)

1 Capa de Detección

2 Capa de Interacción de Datos

DS (Ámbito de Diseño de Interfaz Gráfica)

3 Capa de Integración de la información

4 Capa de Servicio de Aplicación

Figura 2.3 Pertenencia de cada capa al ámbito de un sistema e-Health. 
Finalmente, el desarrollo eficaz de un sistema e-Health, considerando cada una de estas etapas, requiere de la implementación de una estrategia de acción conformada por diversas directrices ${ }^{58}$ referentes a los diferentes ámbitos que lo integran.

\subsubsection{Los sistemas e-Health bajo la conciencia del contexto}

Al hablar de los sistemas e-Health es necesario hacer referencia a los sistemas sensibles al contexto, también conocido como sistemas de conciencia de contexto ${ }^{59}$ (CAS), que son considerados como "sistemas reactivos que se adaptan al comportamiento de acuerdo con las situaciones detectadas [..]" (Barrientos, A., Calderón, J. y Mujica, S., 2020), siendo capaces de entender y reaccionar de acuerdo al contexto de cada usuario.

Así, los sistemas e-Health sensibles a su contexto extraen datos, con relación a la salud de algún paciente o padecimiento, implementando diversos tipos de sensores ${ }^{60}$ que permitan identificar, registrar y clasificar diversas situaciones del contexto con la finalidad de poder tomar o mejorar acciones para el paciente o tratamiento del padecimiento.

\subsection{El impacto de los sistemas e-Health en el manejo de la enfermedad del Alzheimer}

De acuerdo con los planteamientos anteriores, los sistemas e-Health promueven nuevas e importantes perspectivas para el tratamiento enfermedades relacionadas con las demencias, como lo es el Alzheimer, estableciéndose como herramientas tecnológicas que pueden aportar una mejor calidad de vida a las personas que hacen uso de ellas, siempre que sean utilizadas, de acuerdo con Martínez (2018), de forma sensata y personalizada.

Sin embargo, el uso de los sistemas e-Health para mejorar la calidad de vida de las personas con Alzheimer resulta un terreno poco explorado tanto en México como en el resto del mundo y el impacto de este tipo de sistemas hasta hoy ha sido mínimo o, inclusive, nulo.

En ese sentido, son pocas las App e-Health que existen actualmente con relación a este padecimiento. Por un lado, existen algunas App dirigidas específicamente a pacientes con

\footnotetext{
58 Descritas en el capítulo 4 de esta tesis.

Basados en el concepto de Context Awareness, descrito en el apartado 2.1.2 de este capítulo.

Como por ejemplo bluetooth, cámara, micrófono, fotofotoeléctrico, GPS, sensores de movimiento o proximidad y lectores de ondas cerebrales, por mencionar algunos.
} 
Alzheimer -siendo las más reconocidas: Timeless $^{61}$, Marlin ${ }^{62}$ así como Imentia, Stimulus-Brain Challenge y Alzheimer APP TyN ${ }^{63}$, por mencionar algunas- $\mathrm{y}$, por otro, App dirigidas a cuidadores y familiares como "herramientas tecnológicas para mejorar la atención, cuidado y seguridad del enfermo" (Know Alzheimer, s.f.) -por ejemplo: YoTeCuido Azlheimer, Memory box, SuMe, Dependencia, entre otras ${ }^{64}$.

Pese a la existencia de estos sistemas e-Health específicos para el Alzheimer, su interacción con los pacientes, médicos y cuidadores aún resulta un proceso muy complejo, situación que abre oportunidades al desarrollo, principalmente, del diseño de interfaces para sistemas e-Health, las cuales hagan posible un adecuado manejo y tratamiento del padecimiento.

No hay que olvidar que el e-Health está proponiendo novedosas herramientas que hacen posible controlar, supervisar y gestionar, de una manera eficiente, las enfermedades o padecimientos mediante técnicas avanzadas -como son: el uso de la posición geográfica, el estudio de los movimientos mediante giroscopios y acelerómetros, la obtención avanzada de datos de audio y vídeo, entre otras-, haciendo posible predecir situaciones riesgosas de salud para intervenir de manera inmediata y correcta en beneficio del paciente. (Bazzani, et al., citado en Almeida 2017).

En lo esencial, el verdadero reto es identificar las áreas de oportunidad -como es el diseño y la visualización de la información en interfaces gráficas- que plantea el desarrollo de estas nuevas herramientas tecnológicas para, con ello, contribuir con la mejora en la calidad de vida de las personas que padecen la enfermedad del Alzheimer, así como de aquellos involucrados en su padecimiento.

61 App creada por una niña llamada Emma Yang -de 14 años- en los Estados Unidos de América, en virtud del padecimiento de Alzheimer por parte de su abuela, descrita en el apartado 2.2 de este capítulo.

62 App cuyo objetivo es recordar las rutinas de los pacientes, tales como levantarse, comer o ejercitarse, gracias a su sistema de alertas, además ofrece la posibilidad de que el cuidador pueda verificar que efectivamente el paciente está realizando las rutinas, mediante una serie de notificaciones. (El diario de salud, 2017).

63 Imentia, Stimulus-Brain Challenge y Alzheimer APP TyN son App que incentivan la estimulación cognitiva mediante la presentación de juegos y actividades que les permiten mantener el cerebro activo.

64 Es preciso mencionar que la función principal de estas App es brindar a los cuidadores y familiares de pacientes con Alzheimer un espacio en el que encuentren información, consejos y noticias sobre el padecimiento además de promover el diálogo y la resolución de sus dudas e inquietudes al respecto. 


\section{CAPÍTULO 3 Diseño y visualización de la información en interfaces gráficas}




\section{CAPÍTULO 3. DISEÑO Y VISUALIZACIÓN DE LA INFORMACIÓN EN INTERFACES GRÁFICAS}

\subsection{Diseño de interfaces gráficas}

\subsubsection{Definición}

Definir el diseño de interfaces gráficas de usuario implica entender el significado de algunos conceptos que conforman, en sí, al acto de diseño.

Así, por un lado, diseñar ${ }^{65}$ es considerada una actividad base de toda acción humana inmersa en el desarrollo de las sociedades, evolucionando a la par de estas y, por ende, resultando una poderosa herramienta con la cual el ser humano puede moldear sus ambientes e, incluso, a él mismo. El diseño se genera a partir de la necesidad de dar respuesta a diversas problemáticas que las sociedades presentan. (Papanek, 1977).

Por otro lado, el concepto de interfaz hace referencia, de acuerdo con la RAE (2020), a una "conexión o frontera común entre dos aparatos o sistemas independientes." Para Joan Costa (en Tovar, 2014) la interfaz es "el "cara a cara" del individuo con otro individuo, y, por extensión, de éstos con sus aparatos cotidianos [...] cuando entre éste y el individuo existe una capacidad de interacción o de influencia del uno con el otro."

En cuanto a la interacción con sistema digitales, actualmente existen varios tipos de interfaces ${ }^{66}$ que permiten al usuario relacionarse con los objetos o dispositivos dispuestos para ello, siendo la interfaz gráfica o Graphic User Interface (GUI) -tipo de interfaz que, a partir del uso de gramáticas y signos visuales así como de una manipulación directa, posibilita la comunicación del usuario con el sistema informático (Buitrón, 2011)- una de las tipologías mayormente implementadas ${ }^{67}$, debido a que permiten un uso flexible del sistema y, por ende, el aumento de la productividad del usuario

5 Acción definida por Frascara (1988) como la proyección en el espacio y en el tiempo, ordenando secuencias y relaciones en función a solucionar problemas.

66 "Para permitir al usuario interactuar con la computadora existen componentes "físicos" como teclado, mouse, touch screen, tableta gráfica, comandos verbales, entre otros, así como componentes visuales de la llamada interfaz "gráfica" tales como: ventanas, iconos, menús, botones, paletas, pulsadores, entre otros." (Rivera, M. A., 2005).

67 Actualmente la interacción entre personas y dispositivos digitales se realiza principalmente a través de una interfaz gráfica. 
En ese sentido, hablar de interfaces gráficas implica una clara referencia a la interacción del ser humano, como parte fundamental de la acción, con o a través de algún dispositivo, lo cual implica considerar las necesidades y requerimientos del usuario y basado en ello, establecer su diseño.

A partir de las definiciones anteriores, se puede entender al diseño de una interfaz gráfica como la proyección de un elemento de conexión entre un usuario y un sistema informático que, mediante el uso de gramáticas y signos visuales así como de ciertas condiciones del entorno, permita una interacción funcional que incremente la eficiencia del sistema.

\subsubsection{Consideraciones para el diseño de interfaces gráficas}

El diseño de interfaz gráfica resulta un proceso de alta complejidad debido a que de él depende si la interacción de la interfaz con el usuario resulta adecuada y se concreta la acción para la cual se diseña.

Por consiguiente, se requiere de un trabajo multidisciplinar ${ }^{68}$ que incluya, a lo largo del desarrollo del acto creativo, la intervención de especialistas del diseño así como del campo de conocimiento involucrado, quienes aporten en conjunto ideas, desde su experticia, para la adecuada estructura de la interfaz gráfica y, con ello, la obtención de mejores resultados.

Sin embargo, el diseño de una interfaz gráfica no depende exclusivamente de la consideración de los planteamientos aportados por las diversas disciplinas implicadas. Este trabajo multidisciplinar debe estar guiado por una serie de pasos o metodologías de desarrollo ${ }^{69}$, las cuales establezcan las acciones necesarias para llevar a buen fin el proceso.

Existen varias metodologías ${ }^{70}$ que pueden aplicarse al desarrollo de interfaces gráficas, mismas que en general, consideran la planeación del diseño, la estructuración de la información, el diseño y producción de la interfaz gráfica y finalmente, la evaluación de esta.

68 De acuerdo con Buitrón (2011) el diseño de una interfaz gráfica implica un trabajo multidisciplinar, en donde las disciplinas involucradas varían; sin embargo, en la mayoría de los casos, se mantienen de manera constante las disciplinas relativas a los factores humanos y ergonomía, el diseño gráfico, la Interacción y ciencias cognitivas así como las ciencias de la computación.

69

Conjunto de procedimientos basados en principios lógicos, utilizados para alcanzar una gama de objetivos que rigen en una investigación científica. La metodología estudia los métodos para luego determinar cuál es el más adecuado a aplicar o sistematizar en una investigación o trabajo. (EcuRed, s.f.).

70 M. Buitrón (2011) señala -a partir de los planteamientos del Área Ordenadores Portátiles, A. Moreno, P. Lynch y S. Horton- varias metodologías empleadas para el diseño de interfaces gráficas, como son: la Metodología de diseño hipermedia orientado a objetos, la Metodología de diseño para sitios Web, la Metodología de análisis de navegación relacional y el Proceso de desarrollo de sitios Web, por mencionar algunas. 
Por otro lado, parte del éxito de un diseño de interfaz gráfica radica en la consideración de los usuarios como protagonistas del acto creativo, es por eso, que antes de tomar decisiones con respecto al diseño de la interfaz gráfica, se deben tener en cuenta las necesidades así como las capacidades -físicas y mentales- particulares de estos para planear su experiencia con la interfaz gráfica.

A la par de establecer al usuario como parte fundamental del proceso de diseño, diseñar una interfaz gráfica implica, de acuerdo con M. Albornoz (2014), considerar algunos criterios, descritos a continuación:

- Familiaridad del usuario, es decir, que el usuario -a través del uso de recursos conocidospueda apropiarse de la interfaz de una manera natural, evitando la búsqueda de ayudas.

- Uniformidad de la interfaz, en donde el nivel de iconicidad, el código de color y en general, los recursos gráficos que la conforman sean constantes dentro de todo el sistema, conservando una misma lógica de navegación y posicionamiento que le permita al usuario reducir su tiempo de aprendizaje.

- Mínima sorpresa, haciendo que el comportamiento de la interfaz no presente situaciones que al usuario le resulten inesperadas, las cuales le causen irritabilidad y en consecuencia, pierda el interés o su atención en esta.

- Recuperación de estados, proporcionando al usuario la posibilidad de volver a un estado anterior en caso de errores al interactuar con la interfaz gráfica.

- Guías de usuarios, concretas, visibles y constantes, que incluyan apartados de ayuda que provean al usuario de recursos que proporcionen la seguridad que necesitan para desenvolverse sobre la interfaz gráfica. A su vez, se recomienda que al usar por primera vez cualquier interfaz gráfica, exista un recorrido de uso que guíe al usuario para un mejor manejo y apropiación de esta.

- Diversidad de usuarios, considerando opciones de visualización e interacción a partir de sus capacidades y diferencias particulares, evitando con ello una involuntaria exclusión.

- Adopción del punto de vista del usuario, resultando fundamental, antes y durante todo el proceso de diseño, tener presente la función de la interfaz gráfica así como las tareas y la interacción que esta permitirá. 
- Realimentación o retroalimentación, siendo menester de la interfaz indicar, de manera inmediata, una respuesta ante cualquier acción del usuario -al presionar un botón, al enviar una solicitud, entre otros, como enviar información o mensajes precisos y útiles para el usuario.

- Control del usuario sobre la interfaz, que le permita, de manera intuitiva, interactuar con esta fácilmente a través de operaciones accesibles basadas en el uso de menús principales, apartados de preferencias y opciones así como de íconos para cerrar, volver al inicio, ayuda, cancelar o deshacer operaciones, entre otras acciones.

- Mínima necesidad de memorización, a corto plazo, limitando la carga de información presentada en la pantalla al usuario, además del empleo de un lenguaje claro y conciso que le permita recordar fácilmente el mensaje.

- Anticipación de las necesidades del usuario, en donde la interfaz prediga la información que este necesita y evitar tiempo perdido en su búsqueda.

- Percepción de color y tamaño, como conceptos básicos del diseño, siendo necesario utilizar los contrastes de forma, tamaño y color para transmitir de manera correcta el mensaje, partiendo de las necesidades de percepción del usuario.

- Legibilidad, considerando el tamaño, el tipo y variación de la tipografía empleada ${ }^{71}$ requeridos para su correcta visualización en la interfaz gráfica del dispositivo.

- Valores por defecto, utilizando valores estándar ${ }^{72}$-opciones inteligentes y fáciles de modificar- que el usuario tenga como conocimiento previo, el cual se asocie con su bagaje cultural, ubicación geográfica y que además no genere un quebrantamiento en el contexto del usuario.

- Eficiencia, como objetivo de la interfaz gráfica, lograda a partir de la respuesta inmediata de la interfaz así como de la presentación precisa y concreta de la información en un

71 Existen varios principios relativos a la legibilidad de un texto en pantalla, destacando el uso de tipografías serif, con una estructura basada en un espacio interno amplio que permita establecer un contraste adecuado con el fondo y resulte acorde al contexto utilizado.

72 Un claro ejemplo de un valor estándar es el símbolo de Wi-Fi, el cual, inicialmente, no representaba nada más que un punto con tres líneas curvas en la parte superior. Ahora, gracias a su constante implementación y aprendizaje, este símbolo ha llegado a convertirse en el representante universal del concepto. 
tiempo mínimo, entre otras acciones que posibiliten la apropiación de la misma por parte del usuario y, con ello, se produzca el resultado en el momento esperado.

Como puede observarse, estos criterios consideran de manera prioritaria, además de la definición del usuario, al componente de diseño y visualización de la información, el cual establece una serie de fundamentos que determinan el adecuado diseño de una interfaz gráfica.

\subsection{Fundamentos sobre diseño y visualización de la información para diseñar interfaces gráficas}

El diseño de una interfaz gráfica implica, en su ejecución, definir la forma en cómo la información -a través de la organización y el diseño de datos complejos- será representada y visualizada ${ }^{73}$, reforzando y simplificando, con ello, la cognición humana. (Da Silva, C., 2014).

De este modo, el diseño y visualización de la información -rama del diseño- es la disciplina que se encargará de la representación, presentación y comunicación de datos -de manera simplificada y eficiente- explotando la capacidad de percepción visual del usuario con el objetivo de convertir los datos en información y de esta manera, la información se convierta en conocimiento. (Alcalde, 2012).

Para Schuller (2007), lograr una adecuada práctica de diseño y visualización de la información implica "ver el mundo a través de un filtro especial, desarmarlo con curiosidad analítica, para después volver a armarlo de una manera simplificada con un sentimiento de precisión y detalle". Por ello, diseñar una interfaz gráfica requiere la consideración de diversos planteamientos referentes a la Atención Centrada en la Persona (ACP), al modelo de Diseño Centrado en el Usuario (DCU), al diseño inclusivo, a la experiencia del usuario, la usabilidad, al diseño de la interacción así como al diseño de la comunicación gráfica, de manera que estos fundamenten su desarrollo.

73 La visualización de la información es un concepto establecido en 1991 con la creación de la Information Design Association (Information Design Association, 1996)- que hace referencia al estudio de las representaciones visuales de datos que guían al espectador a ver más allá de la información pura y dura. A su ejecución se conoce como el diseño de información. (Da Silva, C., 2014). 


\subsubsection{Atención Centrada en la Persona (ACP)}

Partiendo de ciertas cuestiones cognitivas, el diseño de interfaces gráficas debe, de manera casi obligatoria, priorizar a la persona y no a las circunstancias que la envuelven ${ }^{74}$, reconociendo la importancia de la Atención Centrada en la Persona (ACP) que establece el que la atención del usuario debe contemplar valores y preferencias que, una vez expresados, guiarán al proceso de diseño. (American Geriatrics Society, 2016. en Martínez, 2018).

Sumado a esto, también debe considerarse el enfoque de los cuidados narrativos el cual "parte de la consideración de la importancia de las narraciones de las personas en la construcción y mantenimiento de su identidad personal y social" (Villar y Serrat, 2016) y, con ello, hacer posible la construcción del relato propio del usuario que le aporte valor, significado y veracidad al ser reconocido por sí misma. (Martínez, 2018). A ese respecto, Tejedor de Atenzia, en García (2019), señala que "la personalización del servicio y la tecnología [...] permiten mejorar considerablemente la calidad de vida del usuario".

\subsubsection{Modelo de Diseño Centrado en el Usuario (DCU)}

Como se ha mencionado, el usuario es el componente principal en el proceso de diseño de interfaces gráficas, dado que a partir de sus necesidades se definen la forma, el tamaño, el volumen, el material así como el color a implementar e, inclusive, los efectos psicológicos derivados por la elección de cada uno de los elementos de diseño que conforman la interfaz. Partiendo de lo anterior, el diseño de interfaces gráficas retoma el modelo de Diseño Centrado en el Usuario (DCU), -User Centered Design (UCD)- definido por la Usability Professionals Association como un enfoque de diseño cuyo proceso está dirigido por la información de las personas que van a hacer uso de algún producto. (Hassan y Ortega, 2009).

El modelo DCU consiste en poner al usuario final en el centro del proceso de diseño, desde las fases iniciales de planificación y análisis de requisitos hasta las validaciones finales, buscando asegurar la consecución de la interfaz gráfica a partir de su funcionalidad así como de la adecuada experiencia por parte de su usuario, considerando para ello el desarrollo de 3 fases: el modelo conceptual, ofrecido por el diseñador del sistema; la interfaz, como imagen que el sistema

74 Como ejemplo de la ACP, al hacer referencia -en un sistema e-Health- a una persona que presenta problemas de salud es necesario llamarla por su nombre y no reconocerla por su enfermedad o trastorno que padezca, dotando de mayor importancia a su identidad con el fin de potencializar su experiencia con la interfaz gráfica. 
presenta al usuario; y el modelo mental, desarrollado por el usuario a partir de la imagen. (Norman, 1983).

Finalmente, el diseño centrado en el usuario resulta "un proceso [...] en el que las decisiones de diseño están dirigidas por el usuario y los objetivos que pretende satisfacer el producto, [...] donde la usabilidad del diseño es evaluada de forma iterativa y mejorada incrementalmente." (Hassan y Ortega, 2009).

\subsubsection{Diseño inclusivo}

El desarrollo de las sociedades actuales es considerado excluyente dado que su entorno está diseñado, en general, para una mayoría ${ }^{75}$, obligando a que las minorías forzosamente se adapten pese a no contar con los requerimientos físicos o mentales para hacerlo. En ese sentido, el diseño de interfaces gráficas debe ser una acción inclusiva que, partiendo de la premisa "el diseño para todos", considere a la mayor cantidad de sectores de una sociedad sin omitir a personas con situaciones vulnerables como son: bajos ingresos, necesidades específicas por edad, antropología, estado de salud, discapacidad, entre otras ${ }^{76}$.

Se plantea entonces, un diseño inclusivo ${ }^{77}$ que buscará proyectar y producir objetos o entornos de diseño que puedan ser utilizados, en la mayor medida posible, por diferentes usuarios sin distinción, beneficiando así a un mayor número de personas con relación a sus necesidades ${ }^{78}$ y capacidades particulares, dando así respuesta a los retos relacionados a la diversidad que plantea, día a día, el desarrollo de las sociedades. De acuerdo con Papanek, citado por García, Martínez y Salas (2014), asevera que no se trata de hacer un diseño especial o diferente, sino más bien crear un diseño -incluyente, integrador y accesible para todos- capaz de contemplar e integrar las necesidades de los diferentes grupos y que logre satisfacer las diversas necesidades.

75 La palabra mayoría hace referencia al sector de la población que se considera normal, el cual tiene mayor poder y derechos que el resto de los sectores -generalmente con un menor porcentaje- considerados diferentes y señalados como la minoría, lo cual genera un alto grado de discriminación. (García, 2014).

Por ello, vale la pena desmentir que el diseño inclusivo hace referencia única y exclusivamente a personas con discapacidad.

77 El diseño inclusivo es utilizado en torno a acciones proyectuales vinculadas con la integración de sujetos con diversas dificultades psicofísicas, contemplando sus limitaciones y desarrollando respuestas-productos. (Gallardo y Scaglia, 2011).

78 Las necesidades son universales para todos los individuos, pero se expresan y gratifican de maneras distintas y personalizadas dependiendo del contexto en la que la persona desarrolla su vida. 


\subsubsection{Experiencia de usuario}

Como parte del proceso de diseño de interfaces gráficas, resulta de gran importancia considerar las necesidades de los usuarios, dado que "no sólo diseñamos productos, diseñamos experiencias de usuario" (Hassan y Ortega, 2009), resultando imposible entender al producto desvinculado de su uso, su contexto o de las necesidades del usuario.

Por ello, se debe considerar un análisis preciso de los requerimientos del usuario del sistema, a partir del cual pueda preverse cómo este -a través de la interfaz gráfica- visualizará la información y reaccionará ante esta. Lo anterior, permitirá definir una experiencia del usuario ${ }^{79}$, en particular, que permita mejorar la usabilidad así como la interacción del sistema. (Ryte, 2020).

\subsubsection{Usabilidad}

La usabilidad es un término que ha cobrado mucha importancia en el desarrollo de software y se le ha reconocido como un atributo. De acuerdo con el estándar ISO 9241, citado por Ferré (2000), se le define como "el grado en el que un producto puede ser utilizado por usuarios específicos para conseguir objetivos [...] con efectividad, eficiencia y satisfacción en un determinado contexto de uso".

Retomando a I. Tovar (2014), la usabilidad de una interfaz gráfica debe ir más allá de que esta funcione bien, siendo su objetivo principal lograr una interacción fácil e intuitiva del usuario con el sistema, independientemente de su experiencia y para conseguirlo su diseño debe considerar en igual medida- la estética, la utilidad, la facilidad de fabricación, la comodidad, la funcionalidad, la durabilidad y el costo de su desarrollo. (Norman, 1990).

\subsubsection{Diseño de la interacción}

La interacción ${ }^{80} \mathrm{o}$ acción que ocurre entre el usuario y la interfaz de un sistema es un aspecto importante para el adecuado diseño de interfaces gráficas, la cual no está definida propiamente en esta sino, más bien, se considera inmersa en el código que implementa la funcionalidad de dicho sistema. Así, la interfaz gráfica será la permite visualizar dicha interacción.

9 Como parte de la interacción humano-computadora.

80 La interacción es la acción que ocurre entre el medio y una persona, la cual permite al usuario controlar el contenido y el flujo de información. (Tovar, 2014). 
El diseño de la interacción deberá estar determinado, de acuerdo con Rodríguez, González y Rossi (2014), por un proceso organizado, a partir de la consideración de las restricciones de los recursos disponibles así como de la representación de la experiencia del usuario, "para crear, dar forma y decidir todas las calidades de un artefacto digital [...]", en este caso una interfaz gráfica, "[...] orientadas al uso (estructurales, funcionales, éticas y estéticas)".

De esta manera, el adecuado diseño de interacción puede hacer que un sistema aumente su nivel de usabilidad, misma que puede verse afectada por la mala estructuración y organización de los elementos compositivos, relativos a la comunicación gráfica, que conforman el diseño de su interfaz gráfica.

\subsubsection{Diseño de la comunicación gráfica}

El objetivo principal del diseño de la comunicación gráfica es la resolución de problemas de comunicación a través de diversos medios visuales que, a partir de una idea directriz, aportan resultados estéticos y funcionales viables. Así, el diseño de la comunicación gráfica tendrá un papel determinante en el diseño de interfaces gráficas, debido a que se encarga de la organización y adecuación de los elementos visuales -tipografía, símbolos y color- que las conforman y cuya manipulación puede hacer que se cumplan o no los objetivos planteados por el sistema (Buitrón, 2004). Así, sus aportes resultan significativos para el desarrollo de interfaces claras, flexibles e intuitivas, que mantengan la atención y la motivación del usuario y, con ello, faciliten la interacción con el sistema.

Al respecto, Carlos Marrero (2006) señala que es necesario plantear un diseño de interfaz gráfica que considere recursos ${ }^{81}$ tales como: la metáfora gráfica o visual, los paradigmas W.I.M.P. (Window, Icon, Menu, Pointing device) y WYSIWYG (What You See If What You Get), la manipulación directa, la sintaxis de interacción así como la consistencia en el diseño, todos estos

81 Buitrón (2011), retomando a C. Marrero, establece las definiciones de estos recursos. En primer lugar, señala que las metáforas gráficas son representaciones, a través de iconos -familiares y lógicos al usuario, de recursos, elementos y funciones que hacen posible la interacción intuitiva con el sistema; al paradigma W.I.M.P. lo refiere como el modo genérico de la interacción, a través elementos como son: ventanas, iconos, menús y dispositivos de interfaz humana; al concepto WYSIWYG lo define como principio de diseño en sistemas de cómputo que intenta hacer coincidir los signos representados en la interfaz con la realidad del usuario; señala a la manipulación directa como un recurso de interacción que permite al usuario manipular los elementos de la interfaz como cualquier objeto de la vida real, obteniendo instantánea y directamente el efecto de las acciones que produce y, finalmente, establece la consistencia en el diseño como proceso mediante el cual se define un orden común y coherente en los elementos dispuestos para reducir, con ello, la curva de aprendizaje del sistema por parte del usuario. 
recursos orientados a que la interfaz permita al usuario -de manera natural e intuitiva- interactuar a través de ella y, así, comprender y asimilar adecuadamente la información que se presenta.

Finalmente, el diseño de interfaces gráficas requiere de una cuidadosa consideración de los factores antes mencionados, de manera que las interfaces apoyen realmente y no desvirtúen las intenciones de los sistemas implicados.

\subsection{Diseño de interfaces gráficas para un sistema e-Health}

El diseño de la interfaz gráfica para un sistema e-Health, como la de cualquier otro tipo de sistema, requiere de la implementación de los fundamentos descritos anteriormente. Sin embargo, estos deben ser considerados a partir de las necesidades propias y del contexto del sistema, tales como discapacidades físicas o mentales así como enfermedades -incluyendo su detección, tratamiento y monitorización-, en este caso, implica establecer un conjunto de directrices con relación a los ámbitos de salud, tecnología y diseño, que rijan adecuadamente el proceso. 


\section{CAPÍTULO 4 Directrices para el desarrollo de la interfaz gráfica de un sistema e-Health. Un caso de estudio}




\section{CAPÍTULO 4. DIRECTRICES PARA EL DESARROLLO DE LA INTERFAZ GRÁFICA DE UN SISTEMA E-HEALTH. UN CASO DE ESTUDIO}

\subsection{Estrategia para el diseño de la interfaz gráfica del sistema e-Health}

Desde una perspectiva general, en los capítulos anteriores, puede apreciarse que el diseño de la interfaz gráfica de un sistema e-Health implica establecer una estrategia ${ }^{82}$ que, establecida a partir de directrices referentes a los s diferentes ámbitos involucrados -salud, tecnología y diseño,${ }^{83}$ defina el desarrollo del acto creativo en cuestión. (Ver: Figura 4.1).

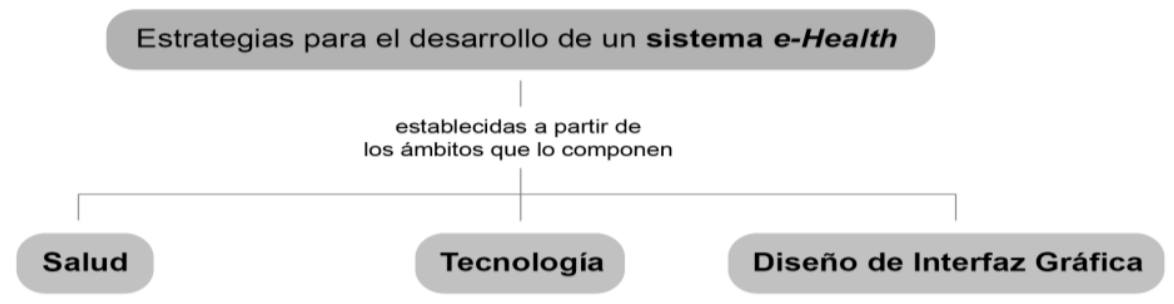

Figura 4.1 Estrategias para el desarrollo de un sistema e-Health.

Así, esta investigación propone una estrategia de diseño de interfaz gráfica para un sistema eHealth ${ }^{84}$, a partir de la definición de una serie de directrices desarrolladas para tal efecto, tomando como caso de estudio su implementación para una adecuada visualización e interpretación de los datos relativos a los pródromos de episodios en pacientes con Alzheimer a través del diseño de la interfaz gráfica.

\subsection{Directrices para el diseño de una interfaz gráfica para sistemas e-Health}

Para definir las directrices que conformen a la estrategia de diseño de la interfaz gráfica ${ }^{85}$ de un sistema e-Health debieron considerarse parámetros de diseño -proyección en el espacio y el

82 Se entiende por estrategia a un "procedimiento organizado, formalizado y orientado a la obtención de una meta claramente establecida”. (Centro Virtual de Técnicas Didácticas, citado en Buitrón, 2004).

83 Cabe señalar que una estrategia para diseñar la interfaz gráfica de un sistema de este tipo, en congruencia con sus objetivos, debe considerar todos los ámbitos que lo conforman -salud, tecnología y diseño de interfaz gráfica-, de manera que el sistema sea concebido como un todo.

84 Dados los objetivos establecidos, esta investigación únicamente abarca el ámbito de diseño de la interfaz gráfica del sistema, siendo las estrategias de salud y tecnología consideradas para una investigación posterior.

85 Pese a no abarcar los ámbitos de salud y tecnología, la definición de las directrices correspondientes al diseño de la interfaz gráfica implicó la consideración de algunos planteamientos sobre los demás ámbitos que conforman al sistema e-Health, dado que no podrían establecerse sin tomar en cuenta a todo el contexto. 
tiempo en función de solucionar problemas (Frascara, 1983)- e interpretación de datos -concebir de modo personal la realidad (RAE, 2020)-, derivados de fundamentos ${ }^{86}$ tales como la ACP, el modelo DCU, el diseño inclusivo, la experiencia del usuario, la usabilidad, el diseño de la interacción así como del diseño de la comunicación gráfica, dentro del contexto tecnológico y sanitario establecido.

Con base en estos fundamentos, se definieron las siguientes directrices: (Ver: Figura 4.2).



Figura 4.2 Directrices que conforman la estrategia de diseño de interfaz gráfica para un sistema e-Health.

1- Trabajar de manera multidisciplinaria con especialistas (stakeholders) -como médicos, enfermeras, psicólogos, terapeutas, cuidadores, diseñadores, entre otros- con la finalidad de obtener conocimientos específicos a cada campo involucrado en el diseño de la interfaz gráfica.

86 Descritos en el capítulo 3 de este documento. 
2- Planear la experiencia de usuario, con base en sus necesidades así como en el mensaje y los objetivos de la interfaz gráfica, considerando dos aspectos fundamentales: por un lado, el situar al usuario como protagonista del proceso -modelo DCU- y, por otro lado, el priorizar a la persona antes que a la enfermedad -ACP- de manera que la identidad de quien la padece sea reconocida y, con ello, se potencialice la experiencia del usuario con la interfaz gráfica. La experiencia del usuario resultante, en conjunto con el diseño de la información, debe considerar el aporte de un alto grado de usabilidad -utilidad, facilidad de uso, facilidad de aprendizaje y apreciación- a la interfaz gráfica diseñada, con el fin de que esta resulte eficiente.

3- Estructurar el mensaje (arquitectura de la información) a partir de la definición y organización de contenidos para crear vínculos lógicos entre estos; además de los contenidos propios del mensaje, deben establecerse guías rápidas de uso de la interfaz gráfica así como apartados de ayuda o resolución de dudas frecuentes con la intención de generar un alto grado de usabilidad en la interfaz gráfica del sistema. Considerando que se trata de una interfaz gráfica que aborda cuestiones de salud, el mensaje debe estar orientado hacia dicho ámbito sin dejar de reconocer que el usuario principal no necesariamente será experto en el padecimiento y lo que este involucra, por lo que el uso de la terminología implementada deberá ser adecuarse a un lenguaje acorde a su contexto.

4- Diseñar la información, retomando la planeación de la experiencia del usuario para traducirla en componentes gráficos que se perciban, a través de la interfaz gráfica, de manera simplificada e intuitiva. Para ello, deben tomarse en cuenta ciertos principios básicos de composición -organización y uniformidad-, fundamentos de leibilidad y legibilidad, la codificación del color en pantalla, entre otros, definidos como valores estándar que, basados en las necesidades particulares del usuario del sistema e-Health, hagan posible establecer una lógica de estructuración visual e interacción uniforme que clarifique el mensaje para lograr una mejor eficiencia de la interfaz gráfica.

5- Implementar condiciones estéticas que permitan a los elementos compositivos de la interfaz gráfica ser agradables al usuario sin dejar de proveer funcionalidad y eficiencia, potencializando así la experiencia de usuario previamente establecida. 
Definidas las directrices, estas fueron implementadas a través del desarrollo de un prototipo de interfaz gráfica ${ }^{87}$ para un sistema e-Health ${ }^{88}$-conformado por un dispositivo vestible provisto de sensores y una App para su interacción, que facilitará la visualización y la interpretación de datos relativos a los pródromos de episodios de pacientes con la EA, a través de esta- (Ver: Figura 4.3) que, establecido como caso de estudio, permitiera -como parte de un experimento- validar la hipótesis de la investigación así como la pertinencia de las mismas, a describirse en el capítulo siguiente.

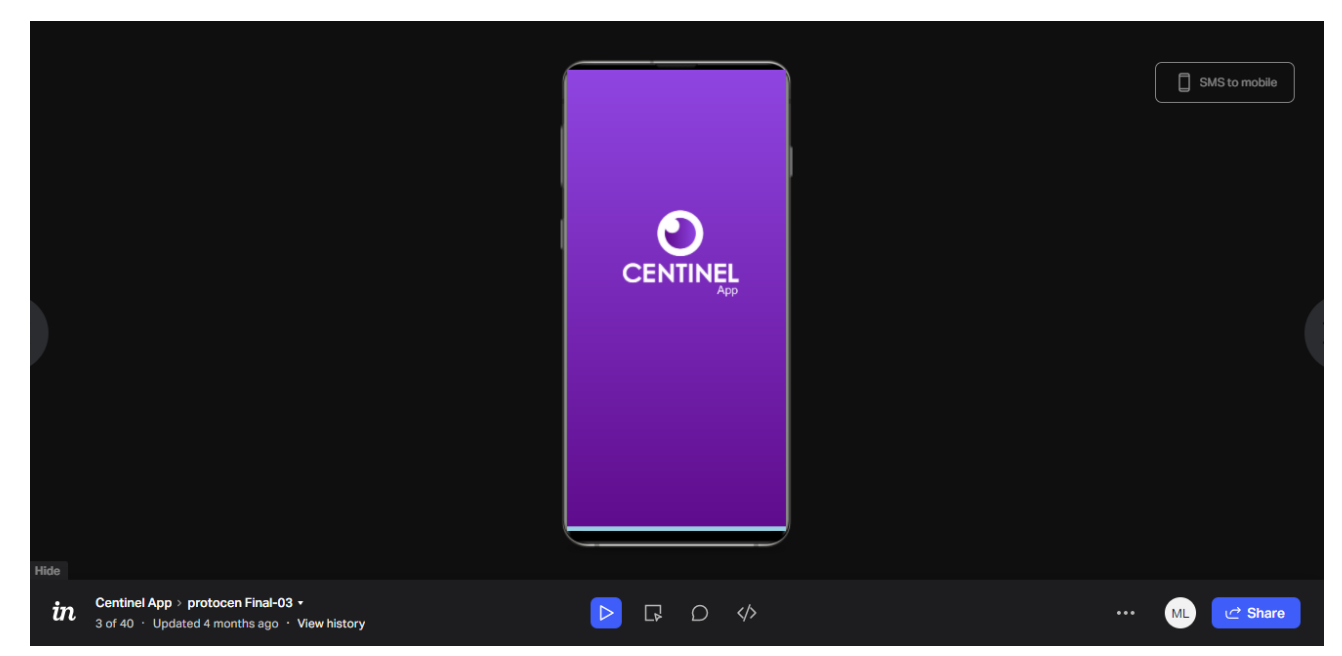

Figura 4.3 Prototipo de interfaz gráfica para el sistema e-Health CENTINEL App.

Ver: Anexo II. Prototipo de la interfaz gráfica de CENTINEL App.

88 Con base en la información recabada del estudio exploratorio inicial, se propone la creación de un sistema e-Health capaz de identificar los pródromos de episodios de Alzheimer con la finalidad de avisar al cuidador cuando un episodio de la EA se avecina, trayendo como consecuencia que el cuidador se anticipe y en el mejor de los casos pueda evitar el episodio. El funcionamiento de dicho sistema será a través de dos componentes: dispositivo vestible y App. En cuanto al dispositivo vestible se refiere, se hace una propuesta inicial del uso de un smartwatch (reloj inteligente) equipado con sensores capaces de identificar dichos pródromos y haciendo llegar los datos recuperados al software de la App que, a través de su interfaz, los visualizará e interpretará para que el usuario del sistema pueda comprender la información y, con ello, conducirse a la acción o a la toma de decisiones. 


\section{CAPÍTULO 5 Metodología de investigación}




\section{CAPÍTULO 5. METODOLOGÍA DE INVESTIGACIÓN}

\subsection{Problema}

Derivado de la insuficiente cantidad de personal capacitado así como de instituciones de salud enfocadas al tratamiento de la enfermedad del Alzheimer en México, son los familiares de los pacientes quienes, generalmente, les proporcionan los cuidados necesarios desde sus propios hogares sin contar con la infraestructura ni los conocimientos requeridos para ello.

Actualmente existen aplicaciones tecnológicas que intentan apoyar al tratamiento, desde casa, de la enfermedad. Sin embargo, en nuestro país, aún no se documenta el desarrollo de sistemas e-Health que permitan a los cuidadores monitorear, desde casa, al paciente con Alzheimer, con el objetivo de identificar los pródromos o síntomas que preceden a los episodios de la enfermedad para controlar y en el mejor de los casos, evitar la crisis.

Esta situación, demanda de investigaciones que permitan determinar las condiciones bajo las cuales se puedan desarrollar las interfaces gráficas adecuadas de dichos sistemas, en virtud de que estas serán las que permitan visualizar e interpretar los datos relativos a la presencia de pródromos de episodios en pacientes con Alzheimer.

\subsection{Preguntas de investigación}

- ¿Cómo la tecnología y, en particular, el Internet de las Cosas pueden influir en el ámbito médico?

- ¿De qué manera el diseño de la visualización de la información puede aportar al ámbito médico?

- ¿Cuáles son las estrategias que harían posible el desarrollo de un sistema e-Health?

- ¿Podría la implementación de un sistema e-Health apoyar al monitoreo y tratamiento de pacientes con Alzheimer?

- ¿El diseño y visualización de la información influye en el desarrollo de interfaces gráficas de sistemas e-Health que posibiliten la adecuada interpretación gráfica de datos proporcionados acerca de pródromos en episodios de Alzheimer? 


\subsection{Objetivos}

\subsubsection{General}

Establecer una serie de directrices -propias del diseño y la visualización de la información, además de su relación con el ámbito de salud y la tecnología- para el desarrollo de la interfaz gráfica de un sistema e-Health que facilite la visualización e interpretación de datos relativos a los pródromos de episodios de pacientes con la enfermedad del Alzheimer, a través de esta.

\subsubsection{Específicos}

1. Revisar el estado del arte de la enfermedad del Alzheimer.

2. Resumir los pródromos de los episodios de pacientes con Alzheimer.

3. Explicar los conceptos que definen al e-Health como parte del paradigma del Internet de las Cosas.

4. Inferir el papel del e-Health en el tratamiento del Alzheimer.

5. Identificar los ámbitos que definen el desarrollo de un sistema e-Health.

6. Resumir directrices para el desarrollo de una interfaz gráfica de un sistema e-Health.

7. Validar con expertos en el objeto de estudio, la viabilidad de las directrices propuestas a través del desarrollo e implementación de una interfaz gráfica de un sistema e-Health para el Alzheimer.

\subsection{Hipótesis}

Aplicar directrices propias del diseño y la visualización de la información, además de establecer su relación con el ámbito de salud y la tecnología al desarrollo de la interfaz gráfica de un sistema e-Health facilitará la visualización e interpretación de datos relativos a los pródromos de episodios de pacientes con la enfermedad del Alzheimer a través de esta.

\subsection{Tipo y metodología de investigación}

Con relación a los objetivos establecidos, esta investigación reside como un estudio de tipo exploratorio y transversal, debido a que se basa, por un lado, en el análisis e investigación de aspectos concretos de la realidad aún no analizados a profundidad y, por otro, en la comparación de determinadas características o situaciones en diferentes sujetos, que comparten la misma temporalidad, en un momento concreto. (Castillero, 2016). 
Su desarrollo se fundamenta en el empleo de una metodología con un enfoque tanto cuantitativo como cualitativo, sustentado en la sistematización del método científico y en la flexibilidad que implica el carácter subjetivo del fenómeno, a través de una serie de fases que involucran las siguientes acciones: (M. Buitrón, citada en López, 2018).

- Fase I. Definición, delimitación y ubicación del problema:

1) Definición del problema.

2) Formulación de la metodología de investigación.

- Fase II. Estructuración del marco teórico y de referencia:

1) Recolección de información.

2) Procesamiento y análisis de datos.

3) Definición de conceptos que justifiquen las teorías de aplicación.

- Fase III. Desarrollo de la propuesta:

1) Definición del método.

2) Epistemología de desarrollo.

3) Definición de estrategias de desarrollo.

- Fase IV. Instrumentación y validación del proyecto:

1) Diseño y aplicación de instrumentos de evaluación.

2) Análisis estadístico.

3) Resultados.

- Fase V. Elaboración de conclusiones.

\subsection{Instrumentación y validación del proyecto}

\subsubsection{Método de validación}

Para validar la hipótesis establecida, se hizo necesario el desarrollo de un experimento capaz de demostrar que la aplicación de directrices de diseño y visualización de la información en el desarrollo de la interfaz de un sistema e-Health facilitará la interpretación gráfica de los datos relativos a los pródromos de episodios en pacientes con Alzheimer. 
Dado el carácter subjetivo de la hipótesis, la validación consideró la implementación del Método Delphi ${ }^{89}$, como herramienta para obtener pronósticos precisos a partir de "un juicio intuitivo emitido por un grupo de expertos" (Bustamante, 2012) y su desarrollo se fundamentó en las siguientes etapas: (Ver: Figura 5.1).

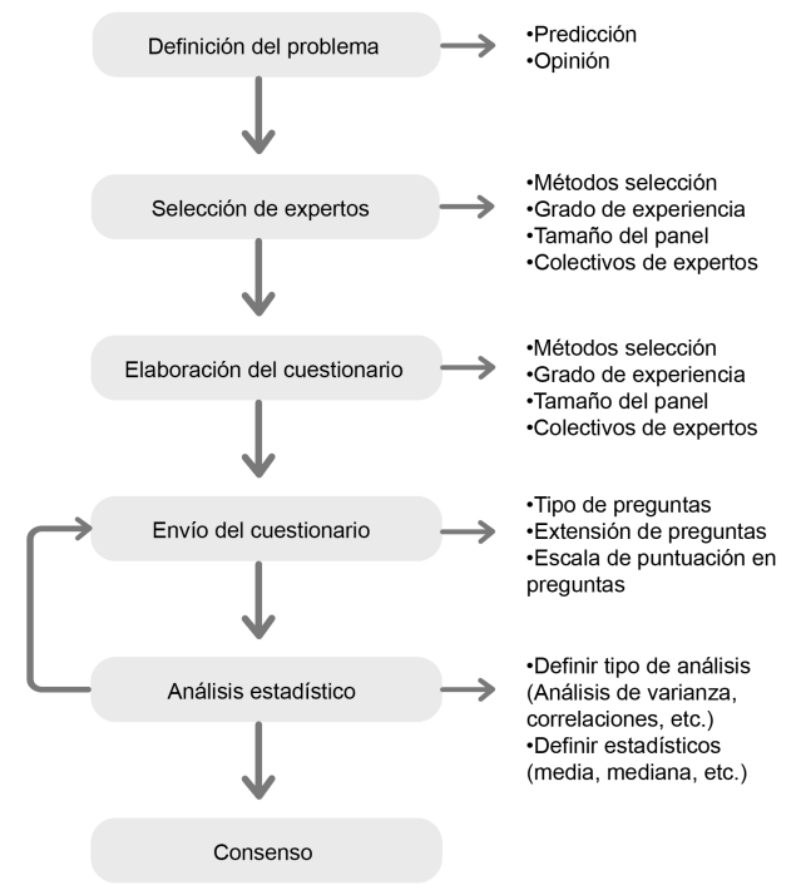

\section{Figura 5.1 Etapas de un análisis Delphi en el estudio de los intangibles, propuestas por María Paloma Sánchez, et al. (Seguí-Mas y Server, 2010).}

\subsubsection{Desarrollo del experimento}

\section{Acciones previas}

Como acciones previas al diseño e instrumentación del experimento, debió definirse un caso de estudio -relativo a la interpretación de datos sobre pródromos de Alzheimer- y, a partir de este,

89 Método subjetivo de prospectiva, que consiste en la selección de un grupo de expertos a los que se les pregunta su opinión sobre cuestiones referidas a acontecimientos del futuro y posea conocimientos sobre el tema consultado (Astigarraga, E. s.f.).

Cabe mencionar que la elección de este método se fundamentó, con base en los objetivos de la investigación, en la necesidad de evaluar la propuesta solo con los especialistas relacionados al campo del conocimiento involucrado, sin considerar para ello al usuario final de la misma. 
desarrollar un prototipo de interfaz gráfica ${ }^{90}$ de un sistema e-Health que permitiera someter a prueba la hipótesis de la investigación.

\section{Etapa I. Definición del problema}

Desarrollado el prototipo de interfaz gráfica, se establecieron las condiciones para el diseño e implementación de un experimento de validación definido en función a la corroboración de la adecuada visualización e interpretación gráfica de los datos relativos a los pródromos de episodios en pacientes con Alzheimer a través de un sistema e-Health, lo cual permitiera evidenciar la efectividad de las directrices para el diseño de interfaces definidas.

\section{Etapa II. Selección de expertos}

Posteriormente, el diseño del experimento requirió de una selección aleatoria de expertos, quienes -gracias a su experticia ${ }^{91}$ en diversos campos relacionados con el cuidado y tratamiento del Alzheimer- pudieran aportar significativamente a la validación correspondiente.

Así, acorde con el tipo y grado de experticia de cada una de las personas seleccionadas, se determinó un panel heterogéneo de estudio ${ }^{92}$ conformado por expertos en diseño y visualización de la información, en e-Health, en medicina -incluyendo médicos, psicólogos y terapeutas-, y finalmente, en cuidados del paciente.

Dicho panel fue conformado por un total de 10 expertos $^{93}$, considerando a 2 expertos en diseño y visualización de la información, 2 expertos en e-Health, 4 expertos en medicina -médico (1), enfermera (1), psicólogo (1) y terapeuta ocupacional (1)- y 2 expertos en cuidados del paciente, todos ellos relacionados con la enfermedad de Alzheimer.

Es importante mencionar que este mismo panel fue considerado en todas las rondas de aplicación del experimento, permitiendo a sus integrantes ahondar en sus opiniones y, con ello, llegar respuestas certeras.

90 Ver: Anexo II. Prototipo de la interfaz gráfica de la App.

91 Experticia, palabra derivada del inglés expertise que indica la "cualidad de una persona [...] en la que se unen la experiencia y la pericia en un campo". (Asociación de Academias de la Lengua Española, en Fundéu RAE, 2013).

92 Por la naturaleza de la hipótesis, para su validación se requirió la participación de individuos expertos en distintas áreas del conocimiento, es decir, un grupo heterogéneo con un alto grado de correspondencia con los temas relevantes en el proyecto de investigación. (Bustamante, 2012).

93 De acuerdo con Betancourt (2015), el tamaño del panel puede oscilar desde los 5 hasta los 100 o más expertos, tomando en cuenta que "entre más participantes, mayor será el tiempo de aplicación". 
Para cumplir con la característica de iteración ${ }^{94}$, propia del método Delphi, a partir de la etapa III, las fases se llevaron a cabo en dos rondas.

\section{Ronda No.1}

\section{Etapa III. Elaboración de cuestionario (R.1)}

Para llevar a cabo la primera prueba con el prototipo de interfaz gráfica desarrollado se requirió diseñar un cuestionario como instrumento de validación (Ver: Figura 5.2), que permitiera evaluar la efectividad de las directrices de diseño y visualización de la información previamente establecidas.

Para ello, se definieron preguntas anónimas de selección múltiple (20) -cuantitativas- y abiertas (1) -cualitativas- estructuradas en función del diseño y la visualización de la información así como de la interpretación gráfica de los datos en el prototipo de interfaz, como indicadores de validación.

Como formato de respuestas y su escala de valoración, se eligió uno basado en la escala tipo Likert $^{95}$, a partir de los siguientes parámetros: Totalmente de acuerdo (10), De acuerdo (8), Ni de acuerdo ni en desacuerdo (6), En desacuerdo (4) y Totalmente en desacuerdo (2).

94 Característica que se obtiene con base, en la presentación del mismo cuestionario más de una vez, con la finalidad de conseguir que los expertos vayan conociendo los diferentes puntos y así, puedan ir modificando su opinión, con el objetivo de precisar la mediana de las respuestas obtenidas. (Bustamante, 2012).

95 Se eligió como escala de valoración al formato de respuestas Likert dado que, a partir de un acercamiento a la percepción de los individuos, propicia la obtención de respuestas de tipo cualitativo con respecto a una posición positiva, neutral o negativa de los encuestados frente al cuestionamiento. 


\section{Cuestionario de validación de directrices}

Cuestionario de validación de directrices para el diseño y la visualización de la información mediante la interfaz gráfica de un sistema e-Health.

¡Hola!, antes de comenzar queremos agradecerte por la ayuda y disposición para contestar este cuestionario. Dicho cuestionario tiene como finalidad corroborar que las directrices propuestas para el desarrollo de la interfaz de un sistema e-Health permiten facilitar la interpretación gráfica de los datos relativos a los síntomas de un episodio de Alzheimer, en función a un caso de estudio simulado, como parte de la investigación para obtener el grado de maestra en Diseño y Visualización de la Información, Posgrado ofrecido por la UAM Unidad Azcapotzalco.

Después de ver el video y, en su caso, revisar el prototipo en línea, se solicita contestar las siguientes preguntas, de la manera más honesta posible. El cuestionario cuenta con dos secciones:

1- Diseño y Visualización de la Información

2- Interpretación gráfica de datos

Datos iniciales

1. Podrías escribir tu correo electrónico: *

Escriba su respuesta

2. Eres experto en: *

Selecciona el más acorde a tu expertise o rol

Diseño y Visualización de la Información

Diseño e-Health

Medicina

Cuidados del paciente

Otros (psicólogos, terapeutas, etc.)

\section{Siguiente}

\section{Cuestionario de validación de directrices}

* Obligatorio

Diseño y Visualización de la Información

$\underset{\star}{3 .}$ ¿El tamaño y fuente de la tipografía elegida facilita la visualización de la información presentada?

Totalmente de acuerdo

De acuerdo

Ni de acuerdo ni en desacuerdo

En desacuerdo

Totalmente en desacuerdo 
4. ¿Los colores implementados son los indicados para una adecuada visualización de la información presentada?"

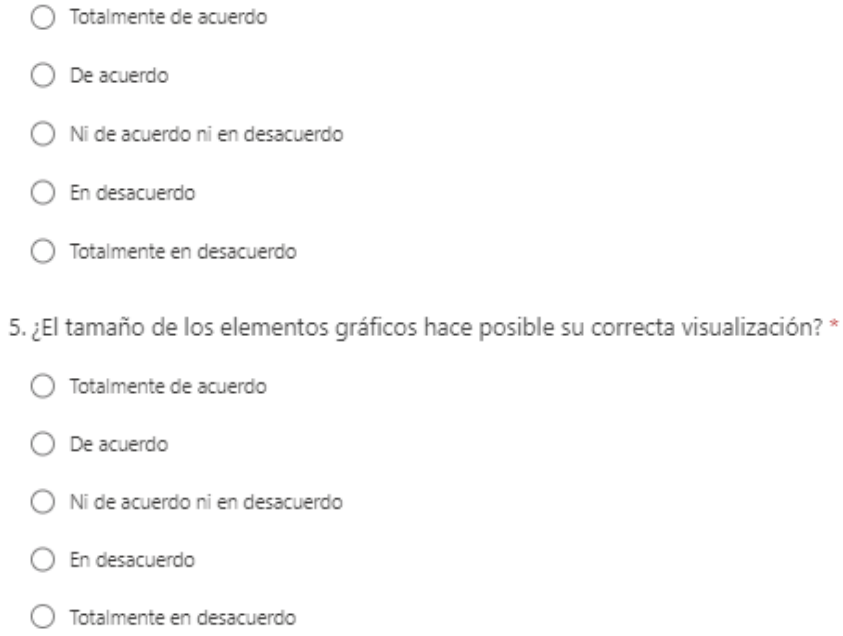


9. ¿Las pantallas presentan información de una manera clara y sencilla, sin saturar la pantalla? *

Totalmente de acuerdo

De acuerdo

Ni de acuerdo ni en desacuerdo

En desacuerdo

Totalmente en desacuerdo

10. ¿La información está organizada y estructurada de manera que jerárquicamente se presentan los contenidos? *

Totalmente de acuerdo

De acuerdo

Ni de acuerdo ni en desacuerdo

En desacuerdo

Totalmente en desacuerdo

11. ¿Considera que la interacción planteada resulta ágil para navegar en la interfaz? *

Totalmente de acuerdo

De acuerdo

Ni de acuerdo ni en desacuerdo

En desacuerdo

Totalmente en desacuerdo

12. ¿Resulta claro el regreso a un estado anterior y, posteriormente, la posibilidad de continuar? *
Totalmente de acuerdo
De acuerdo
Ni de acuerdo ni en desacuerdo
En desacuerdo
Totalmente en desacuerdo 
Cuestionario de validación de directrices

* Obligatorio

Interpretación gráfica de datos

13. ¿El diseño y visualización de la información de la interfaz gráfica corresponde a una app de ámbito médico? *

Totalmente de acuerdo

De acuerdo

Ni de acuerdo ni en desacuerdo

En desacuerdo

Totalmente en desacuerdo

14. ¿ldentificó fácilmente cada apartado -indicadores en tiempo real, históricos por día, semana y mes, menú, ayuda, entre otras- de la aplicación? * [?,

Totalmente de acuerdo

De acuerdo

Ni de acuerdo ni en desacuerdo

En desacuerdo

Totalmente en desacuerdo

15. ¿La información proporcionada por los indicadores -oxigenación sanguínea, ritmo cardíaco, temperatura y presión arterial- en tiempo real resulta fácil de entender? *

Totalmente de acuerdo

De acuerdo

Ni de acuerdo ni en desacuerdo

En desacuerdo

Totalmente en desacuerdo

16. ¿La información proporcionada por los indicadores de oxigenación sanguínea, ritmo cardíaco y temperatura, en histórico, a través de gráficas de línea resulta fácil de entender? *

Totalmente de acuerdo

De acuerdo

Ni de acuerdo ni en desacuerdo

En desacuerdo

Totalmente en desacuerdo 
17. ¿La información proporcionada por el indicador de presión arterial, en histórico, a través de tablas resulta fácil de entender? *

Totalmente de acuerdo

De acuerdo

Ni de acuerdo ni en desacuerdo

En desacuerdo

Totalmente en desacuerdo

18. ¿Resulta clara la forma en que se clasifican los 3 tipos de registros (normal, notificado y de episodio registrado)? *

Totalmente de acuerdo

De acuerdo

Ni de acuerdo ni en desacuerdo

En desacuerdo

Totalmente en desacuerdo

19. ¿Resulta funcional el registro de los episodios de Alzheimer con la finalidad de llevar un control del paciente? *

Totalmente de acuerdo

De acuerdo

Ni de acuerdo ni en desacuerdo

En desacuerdo

Totalmente en desacuerdo

20. ¿El diseño y la visualización de la información en el historial es clara con referencia al día y hora en los que fue registrado un episodio? *

Totalmente de acuerdo

De acuerdo

Ni de acuerdo ni en desacuerdo

En desacuerdo

Totalmente en desacuerdo

21. ¿La interfaz se adapta a las necesidades particulares de cada usuario, haciendo referencia al cuidador y al paciente? *

Totalmente de acuerdo

De acuerdo

Ni de acuerdo ni en desacuerdo

En desacuerdo

Totalmente en desacuerdo 


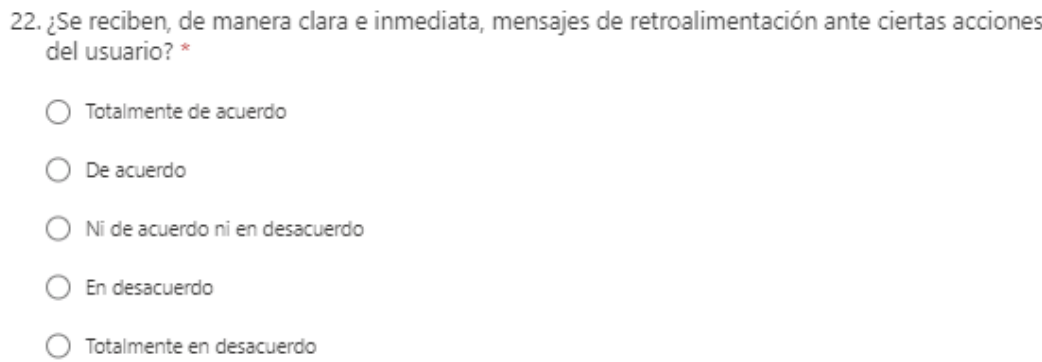

\section{Cuestionario de validación de directrices}

* Obligatorio

Para terminar..

23. ¿Consideras que contar con un sistema e-Health que notifique oportunamente el comienzo de un episodio de Alzheimer permitiría manejarlo de una manera más adecuada y, en el mejor de los casos, evitarlo? *

Explica ¿por qué?

\section{Escriba su respuesta}

Figura 5.2 Cuestionario (R.1).

\section{Etapa IV. Envío del cuestionario (R.1)}

Definido el instrumento de validación, se envió al panel de expertos para ser debidamente requisitado posterior a la revisión del prototipo de diseño.

Sucede pues, que su aplicación implicó, por un lado, sostener una entrevista personal -vía videoconferencia ${ }^{96}{ }_{-}$con cada uno de los expertos seleccionados para proporcionarles información sobre las condiciones para el desarrollo del procedimiento de validación y, posteriormente, enviarles -por correo electrónico- un video ${ }^{97}$ con las instrucciones y las ligas de

96 La entrevista previa a la aplicación del instrumento se llevó a cabo, de manera individual, con cada uno de los expertos a través de la plataforma Google Meet.

97 La explicación en video hacía referencia, en primer lugar, a una revisión e interacción previa con el prototipo de la interfaz en el dispositivo digital que ellos dispusieran y, a partir de ello, contestar y enviar el cuestionario. 
acceso correspondiente al prototipo de interfaz gráfica del sistema e-Health propuesto y del cuestionario de validación. (Ver: Figura 5.3).

MONICA YAZMIN LOPEZ LOPEZ <myII@azc.uam.mx>

« :

Estimado experto

Espero que usted y su familia se encuentren muy bien ante la situación que estamos atravesando

A través de este medio me permito enviarle el cuestionario I, del cual previamente habiamos hablado, esto con la finalidad de validar las directrices de diseño y visualización de la información propuestas en el proyecto de investigación que me encuentro desarrollando

Sin embargo, antes de contestar dicho cuestionario es necesario revisar el siguiente video que contiene una breve explicación del prototipo de la App Centinel en el cual se encuentran aplicadas las directrices propuestas en este proyecto de investigación: https://youtu.be/q7J4JKXA7WY

Posteriormente se le recomienda interactuar con el prototipo: https://germonkeys. invisionapp.com/overview/Centinel-App-ckc5rwh800dfk018grkja6sv0/ $\underline{\text { screens }}$

Finalmente se deberá contestar el cuestionario: https://forms.office.com/Pages/ResponsePage.aspx?id=mx5m8E_sWkWulDiYHCeMr3TrT8ig= JdGoADYg 42dr7BUN09MOEEyRIZWRUZSMDkzNUFFSjgxSUQ1My $\underline{4 u}$

Muchas gracias por su ayuda, si existe alguna duda o comentario no dude en contactarme. Saludos cordiales.

DCG.Mónica López

Figura 5.3 Envío de correo electrónico a expertos (R.1).

\section{Etapa V. Análisis estadístico (R.1)}

Habiendo obtenido los resultados de la aplicación del instrumento de validación, se procedió a hacer su análisis estadístico ${ }^{98}$.

En primer lugar, se vaciaron y ordenaron los datos recabados, derivando en la siguiente tabla de resultados (Ver: Tabla 5.1).

98 Pese a que los resultados obtenidos fueron de tipo cualitativo, estos debieron ser analizados bajo un enfoque cuantitativo (estadística descriptiva) con la finalidad de arrojar datos precisos obtenidos de la subjetividad de los indicadores de validación. 


\begin{tabular}{|c|c|c|c|c|c|c|}
\hline PRESUNTA & $\begin{array}{l}\text { TOTAL MENTE } \\
\text { DEACUERLO }\end{array}$ & DE ACUERDO & $\begin{array}{c}\text { NI DEACUERDO } \\
\text { NIEN } \\
\text { DESACUERLO }\end{array}$ & EN DESACUERLO & $\begin{array}{l}\text { TOTALLMENTE EN } \\
\text { DESACUERTO }\end{array}$ & TOTAL \\
\hline \multicolumn{7}{|c|}{ Secclon: C1ı noy Wiuallizacion de is ntom acion } \\
\hline 3- ¿El taman̂́o y fuente de la tipografía elegida facilita la visualiz ación de la in brmación presentada? & 7 & 2 & 0 & 1 & 0 & 10 \\
\hline $\begin{array}{l}4 \text { ¿Los colores implementados son los indicados para una adecuada visualiz ación de la informa ción } \\
\text { presentada? }\end{array}$ & 4 & 5 & 0 & 1 & 0 & 10 \\
\hline 5. ¿El taman̂́o de los elementos gráícos hace pos sible su correcta visualización? & 9 & 1 & 0 & 0 & 0 & 10 \\
\hline $\begin{array}{l}\text { 6- ¿Eltipo de representación de los elementos gráicos hace que sean identificables, de acuerdo a sus } \\
\text { inciones? }\end{array}$ & 7 & 2 & 1 & 0 & 0 & 10 \\
\hline 7. ¿Existe uniformidad en la representación grá ica de la in tomación? & 7 & 3 & a & 0 & 0 & 10 \\
\hline $\begin{array}{l}\text { 8- ¿La disposición ycomposición de los elementos gráicos facilitan la visualiz ación y comprensión de la } \\
\text { información? }\end{array}$ & 7 & 3 & 0 & 0 & 0 & 10 \\
\hline 9. ¿Las pantallas presentan intormación de una manera clara y sencilla, sin saturar la pantalla? & 7 & 2 & 0 & 1 & 0 & 10 \\
\hline $\begin{array}{l}\text { 10. ¿La información está organiz ada ye structura da de manera que jerárquicamente se presentan los } \\
\text { contenidos? }\end{array}$ & 6 & 3 & 1 & 0 & 0 & 10 \\
\hline 11. ¿Considera que la interacción plante ada resulta ágil para navegar en la interfaz? & 6 & 3 & 1 & 0 & 0 & 10 \\
\hline 12- ¿Fesulta claro el regreso a un estado anterior y. posteriom ente, la posibilidad de continuar? & 6 & 3 & 1 & 0 & 0 & 10 \\
\hline \multicolumn{7}{|c|}{ Seccion: ntarprétacion gra nea de dator } \\
\hline $\begin{array}{l}\text { 13. ¿日 diseño y visualización de la informacóón de la intertaz gráfica corresponde a una app de ámbito } \\
\text { médico? }\end{array}$ & 5 & 3 & 0 & 2 & 0 & 10 \\
\hline $\begin{array}{l}\text { 14 ¿de lientifó f́́cilmente cada apartado -in dicadores en tiempo real, históricos por día, semana y mes. } \\
\text { menú, ayuda, entre otras- de la aplicación? }\end{array}$ & 6 & 3 & 1 & 0 & 0 & 10 \\
\hline $\begin{array}{l}\text { 15. ¿La intormación proporcionada por los indicadores -oxigenación sanguín ea, ritumo cardíaco. } \\
\text { temperatura y presión arterial- en tiempo real resulta tácil de entender? }\end{array}$ & 6 & 3 & 1 & 0 & 0 & 10 \\
\hline  & 5 & 5 & 0 & 0 & 0 & 10 \\
\hline $\begin{array}{l}\text { 17. ¿La información proporcionada por el indicador de presión arterial, en histórioo, a través de tablas } \\
\text { resulta facil de entender? }\end{array}$ & 8 & 4 & 0 & 0 & 0 & 10 \\
\hline $\begin{array}{l}\text { 18- ¿Ressulta clara la forma en que se dasiican los } 3 \text { tipos de registros (nomal, noticado y de episodio } \\
\text { registrado)? }\end{array}$ & 7 & 2 & 1 & 0 & 0 & 10 \\
\hline $\begin{array}{l}\text { 19- inesylta funcional el registro de los episo dios de Azheimer con la finalidad de llevar un control del } \\
\text { paciente? }\end{array}$ & 8 & 2 & 0 & 0 & 0 & 10 \\
\hline $\begin{array}{l}\text { 20. ¿日 diseño y la visualización de la información en el historial es clara con referencia al día yhora en los } \\
\text { que tue registrado un episodio? }\end{array}$ & 6 & 3 & 1 & 0 & 0 & 10 \\
\hline $\begin{array}{l}\text { 21. i La interfaz se adapta a las necesidades particulares de cada usuario, haciendo referencia al cuidador } \\
\text { yal paciente? }\end{array}$ & 5 & 3 & 1 & 1 & 0 & 10 \\
\hline $\begin{array}{l}\text { 22. ¿Se reciben, de manera clara e inmediata, mensajes de retroalimentación ante ciertas acciones del } \\
\text { usuario? }\end{array}$ & 4 & 5 & 0 & 0 & 1 & 10 \\
\hline \multicolumn{7}{|c|}{  } \\
\hline \multicolumn{7}{|c|}{ 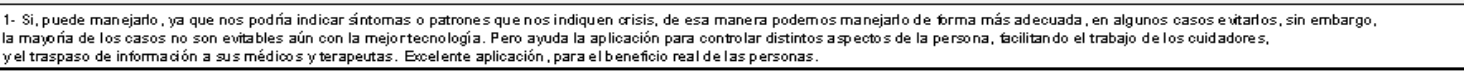 } \\
\hline \multicolumn{7}{|c|}{ 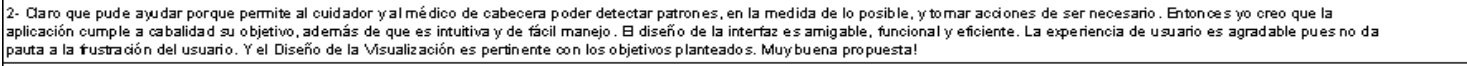 } \\
\hline \multicolumn{7}{|c|}{$\begin{array}{l}\text { 3. Aaro, ya que puedes tener una mejor respue sta y quizátener preparadas algunas herramientas que ayuden a estabilizar al paciente, en comparación a que no tengas un aviso previo } \\
\text { yte encuentres, obien en otro lugar o haciendo otras cosas. Por otro lado el tener re gistros de los episodios puede llevar a tener un común denomina dor que pueda ayudar en un nuturo a } \\
\text { las in vestigaciones sobre la enferme dad. }\end{array}$} \\
\hline \multicolumn{7}{|c|}{$\begin{array}{l}\text { 4. S1, justamente por que uno pue de identificar esos indicadores que son previos a una crisis, porlo cual uno puede estarprevenido con su paciente e induso hacer algunas acciones que } \\
\text { han demostrado pueden extar la crisis }\end{array}$} \\
\hline \multicolumn{7}{|c|}{ 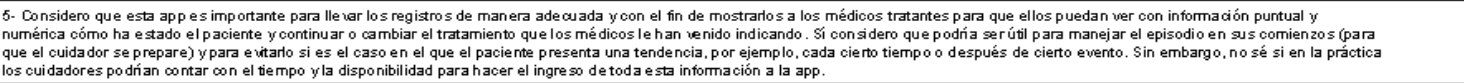 } \\
\hline \multicolumn{7}{|c|}{ 6- Si, es adecuado anticip arse al evento, sin embargo se debeńa de brindar un cuademillo de estrate gias de cómo atender a los episodios. } \\
\hline \multicolumn{7}{|c|}{ 7. Si, debido a que es importante estar atentos al momento del episodio para que el paciente no se encuentre re aliz ando alguna actividad que pueda poner en peligro su integridad. } \\
\hline \multicolumn{7}{|c|}{$\begin{array}{l}\text { 8. Es importante contar con la stención personalizada para el paciente y mantener a sus tamiliare so cuidadores informados del estado de salud actual de la persona con Azheimer. } \\
\text { La tecología es un apoyo inmediato que pue de prop orcionar dicha información y estar al pendie nte del mismo. Considero que las personas que se encuentran al cuidado del este tipo de pacientes } \\
\text { pueden manejar mejor el episodio ycon más experiencia cada vez que aparez can los indioadores. }\end{array}$} \\
\hline
\end{tabular}

Tabla 5.1 Tabla de resultados (R.1).

Ordenados los datos, fueron codificados (Ver: Tabla 5.2) con la finalidad de implementar un análisis de estadística descriptiva ${ }^{99}$, complementada con la información del apartado cualitativo del instrumento.

99 La estadística descriptiva, "recolecta, presenta y caracteriza un conjunto de datos con el fin de describir apropiadamente las diversas características de ese conjunto." (Becerra, s.f.). 


\begin{tabular}{|c|c|c|c|c|}
\hline $\begin{array}{c}\text { Totalmente de } \\
\text { acuerdo }\end{array}$ & De acuerdo & $\begin{array}{c}\text { Ni de acuerdo ni en } \\
\text { desacuerdo }\end{array}$ & En desacuerdo & $\begin{array}{c}\text { Totalmente en } \\
\text { desacuerdo }\end{array}$ \\
\hline 10 & 8 & 6 & 4 & 2 \\
\hline
\end{tabular}

Tabla 5.2 Valores para la codificación de datos.

El análisis estadístico contempló la obtención de las medidas de tendencia central -media, mediana y moda- ${ }^{100}$ (Ver: Figura 5.3), a través de las cuales se interpretó la información para la obtención de los resultados de la validación, mostradas a continuación:
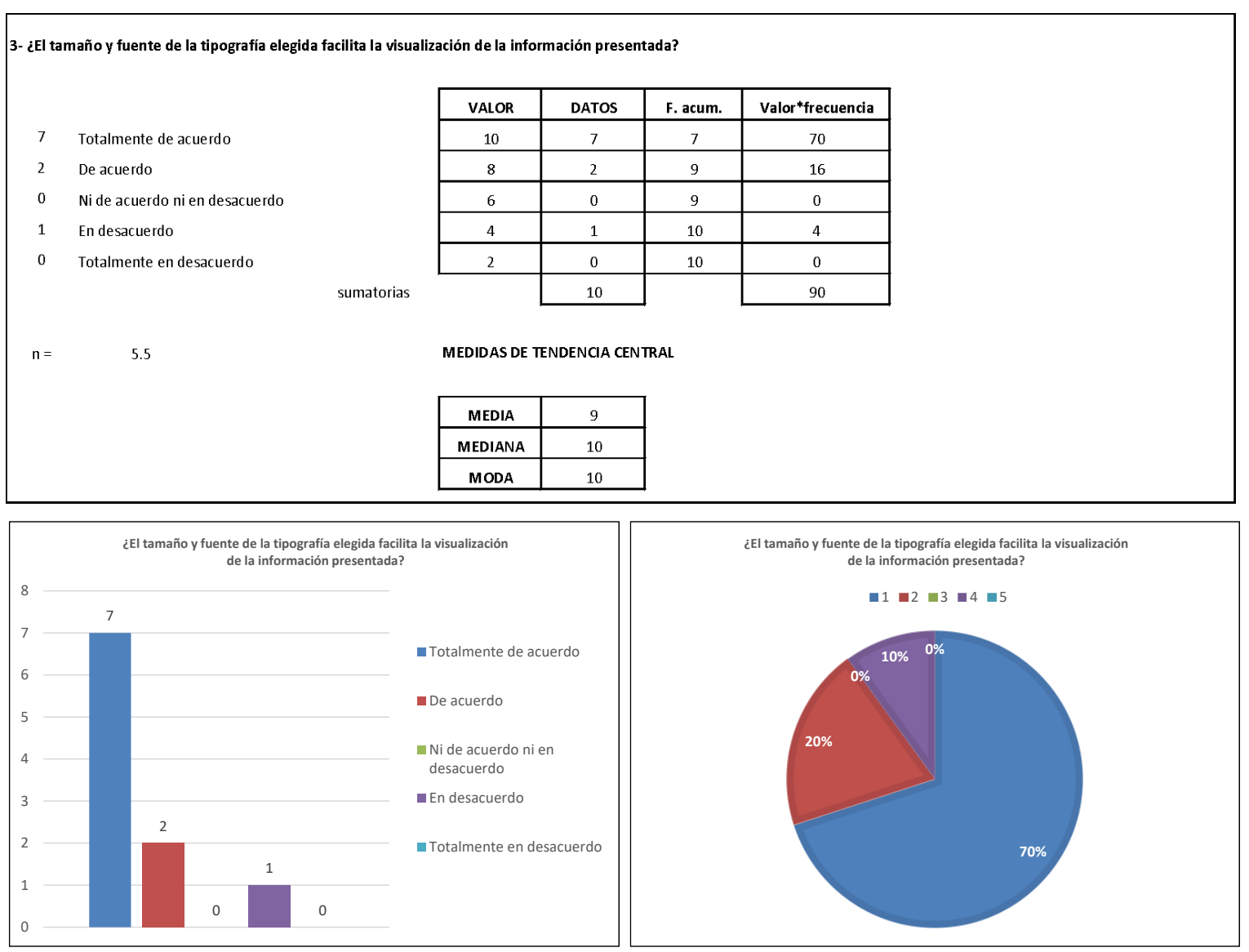

Los datos obtenidos a través del instrumento de validación permiten observar que la media a esta cuestión corresponde a un 9 lo cual equivale en la tabla de valor a: totalmente de acuerdo. Lo anterior indica que el tamaño y la fuente de la tipografía efectivamente facilitan la visualización de la información presentada en la App.

Figura 5.4 Análisis e interpretación de los datos obtenidos del instrumento de validación (R.1).

100 En este apartado se muestra solamente el análisis estadístico de la primera pregunta del instrumento de validación, con fines explicativos. Los resultados de todas las preguntas se pueden consultar en el Anexo III. Análisis estadístico. 


\section{Etapa VI. Consenso (R.1)}

Partiendo de los resultados obtenidos en la primera ronda de validación, se pudo consensuar que, por un lado, los expertos consideraron, en virtud de que las medias de las preguntas correspondientes al indicador de diseño y visualización de la información arrojaron valores entre 8.4 - 9.8, que el tamaño y la fuente de la tipografía, el tamaño por el tipo de representación de la disposición y la composición de los elementos gráficos hacen posible la correcta visualización de la información presentada en el prototipo de CENTINEL App, logrando con ello una adecuada comprensión así como la adquisición de la información. Además, se corroboró que existe uniformidad en la representación gráfica de la información gracias al uso de una jerarquía visual de los contenidos.

Se observa, por otro lado, que los expertos consideraron, en virtud de que las medias de las preguntas correspondientes al indicador de interpretación gráfica de la información entre 8.2 9.6, que cada apartado de la App era identificado fácilmente así como la información referente a cada uno de los indicadores -tanto en tiempo real como en histórico- gracias a las gráficas y tablas empleadas. Además, los datos proporcionados por CENTINEL App se adaptan a las necesidades particulares de cada usuario y son presentados de una manera clara e inmediata ante sus acciones, dando como resultado un mejor control del paciente.

En congruencia con la aplicación del Método Delphi, a partir de las interpretaciones de las respuestas obtenidas del primer instrumento de validación, debieron seleccionarse aquellas preguntas que arrojaban resultados ambiguos o, incluso, negativos para poder asegurar la veracidad de las respuestas. En relación a ello, se estableció una nueva ronda de validación, descrita a continuación.

\section{Ronda No. 2}

\section{Etapa III. Elaboración de cuestionario (R.2)}

Con base en los resultados obtenidos en la primera ronda, se diseñó un nuevo instrumento de validación que replanteaba, de manera anónima y conservando el mismo formato y escala, algunas preguntas de selección múltiple -cuantitativas (7)- y abiertas -cualitativas (1)- relativas a 
aquellos resultados del primer instrumento que dieron lugar a dudas, con las cuales se pudiera corroborar la opinión del experto.

Concretamente, las preguntas reformuladas fueron aquellas que dieron por resultado un valor promedio dentro de un intervalo de 0 a 8.9, acorde a la escala de validación establecida ${ }^{101}$, siendo a partir del 9.0 en adelante el valor esperado. Lo anterior dio como resultado el siguiente cuestionario de validación: (Ver: Figura 5.5).

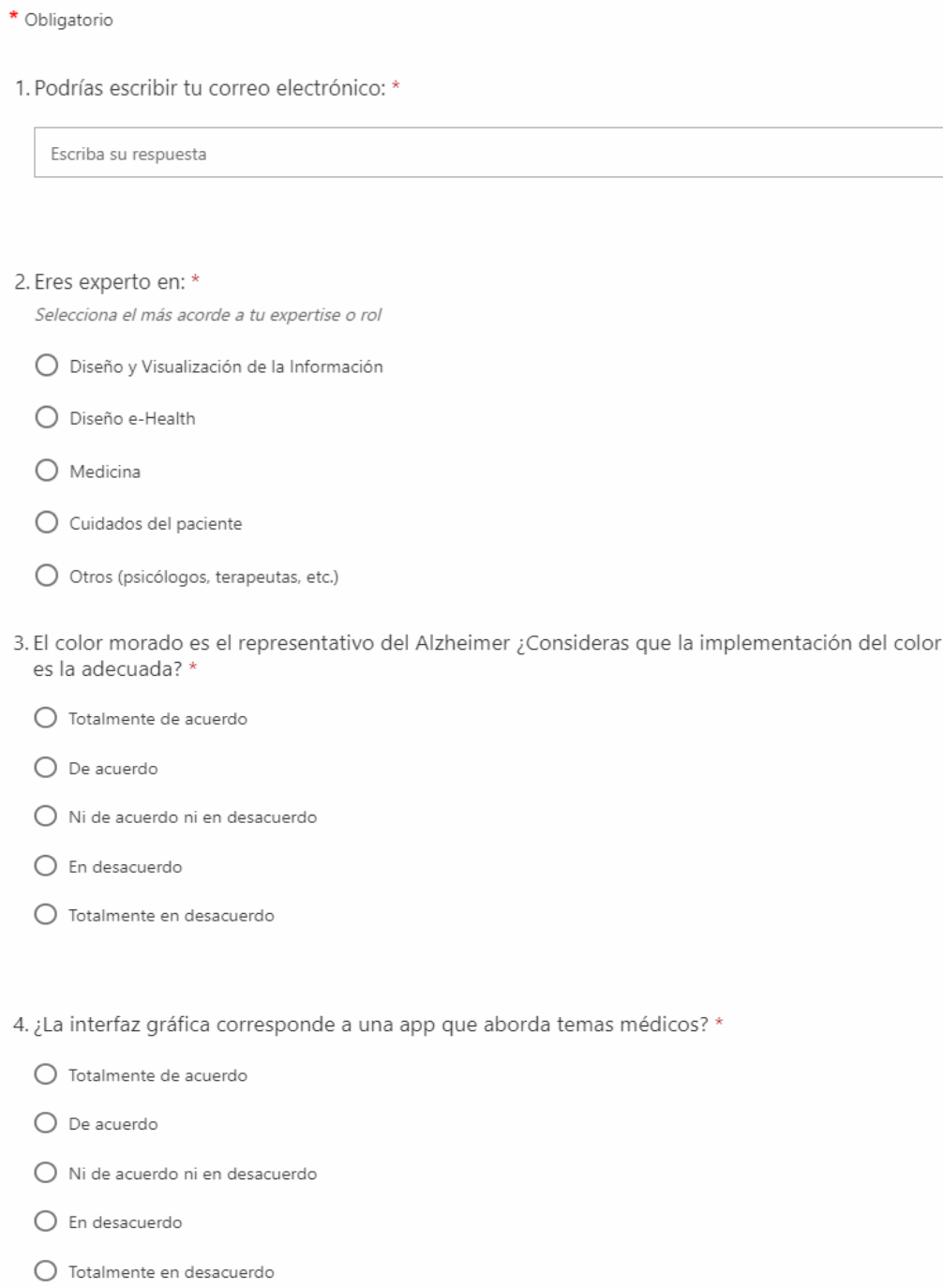

101 Al obtener un valor promedio por debajo de 9.0, las preguntas del Cuestionario 1 que se retomaron para establecer el segundo cuestionario fueron la No. 4 ¿Los colores implementados son los indicados para una adecuada visualización de la información presentada? (8.4), la No. 13 ¿El diseño y visualización de la interfaz gráfica corresponde a una App de ámbito médico? (8.2), la No. 21 ¿La interfaz se adapta a las necesidades particulares de cada usuario, haciendo referencia al cuidado y al paciente? (8.4) y la No. 22 ¿Se reciben, de manera inmediata, mensajes de retroalimentación ante ciertas acciones del usuario? (8.2). 


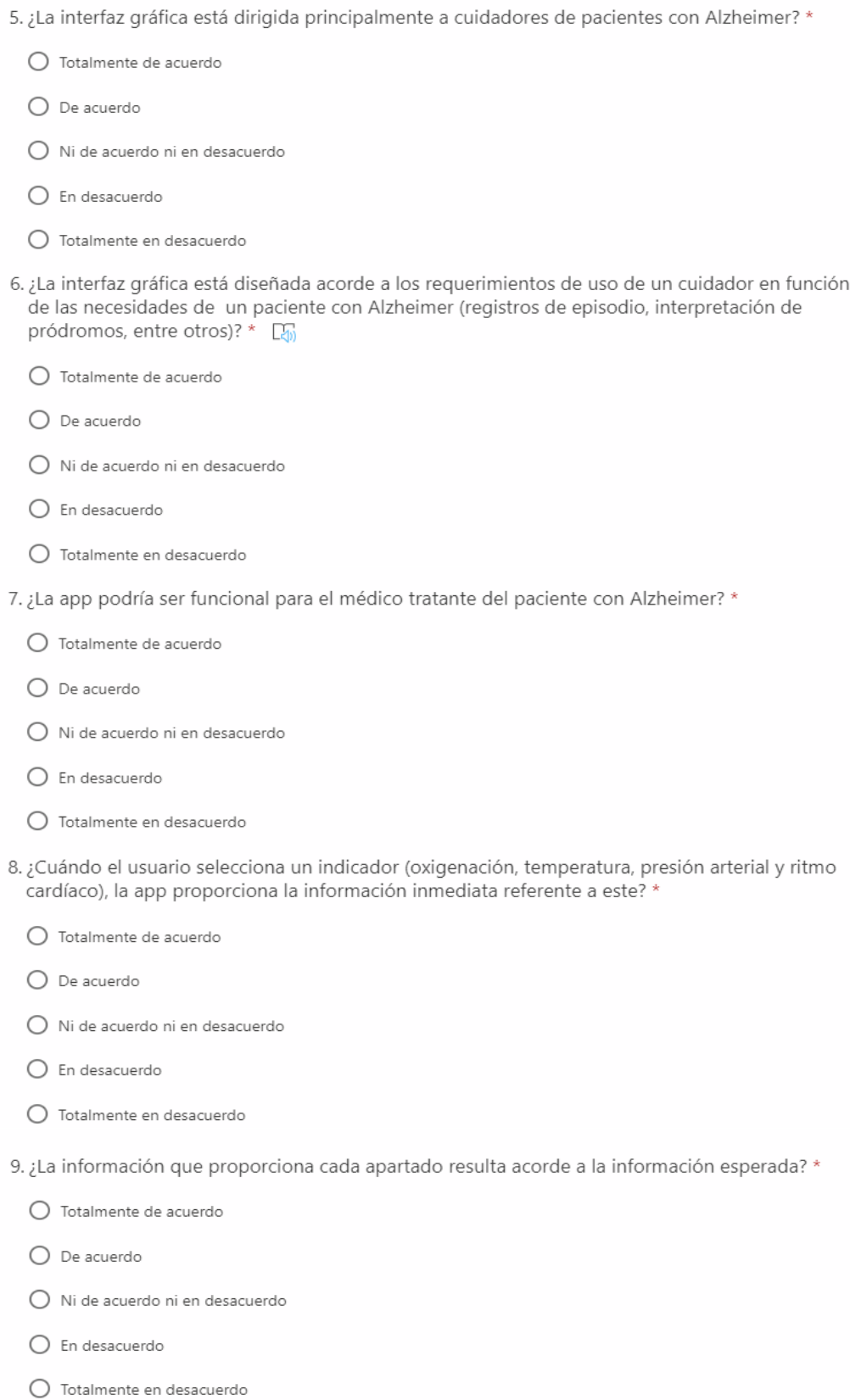

10. Observaciones generales de la interfaz gráfica: *

Escriba su respuesta

Escriba su respuesta

Figura 5.5 Cuestionario (R.2). 


\section{Etapa IV. Envío del cuestionario (R.2)}

Habiendo definido el segundo cuestionario, se envió un correo electrónico al panel de expertos con la liga de acceso al nuevo instrumento, explicándoles brevemente la dinámica para llevar a cabo esta segunda ronda de validación (Ver: Figura 5.6). El cuestionario incluía un feedback de los resultados del análisis de las respuestas del instrumento previo así como la justificación del por qué una segunda validación. (Ver: Figura 5.7).

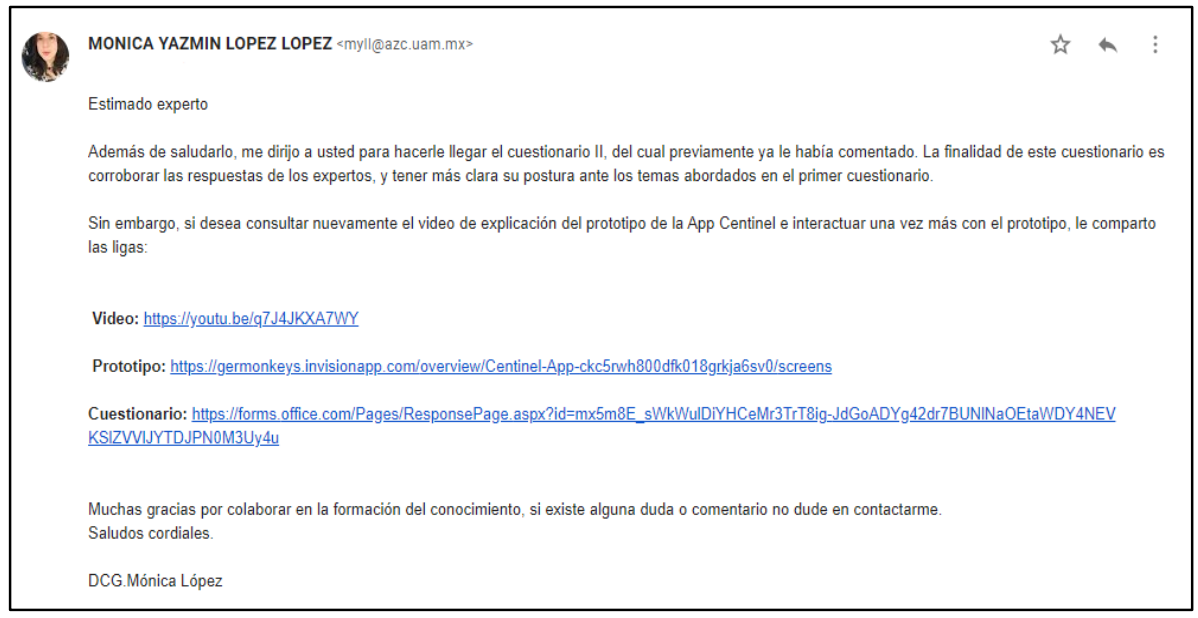

Figura 5.6 Correo electrónico para el Cuestionario (R.2).

Cuestionario de validación de directrices para el diseño y la visualización de la información mediante la interfaz gráfica de un sistema e-Health.

¡Hola!, antes de comenzar queremos agradecerte por la ayuda y disposición para contestar este segundo cuestionario, relacionado con las directrices propuestas para el desarrollo de la interfaz de un sistema e-Health que permitan facilitar la interpretación gráfica de los datos relativos a los síntomas de un episodio de Alzheimer, en función a un caso de estudio simulado, como parte de la investigación para obtener el grado de maestra en Diseño y Visualización de la Información, Posgrado ofrecido por la UAM Unidad Azcapotzalco.

Con anterioridad ya se había realizado un primer cuestionario, con base en las respuestas se obtuvieron las siguientes datos: las respuestas tuvieron un valor promedio entre un intervalo de 8.2 a 9.8. Para asegurar que las respuestas de los expertos son correctas y se mantienen en la postura inicial se decidió utilizar los valores menores a 9, correspondiendo al valor en media 8.2 y 8.4 para formular diferentes preguntas, pero que se siguen refiriendo a los mismos temas abordados en las preguntas planteadas en el cuestionario 1.

Se recomienda volver a ver el video $y$, en su caso, revisar el prototipo en línea, con la finalidad de contestar las siguientes preguntas, de la manera más honesta posible.

-Video: https:/Lyoutu.be/q7J4JKXA7WY

-Prototipo: https://germonkeys.invisionapp.com/console/Centinel-App-ckc5rwh800dfk018grkjabsv0

Figura 5.7 Feedback de los resultados del análisis de las respuestas del instrumento previo y justificación de la segunda validación. 


\section{Etapa V. Análisis estadístico (R.2)}

El análisis de los resultados de esta segunda ronda de validación consideró los mismos aspectos relacionados a la estadística descriptiva implementada en el análisis previo.

Los datos obtenidos fueron vaciados y ordenados dando por resultado una tabla de resultados (Ver: Tabla 5.3), a partir de la cual fueron codificados para la obtención de las medidas de tendencia central e interpretación correspondientes, dando los siguientes resultados ${ }^{102}$ : (Ver: Figura 5.8).

\begin{tabular}{|c|c|c|c|c|c|c|}
\hline PREgUH TA & $\begin{array}{l}\text { TOTALMENTE } \\
\text { DE ACUERDO }\end{array}$ & DE ACUERDO & $\mid \begin{array}{c}\text { MIDE ACUERDO } \\
\text { HIEN DESACUERDO }\end{array}$ & EN DESACUERDO & $\begin{array}{l}\text { TOTALMENTE EN } \\
\text { DESACUERDO }\end{array}$ & TOTAL \\
\hline $\begin{array}{l}\text { 3- El color morado es el representativo del Alzheimer ¿Consideras que la implementación del color es } \\
\text { la adecuada? }\end{array}$ & 6 & 4 & 0 & 0 & 0 & 10 \\
\hline 4- ¿La interfaz gráfica corresponde a una app que aborda temas médicos? & 8 & 2 & 0 & 0 & 0 & 10 \\
\hline 5- ¿La interfaz gráfica está dirigida principalmente a cuidadores de pacientes con Alzheimer? & 10 & 0 & 0 & 0 & 0 & 10 \\
\hline $\begin{array}{l}\text { 6- ¿La interfaz gráfica está diseñada acorde a los requerimientos de uso de un cuidador en función } \\
\text { de las necesidades de un paciente con Alzheimer (registros de episodio, interpretación de } \\
\text { pródromos, entre otros)? }\end{array}$ & 9 & 1 & 0 & 0 & 0 & 10 \\
\hline 7- ¿La app podría ser funcional para el médico tratante del paciente con Alzheimer? & 9 & 1 & 0 & 0 & 0 & 10 \\
\hline $\begin{array}{l}\text { 8- ¿Cuándo el usuario selecciona un indicador (oxigenación, temperatura, presión arterial y ritmo } \\
\text { cardíaco), la app proporciona la información inmediata referente a este? }\end{array}$ & 10 & 0 & 0 & 0 & 0 & 10 \\
\hline 9- ¿La información que proporciona cada apartado resulta acorde a la información esperada? & 10 & 0 & 0 & 0 & 0 & 10 \\
\hline \multicolumn{7}{|c|}{ 10- Observaciones generales de la interfaz gráfica: } \\
\hline \multicolumn{7}{|c|}{$\begin{array}{l}\text { 1- Qué bueno que hayan incluído pre guntas sobre si la interfaz gráfica es útil tanto para el cuidador como para el médico tratante, pues considero que tiene el equilibrio justo para ambas personas, } \\
\text { con conocimientos sobre el padecimiento como para los no expertos, es amigable, los resultados son los esperados y el color es perfecto para su objetivo. }\end{array}$} \\
\hline \multicolumn{7}{|c|}{$\begin{array}{l}\text { 2- La gráfica es indicada para llevar el tema de salud. Los iconos bien pensados y bien trabajados. Los call to action están bien ejecutados. Los usuarios que utilicen la aplica ción no tendrán problema para poder } \\
\text { interactuar y utilizarla de manera correcta. }\end{array}$} \\
\hline \multicolumn{7}{|c|}{$\begin{array}{l}\text { 3- Es bastante clara, concisa y tiene una buena representación de los datos que se requieren para un cuidador además de ver cómo evoluciona o llega a tener un episodio y se crea un registro, } \\
\text { muy buena aplicación }\end{array}$} \\
\hline \multicolumn{7}{|c|}{$\begin{array}{l}\text { 4- Es una buena forma de llevar registro y monitoreos de síntomas tan importantes, como son los escogidos. Además, es confiable en relación a los datos obtenidos, para poder entregarlos al } \\
\text { médico tratante o a los terapeutas que también podrán ingresar datos, lo que favorece una intervención más completa y certera. Excelente aplicación! }\end{array}$} \\
\hline \multicolumn{7}{|l|}{ 5- Lo único que no me gusta es el nombre } \\
\hline \multicolumn{7}{|c|}{ 6- Considero que esta app es importante para el manejo de episodios en sus comienzos para que el cuidador se pueda preparar y también poder evitarlos. } \\
\hline \multicolumn{7}{|c|}{ 7- Interesante propuesta, muy útil principalmente para los cuidadores y para otros especialistas del cuidado del Alzheimer. } \\
\hline \multicolumn{7}{|c|}{ 8- Me parece fácil de usar y útil para un registro general de los datos del paciente, ideal para identificar detonantes de las crisis de Alzheimer. } \\
\hline \multicolumn{7}{|c|}{$\begin{array}{l}\text { 9- El proyecto CENTINEL es acorde a las necesidades de las personas que están implicadas en la enfermedad del Alzheimer, la aplicación puede ayudar en el control y registros de los episodos del } \\
\text { paciente. La interfaz gráfica contiene elementos que facilitan acceso y uso de la aplicación de forma fácil. Todos los elementos representados como: menú, iconos, tipografía, datos, etc. tiene un diseño simplificado y } \\
\text { ordenado, que permiten que los usuarios visualicen fácilmente toda la información de cada indicador. }\end{array}$} \\
\hline
\end{tabular}

\section{Tabla 5.3 Tabla de resultados (R.2).}

102 Al igual que con los resultados de la ronda 1 de validación, en este apartado se muestra solamente el análisis estadístico de la primera pregunta del instrumento pudiendo consultarse los resultados de todas las preguntas en el Anexo III. Análisis estadístico. 



Con base en lo datos obtenidos en el instrumento de validación se muestra que 6 encuestados indicaron la respuesta totalmente de acuerdo, mientras que 4 contestaron de acuerdo, lo cual, con base en las medidas de tendencia central se mantienen en el rango de 9.2 - 10 equivalentes a totalmente de acuerdo, lo que indica que la implementación del color morado, representativo del Alzheimer en CENTINEL App es el adecuado.

Figura 5.8 Análisis e interpretación de los datos obtenidos del instrumento de validación (R.2).

\section{Etapa VI. Consenso (R.2)}

A partir de los resultados obtenidos en la segunda ronda de validación, se pudo consensuar que los expertos consideraron, en virtud de que las medias de las preguntas correspondientes a ambos indicadores arrojaron valores entre 9.2 - 10, que la interfaz gráfica de CENTINEL App aborda temas médicos y como usuario primario se considera, principalmente, a los cuidadores de pacientes con Alzheimer. Sin embargo, también podría resultar funcional para el médico tratante, debido a la interpretación gráfica de los datos referentes a los pródromos de episodios de Alzheimer, así como por la visualización del registro de episodios. 
En cuanto a los elementos compositivos de la App, se concluyó que la implementación del color morado -representativo del Alzheimer- resulta adecuado así como que la información proporcionada por la interfaz gráfica es inmediata y útil, acorde a lo esperado por el usuario.

\subsection{Conclusiones del experimento}

La validación en 2 rondas, de los indicadores establecidos para la corroboración de la hipótesis, permitió, por un lado, obtener datos que dieron lugar a una comparación de las respuestas a preguntas que -en la primera ronda- podrían haber resultado ambiguas o negativas en cuanto a los resultados esperados se refiere y, por otro lado, dar oportunidad de que los expertos reconsideraran su opinión al respecto, es por eso, que resultó un hecho favorable a la validación de la investigación.

Así, a partir de los resultados obtenidos en ambas rondas, se observa como los datos analizados corresponden a 2 indicadores de validación: el diseño y visualización así como la interpretación gráfica de la información, pudiendo concluirse lo siguiente:

Con respecto al primer indicador -Diseño y visualización de la información-, los expertos consideraron que la interfaz gráfica de CENTINEL App hace posible una fácil y adecuada visualización de la información, generando en consecuencia su correcta comprensión y adquisición.

Con respecto al segundo indicador -Interpretación gráfica de la información-, los expertos consideraron que la información presentada en la interfaz gráfica resulta útil y fácil de entender, presentándose de manera inmediata acorde a las necesidades de su usuario, lo que da como resultado un mejor control del paciente.

Finalmente, la segunda ronda de validación permitió que los expertos tuvieran otra perspectiva sobre el diseño de la interfaz gráfica, gracias a ello pudieron emitir una segunda opinión, más certera, arrojando resultados más favorables para la validación.

Pese a los buenos resultados, las respuestas con una media correspondiente al valor "De acuerdo" 103 muestran las áreas de oportunidad que tiene el diseño de la interfaz gráfica de la App, mismas que serán consideradas para siguientes investigaciones.

103 Referidas en el apartado: Etapa III Elaboración de cuestionario (R.2), en este capítulo. 
CONCLUSIONES 


\section{CONCLUSIONES}

Con base en los fundamentos para el diseño y visualización de la información de interfaces gráficas -dentro de un contexto tecnológico y sanitario- establecidos, se pudo determinar una estrategia de diseño de interfaz gráfica que, basada en la definición de una serie de directrices desarrolladas para tal efecto, así como su implementación en un caso de estudio, permitió corroborar las aseveraciones que refieren al diseño y la visualización de la información como elementos facilitadores de la interpretación de datos relativos a los pródromos de episodios de pacientes con la enfermedad del Alzheimer.

Tales afirmaciones se infieren a partir del logro del objetivo general de la investigación, que se refiere a: "Establecer una serie de directrices -propias del diseño y la visualización de la información y su relación con el ámbito de salud y la tecnología- para el desarrollo de la interfaz gráfica de un sistema e-Health que facilite la visualización e interpretación de datos relativos a los pródromos de episodios de pacientes con la enfermedad del Alzheimer, a través de esta."

Este objetivo fue alcanzado, al término de la investigación, con:

- La definición de un marco referencial y teórico con respecto a la enfermedad del Alzheimer (Capítulo 1, pp. 6-21).

- El resumen de los conceptos que definen a los sistemas e-Health como parte del paradigma del Internet de las Cosas (Capítulo 2, pp. 29-32) así como su implementación en el tratamiento del Alzheimer (Capítulo 2, pp. 32-33).

- La identificación de los ámbitos que definen el desarrollo de un sistema e-Health. (Capítulo 2, pp. 30-31).

- La determinación de una estrategia de diseño de interfaz gráfica para un sistema eHealth (Capítulo 4, p. 46), a partir de la definición de una serie de directrices desarrolladas para tal efecto (Capítulo 4, pp. 46-49).

- La validación de la viabilidad de las directrices propuestas (Capítulo 5, pp. 53-72), a través del desarrollo e implementación de una interfaz gráfica de un sistema e-Health para el Alzheimer. (Anexo II, pp. 93-99).

El logro de estos objetivos se sustentó en el planteamiento de la hipótesis, que afirma que "Aplicar directrices propias del diseño y la visualización de la información y su relación con el ámbito de salud y la tecnología en el diseño de la interfaz gráfica de un sistema e-Health facilitará la 
visualización e interpretación de datos relativos a los pródromos de episodios de pacientes con la enfermedad del Alzheimer a través de esta."

Este planteamiento pudo ser verificado mediante un diseño experimental, el cual contempló el diseño de la interfaz gráfica de un sistema e-Health que fue sometida a un análisis estadístico basado en el método Delphi-.

Para ello se requirió de la aplicación de un instrumento a expertos relacionados con el objeto de estudio con el fin de corroborar la adecuada visualización e interpretación gráfica de los datos relativos a los pródromos de episodios en pacientes con Alzheimer a través de la interfaz gráfica en cuestión, que a su vez permitió evidenciar la efectividad de las directrices para el diseño de interfaces definidas.

Los aspectos para evaluar fueron de tipo cualitativo y cuantitativo, siendo los indicadores de validación el diseño y visualización así como la interpretación gráfica de la información presentada a través de la interfaz gráfica.

Los instrumentos de validación se aplicaron en dos rondas, arrojando resultados que, en su mayoría, correspondían a las respuestas de "totalmente de acuerdo" -valores codificados correspondientes a los valores entre 9 a 10- lo cual permitió confirmar que la interfaz gráfica del sistema e-Health propuesta, diseñada a partir de la aplicación de directrices de diseño y visualización de la información, facilita la visualización e interpretación de los datos de pródromos en pacientes con Alzheimer, validando así la hipótesis de la investigación. Sin embargo, a partir de las respuestas correspondientes al resto de los valores de codificación ( 0 a 8.9), se evidenció la existencia de áreas de oportunidad, adicionalmente la mejora en el diseño de la interfaz gráfica propuesta y el logro de sus objetivos, mismas que serán consideradas para investigaciones posteriores.

Es conveniente acotar que con la validación de la hipótesis se concluye este trabajo de investigación, pudiendo aseverar que la aplicación de directrices de diseño y visualización de la información -como parte de una estrategia de diseño- en el desarrollo de la interfaz gráfica para un sistema e-Health resulta satisfactoria para el logro de los objetivos del sistema, es decir, facilita la visualización e interpretación de la información en esta presentada y, por ende, la comprensión y adquisición de esta. 


\section{Aportes al campo de conocimiento}

Esta investigación pretende contribuir al campo del Diseño y del e-Health con la definición, por un lado, de una serie de directrices -propias del diseño y la visualización de la información y su relación con el ámbito de salud y la tecnología- que permitan desarrollar interfaces gráficas para sistemas e-Health que faciliten la visualización e interpretación de los datos, en ella, presentados y, por otro lado, de un proceso de validación de interfaces gráficas.

Además, se aspira a que la investigación resulte una guía para más estudios relacionados con la creación de sistemas e-Health, abriendo posibilidad a diversas perspectivas de estudio.

\section{Prospectiva}

Este proyecto de investigación, acorde a los objetivos establecidos, contempló solamente la definición de una de las tres estrategias que establecen el desarrollo de un sistema e-Health. En este sentido, se pretende continuar esta línea de investigación profundizando en el trabajo con equipos interdisciplinarios -diseñadores, profesionales de la salud, familiares, cuidadores, pacientes con EA, entre otros-, que consideren en su totalidad a los ámbitos implicados para el desarrollo de sistemas e-Health.

Con respecto al caso de estudio, se buscará enriquecer el sistema propuesto con la detección y seguimiento de síntomas que formen parte del espectro de signos prodrómicos de la EA más complejos, como son los clasificados dentro del rubro de síntomas subjetivos -relativos a dimensiones psicológicas y psiquiátricas-, los cuales no son fáciles de objetivar con sensores debido a que, en su mayoría, son de carácter sensible.

Finalmente, pese a haberse cumplido los objetivos de la investigación, se buscará la adecuación de las directrices de diseño propuestas de manera que cumplan de mejor manera sus objetivos y, con ello, cubran en su totalidad las necesidades de diseño y visualización que requiere la interpretación de información, dando cabida a una expansión y/o generalización de estas para ser un paradigma en el campo del diseño y el e-Health. 


\section{REFERENCIAS BIBLIOGRÁFICAS}




\section{REFERENCIAS BIBLIOGRÁFICAS}

- AFAGI (s.f.). Estimulación cognitiva. Recuperado en abril de 2019. Disponible en: http://afagi.eus/ es/programa-preventivo-de-psicoestimulacion-cognitiva-para-personas-con-alzheimer-y-otrasdemencias-en-fase-inicial/

- Albornoz, M. (2014). Diseño de Interfaz Gráfica. Departamento de Informática, Facultad de Ciencias Físico, Matemáticas y Naturales. Universidad Nacional de San Luis, Argentina. WICC 2014 XVI Workshop de Investigadores en Ciencias de la Computación. (pp. 540- 544).

- Alcalde. I. (2012). Visualización de información: ¿arte o ciencia? Recuperado en marzo de 2020. Disponible en: https://ignasialcalde.es/visualizacion-de-informacion-arte-o-ciencia/

- Almeida, E. (2017). Propuesta de un sistema para el monitoreo de adultos mayores con depresión: uso de biomarcadores y patrones de conducta. Tesis para la obtención del grado de Doctor en Diseño. No publicado. Universidad Autónoma Metropolitana-Azcapotzalco. México.

- Alzheimer's Association, (2018). ¿Qué es el Alzheimer?. Recuperado en abril de 2019. Disponible en: https://www.alz.org/alzheimer-demencia/que-es-la-enfermedad-de-alzheimer

- Alzheimer's Disease International (ADI) (2019). World Alzheimer Report 2019 - Attitudes to dementia. London. Recuperado en febrero de 2020. Disponible en: https://www.alz.co.uk/research/WorldAlzheimerReport2019.pdf

- Alzheimer's Association (s.f.) Alzheimer y Demencia. Recuperado en enero del 2021. Disponible en: https://www.alz.org/alzheimer-demencia/etapas?lang=es-MX\#: :text=La\%20enfermedad \%20de\%20Alzheimer\%20generalmente,Alzheimer\%20de\%20una\%20forma\%20distinta

- APAES (2016). ¿Qué es el Alzheimer?. Recuperado en enero de 2018. Disponible en: http://apaes.com.mx/documentos/QueEsAz.cfm

- APD (2019). ¿Qué es Machine Learning y cómo funciona? Recuperado en enero de 2020. Disponible en: https://www.apd.es/que-es-machine-learning/

- Asamblea Legislativa del Distrito Federal (1995). Ley para las Personas con Discapacidad del Distrito Federal. Recuperado en mayo de 2018. Disponible en: https://www.colegiodearquitectoscdmx.org/ wp-content/uploads/2017/02/4.10LeyPersonasDiscapacidadDF_29jul10.pdf

- Asociación de familiares de personas con Alzheimer y otras demencias de Huelva (s.f.). Tratamiento no farmacológico. Recuperado en septiembre de 2019. Disponible en: http://www.afahuelva.org/tratamiento-no-farmacologico/

- Astigarraga, E. (s.f.). El método Delphi. Universidad de Deusto. Facultad de CC.EE. y Empresariales. ESTE Mudaiz, 50 Apartado 1.359 E-20.080 Donostia- San Sebastián. Recuperado en agosto de 2019. Disponible en: http://www.prospectiva.eu/zaharra/Metodo_delphi.pdf 
- Balsamiq (2020). Balsamiq Wireframes. Recuperado en febrero de 2020. Disponible en: https://balsamiq.com/wireframes/

- Barrientos, A., Calderón, J. y Mujica, S. (2020). Context Awareness \& Pervasive Computing: Arquitectura lógica de un sistema perceptivo al contexto de un usuario. Universidad Peruana de Ciencias Aplicadas (UPC). Recuperado en agosto de 2020. Disponible en: https://repositorioacademico.upc.edu.pe/bitstream/handle/10757/608513/CA164ET15.pdf?sequence= 1\&isAllowed=y

- Becerra, J. (s.f.). Estadística descriptiva. Facultad de Contaduría y Administración. UNAM. Recuperado en julio de 2019. Disponible en: http://132.248.164.227/publicaciones/docs/ apuntes_matematicas/34.\%20Estadistica\%20Descriptiva.pdf

- Betancourt, D. (2015). Método Delphi: Qué es y cómo se aplica. Recuperado en julio de 2020. Disponible en: www.ingenioempresa.com/metodo-delphi

- Bitbrain (2018). Qué es la estimulación cognitiva y para qué sirve. Recuperado en abril de 2019. Disponible en: https://www.bitbrain.com/es/blog/que-es-estimulacion-cognitiva

- BrightFocus Foundation (2017). Enfermedad de Alzheimer: Datos y Cifras. Recuperado en octubre de 2018. Disponible en: https://www.brightfocus.org/espanol/ la-enfermedad-de-alzheimer-y-la-demencia/enfermedad-de-alzheimer-datos-y-cifras

- BrightFocus Foundation (2017). Los signos y síntomas de la enfermedad de Alzheimer. Recuperado en enero de 2018. Disponible en: http://www.brightfocus.org/espanol/ la-enfermedad-de-alzheimer-y-la-demencia/enfermedad-de-alzheimer-sintomas-y-etapas

- Buitrón, M. (2011). Modelo didáctico para la creación de ambientes virtuales de aprendizaje. Estrategia didáctica y de diseño de interfaz para la construcción de un aula virtual. Tesis para la obtención del grado de Doctora en Diseño. No publicado. Universidad Autónoma Metropolitana. Unidad Azcapotzalco. México.

- Buitrón, M. (2004). Consideraciones para el diseño de interfaces gráficas de usuario en ambientes virtuales educativos. Tesis para la obtención del grado de Maestra en Diseño. No publicado. Universidad Autónoma Metropolitana. Unidad Azcapotzalco. México.

- Bustamante, N. (2012). ¿Qué es el método Delphi?. Recuperado en noviembre de 2019. Disponible en: https://www.eoi.es/blogs/nataliasuarez-bustamante/2012/02/11/¿que-es-el-metodo-delphi/

- Cabo, J. (2020). Sanidad del Futuro (e-Health, m-Health e Inteligencia Ambiental). UDIMA. Recuperado en enero de 2020. Disponible en: https://www.gestion-sanitaria.com/sanidad-futuro-ehealth-m-health-inteligencia-ambiental.html 
- Carnero, C. (2005). El Eurotest: test europeo de detección del deterioro cognitivo. Memoria para optar al grado de Doctor en Medicina y Cirugía. Universidad de Granada. Recuperado en marzo de 2018. Disponible en: https://www.researchgate.net/publication/ 46589269_EI_EUROTEST_test_europeo_de_deteccion_de_deterioro_cognitivo

- Castillero, O. (2016). Los 15 tipos de investigación y sus características. Recuperado en abril de 2018. Disponible en: https://psicologiaymente.com/miscelanea/tipos-de-investigacion

- Ceuta (s.f.). ¿Qué es una APP?. Recuperado en noviembre de 2019. Disponible en: http://www.lineaverdeceutatrace.com/lv/consejos-ambientales/apps-ambientales/que-es-una-app.asp

- Chappotin, D. (2019). Diferencia entre Alzheimer y demencia senil. Titi. Recuperado en enero de 2020. Disponible en: https://infotiti.com/2019/05/diferencia-entre-demencia-senil-y-alzheimer/

- Cruz, A., (2019) Experta: el Alzheimer, abatible con sólo modificar estilo de vida. La Jornada. Recuperado en junio de 2020. Disponible en: https://www.jornada.com.mx/2019/09/18/sociedad/034n2soc

- Da Silva, C. (2014). La identidad del diseñador en el diseño de la información. Casiopea. Escuela de Arquitectura y Diseño, PUCV. Recuperado en marzo de 2020. Disponible en: https://wiki.ead.pucv.cl/ La_identidad_del_dise\%C3\%B1ador_en_el_dise\%C3\%B10_de_informaci\%C3\%B3n

- De Madeiros, A. (2016). ¿Qué es la estimulación cognitiva? Neurona Academia Cognitiva. Recuperado en febrero de 2019. Disponible en: https://academianeurona.com/que-es-la-estimulacioncognitiva

- Diccionario Médico (s.f.). Neuroimagen. Recuperado en diciembre de 2020. Disponible en: https://www.cun.es/diccionario-medico/terminos/neuroimagen

- DISCAPNET. El portal de las personas con discapacidad (s.f.). Desarrollo Cognitivo: Alzheimer. Fundación ONCE. Recuperado en noviembre de 2018. Disponible en: https://www.discapnet.es/areas-tematicas/salud/discapacidades/desarrollo-cognitivo/alzheimer

- Dueñas, E., Martínez, M. A., Morales, B., Muñoz, C., Viáfara, A. S. y Herrera, J. A. (2014). Síndrome del cuidador de adultos mayores discapacitados y sus implicaciones psicosociales. Recuperado en enero de 2019. Disponible en: http://www.repositoriocdpd.net:8080/handle/123456789/166

- EcuRed (s.f.). Metodología. Recuperado en noviembre de 2020. Disponible en: https://www.ecured.cu/Metodología

- El diario de salud (2017). Marlin, una app para ayudar a cuidadores y pacientes con alzhéimer. Recuperado en enero de 2019. Disponible en: https://eldiariodesalud.com/investigacion/ marlin-una-app-para-ayudar-cuidadores-y-pacientes-con-alzheimer

- Evans, D. (2011). Internet de las cosas. Cómo la próxima evolución de Internet lo cambia todo. Cisco Internet Bussiness Solutions Group-IBSG, 11(1), 4-11. 
- Falgàs, N., Sánchez-Valle, R., y Barreriro, S. (2018). ¿Qué es la enfermedad del Alzheimer?. PortalCLíNIC Barcelona. Recuperado en febrero de 2019. Disponible en: https://portal.hospitalclinic.org/enfermedades/alzheimer/definicion

- Ferré, X. (2000). Principios básicos de usabilidad para ingenieros software. V Jornadas Ingeniería de Software y Bases de Datos (JISBD 2000), Valladolid. Universidad Politécnica de Madrid. Recuperado en marzo de 2020. Disponible en: https://www.researchgate.net/ publication/221595210_Principios_Basicos_de_Usabilidad_para_Ingenieros_Software

- FIDISP (2018). Avizor, la app centinela de la seguridad del paciente en Andalucía. Recuperado en diciembre de 2019. Disponible en: https://fidisp.org/avizor-app-seguridad-paciente-andalucia/

- Fraile, M. (2019). Claves para el tratamiento de las AVDB de las personas con demencia en domicilio desde la terapia ocupacional [Material del curso]. Teleformación del Imserso. Gobierno de España. Recuperado en junio de 2019. Disponible en: https://sede.imserso.gob.es/crealzheimer_01/formacion/tele_formacion/2019/index.htm

- Frascara, J. (1988). Diseño de Comunicación Visual I, Colección Escritos, Instituto Superior de Diseño Industrial, La Habana.

- Fuentes, P. (2008). Funcionalidad y Demencia. Revista Hospital Clínico Universidad de Chile.

- Fundación Alzheimer España (2015). ¿Debe considerarse como una "discapacidad”?. Recuperado en octubre de 2018. Disponible en: http://www.alzfae.org/fundacion/172

- Fundación Telefónica (2016). La Sociedad de la Información en España 2016. Barcelona: Ariel S.A.

- Fundéu RAE (2013). Experiencia, pericia y experticia, alternativas a expertise. Recuperado en octubre de 2020. Disponible en: https://www.fundeu.es/recomendacion/experiencia-periciay-experticia-alternativas-a-expertise/\#: :text=El\%20Diccionario\%20de\%20americanismos\%20de, la\%20pericia\%20en\%20un\%20campo\%27

- Gallardo, A. V. C. y Scaglia, J. (2011). Diseñar La inclusión, incluir al Diseño. Buenos Aires, Ediciones Azzurras. Recuperado en julio de 2018. Disponible en:

http://www.habitatinclusivo.com.ar/publicaciones/disenar-la-inclusion.pdf

- García, D. (2014). Construcción social de la discapacidad. Antologías. Diseño para la discapacidad. Universidad Autónoma Metropolitana. México.

- García, D., Martínez, A. y Salas, B. (2014). Diseñamos, ¿para el mundo real? Victor Papanek, un visionario del diseño. Antologías. Diseño para la discapacidad. UAM. México.

- García, S. (2019). Teleasistencia avanzada. Un paso más hacia la integración sociosanitaria. Balance sociosanitario de la dependencia y la discapacidad. Recuperado en abril del 2020. Disponible en: https://www.balancesociosanitario.com/Teleasistencia-avanzada-Un-paso-mas-hacia-la-integracionsociosanitaria_a6492.html 
- Gay, F., et al. (s.f.) Guía de orientación en la práctica profesional de la valoración reglamentaria de la situación de dependencia en personas con enfermedad de alzheimer y otras demencias. Centro de Referencia Estatal de Alzheimer y otras Demencias, del Imserso. Salamanca. España.

- Gay, F. (2017). Síntomas Psicológicos y Conductuales de las demencias (SPD) [Material del curso]. Teleformación del Imserso. Gobierno de España. Recuperado en noviembre de 2017. Disponible en: https://sede.imserso.gob.es/crealzheimer_01/formacion/tele_formacion/cursos_2017/index.htm

- González, M. S. (2013). Historia de Internet - nacimiento y evolución, en Redes Telemáticas. Recuperado en julio de 2019. Disponible en: http://redestelematicas.com/historia-de-internetnacimiento-y-evolucion/

- González, M.S. (2013). Historia de Internet - nacimiento y evolución, en Redes Telemáticas. Recuperado de: http://redestelematicas.com/historia-de-internet-nacimiento-y-evolucion/

- Giusto, D., lera, A., Morabito, G. y Atzori, L. (2010). The Internet of Things. Springer

- Guillén, M., Ruíz, I. y Suárez, R. (2019). Atención integral de la persona enferma en el domicilio [Material del curso]. Teleformación del Imserso. Gobierno de España. Recuperado en noviembre de 2019. Disponible en: https://sede.imserso.gob.es/crealzheimer_01/formacion/tele_formacion/2019/

- Guillén, M. (2019). Adaptación del binomio paciente-familia en centros residenciales [Material del curso]. Teleformación del Imserso. Gobierno de España. Recuperado en mayo de 2019. Disponible en: https://sede.imserso.gob.es/crealzheimer_01/formacion/tele_formacion/2019/index.htm

- Hassan, Y. y Ortega, S. (2009). Informe APEI sobre Usabilidad. Gijón: Asociación Profesional de Especialistas en Información, 2009, ISBN: 978-84-692-3782-3. Recuperado en septiembre de 2018. Disponible en: http://eprints.rclis.org/13253/1/informeapeiusabilidad.pdf

- Herrera-Lasso, M. (2005). Discapacidad y construcción. Memorias del diplomado "Discapacidad, vejez y diseño del entorno construido" Universidad Autónoma Metropolitana - Xochimilco. México.

- IGI Global (s.f.). What is u-Health. Recuperado en febrero de 2020. Disponible en: https://www.igiglobal.com/dictionary/city-next-paradigm-urban-development/30797

- IIEMD (2016). Qué es wearable: definición. Recuperado en febrero de 2018. Disponible en: https://iiemd.com/wearable/que-es-wearable

- IMSS (2015). Enfermedad de Alzheimer. Recuperado en noviembre de 2019. Disponible en: http://www.imss.gob.mx/salud-en-linea/enfermedad-alzheimer

- Information Design Association (1996). The origins of the Information Design Association. Annual Report of the IDA. Recuperado en marzo de 2020. Disponible en: http://www.robwaller.org/IDA_origins_RW.pdf

- Instituto de Ingeniería del Conocimiento (s.f.). ¿A qué llamamos Big Data?. Recuperado en marzo de 2020. Disponible en: https://www.iic.uam.es/big-data/ 
- Instituto Nacional de Estadística (INE) (2017). Defunciones según la Causa de Muerte Año 2016. España. Recuperado en febrero de 2018. Disponible en: https://www.ine.es/prensa/edcm_2016.pdf

- InnoWiki (2014). Inteligencia ambiental. Recuperado en diciembre de 2019. Disponible en: http://185.5.126.23/innowiki/index.php/Inteligencia_ambiental

- IntraMed (2012). ¿Qué es e-Salud o e-Health?. Recuperado en diciembre de 2018. Disponible en: https://www.intramed.net/contenidover.asp?contenidolD=78457

- Invision (2020). Invision. Recuperado en febrero de 2020. Disponible en: https://www.invisionapp.com/

- Ionos (2020). ¿Qué es la RFID?. Recuperado en noviembre de 2020. Disponible en: https://www.ionos.mx/digitalguide/servidores/know-how/rfid/

- Joyners (s.f.). Aplicación móvil de cuidado para personas mayores y dependientes. Recuperado en agosto de 2020. Disponible en: https://www.joyners.com/es/aplicacion-movil

- Know Alzheimer (s.f.). Alzheimer: 5 App's móviles gratuitas para cuidadores (I). Recuperado en febrero de 2020. Disponible en: https://knowalzheimer.com/aplicaciones-moviles-para-cuidadores-i/

- Lanfranco, R., Manríquez-Navarro, P., Avello, L. y Canales-Johnson, A. (2012). Evaluación de la enfermedad de Alzheimer en etapa temprana: biomarcadores y pruebas neuropsicológicas. Artículo de Revisión. Chile.

- Lara, L., Díaz, D., Herrera, E. y Silveira, P. (2001). Síndrome del" Cuidador" en una población atendida por equipo multidisciplinario de atención geriátrica. Revista Cubana de Enfermería, 17(2), 107-111. Recuperado en febrero de 2018. Disponible en: http://scielo.sld.cu/pdf/enf/v17n2/enf07201.pdf

- López, M. y Buitrón, M., (2018). Estrategias para el desarrollo de un sistema de monitoreo para pacientes con Alzheimer. Memorias del evento: Avances de las mujeres en las ciencias, las humanidades y todas las disciplinas. No publicado (aprobado para publicación). México, Universidad Autónoma Metropolitana-Azcapotzalco.

- Marrero, C. (2006). Interfaz gráfica de usuario. Aproximación semiótica y cognitiva. Reporte de investigación. Universidad de la Laguna, Tenerife.

- Martínez, A. y Cueva, J. (2001). Estándares y guías. Universidad de Oviedo. Recuperado en marzo de 2020. Disponible en: https://aipo.es/libro/pdf/09Estand.pdf

- Martínez, T. (2018). Atención centrada en la persona. [Material del curso]. Teleformación del Imserso. Gobierno de España. Recuperado en junio de 2018. Disponible en: https://crealzheimer.imserso.es/crealzheimer_01/formacion/tele_formacion/2018/index.htm 
- Mayo Clinic (2020). Diagnóstico y tratamiento. Recuperado en enero de 2021.

Disponible en: https://www.mayoclinic.org/es-es/diseases-conditions/alzheimers-disease/ diagnosis-treatment/drc-20350453

- Mayo Clinic (s.f.). Labilidad emocional. Recuperado en mayo de 2020. Disponible en: https://www.mayoclinic.org/es-es/diseases-conditions/pseudobulbar-affect/symptoms-causes/ syc-20353737

- Medciclopedia (2019). Episodio. Recuperado en octubre de 2019. Disponible en: https://www.iqb.es/diccio/e/ep.htm

- Mesa Editorial (2016). Los colores enarbolan causas médicas, ¿recuerdas las más importantes?. Recuperado en noviembre de 2019. Disponible en: https://www.saludiario.com/ los-colores-enarbolan-causas-medicas-recuerdas-las-masimportantes/\#: :text=Púrpura,al\%20cáncer\%20en\%20lo\%20general

- Microsoft Azure (s.f.). ¿Qué es la nube?. Recuperado en diciembre de 2019. Disponible en: https://azure.microsoft.com/es-es/overview/what-is-the-cloud/

- NeuronUP (s.f.). Gnosias. Recuperado en noviembre de 2020. Disponible en: https://www.neuronup.com/es/areas/functions/gnosis

- Norman, D. (1990). La psicología de los objetos cotidianos. Madrid: Nerea.

- Norman, D. (1983). Design principles for human-computer interfaces. In Proceedings of the SIGCHI conference on Human Factors in Computing Systems. Boston, Massachusetts, EE. UU.

- Oracle (s.f.). ¿Qué es el Internet of Things (IOT)?. Recuperado en enero de 2020. Disponible en: https://www.oracle.com/mx/internet-of-things/what-is-iot.html

- Organización Mundial de la Salud (s.f.). ¿Cómo define la OMS la salud?. Recuperado en septiembre de 2019. Disponible en: https://www.who.int/es/about/who-we-are/frequently-asked-questions

- Organización Mundial de la Salud (2020). Demencia. Recuperado en diciembre de 2020. Disponible en: https://www.who.int/es/news-room/fact-sheets/detail/dementia

- Organización Mundial de la Salud (2019). Definición de discapacidades. Recuperado en marzo de 2019. Disponible en: https://www.who.int/topics/disabilities/es/

- Organización Mundial de la Salud (2019). Demencia. Recuperado en octubre de 2019. Disponible en: https://www.who.int/topics/disabilities/es/

- Organización Mundial de la Salud (2018). Discapacidad y salud. Recuperado el 20 de octubre de 2018 de https://www.who.int/es/news-room/fact-sheets/detail/disability-and-health

- Organización Mundial de la Salud (2016). ¿Qué son los trastornos neurológicos? Recuperado en noviembre de 2018. Disponible en: http://www.who.int/features/qa/55/es/ 
- Papanek, V. (1977). Diseñar para el mundo real. Barcelona: Akal, S.A.

- Pérez, M. J. (2005). Cuidadores informales en un área de salud rural: perfil, calidad de vida y necesidades. Biblioteca Lascasas, Recuperado en julio de 2019. Disponible en: http://www.indexf.com/ lascasas/documentos/lc0015.php.

- RAE (2020). Etiología. Recuperado en marzo de 2020. Disponible en: https://dle.rae.es/?w=etiolog\%C3\%ADa

- RAE (2020). Interfaz. Recuperado en enero de 2021. Disponible en: https://dle.rae.es/interfaz

- RAE (2005). Ubicuidad. Recuperado en abril de 2019. Disponible en: https://www.rae.es/dpd/ubicuidad

- RedHat (s.f.). ¿Qué es una API?. Recuperado en enero de 2020. Disponible en: https://www.redhat.com/es/topics/api/what-are-application-programming-interfaces

- RedHat (s.f.). ¿Qué es el Internet de las Cosas (IOT)?. Recuperado en febrero de 2020. Disponible en: https://www.redhat.com/es/topics/internet-of-things/what-is-iot

- Reinosa, A. (2018). España, el tercer país del mundo con más enfermos de Alzheimer. Rois Medical. Recuperado en enero de 2019. Disponible en: http://roismedical.com/espana-el-tercer-pais-delmundo-con-mas-enfermos-de-alzheimer/

- Reisberg, B., y Franssen, E. H. (1999). Clinical stages of Alzheimer's disease. An atlas of Alzheimer's disease. New York, London: The Parthenon Publishing Group, 11-29. Recuperado en febrero de 2018. Disponible en: http://www.navarra.es/NR/rdonlyres/98BBFCB8-461F-49AD-A595232D6314F8A9/179988/

Publicacion4BarriReisberg1.pdf

- Revista de Robots (2020). ¿Qué es la Inteligencia Artificial y para qué sirve la IA? Recuperado en diciembre de 2020. Disponible en: https://revistaderobots.com/inteligencia-artificial/que-es-lainteligencia-artificial/

- Ribera, J. (s.f.). Inteligencia Ambiental. Departament of Computer Science. Universitat Politécnica de Catalunya. Recuperado en octubre de 2019. Disponible en: https://www.cs.upc.edu/ bejar/ia/material/trabajos/Inteligencia\%20Ambiental.pdf

- Rivera, M. A. (2005). El Diseño de Interfaz gráfica para cursos en línea. Recuperado en junio de 2018. Disponible en: http://e-spacio.uned.es/fez/eserv/bibliuned:19420/n03rodriguriv05.pdf

- Rodríguez A., González P. y Rossi G. (2014). Bocetado para el diseño de interacciones enactivas. Interacción 2014. Recuperado en septiembre de 2019. Disponible en: https://aipo.es/files/actas/10Diseño\%20de\%20la\%20Interacción.pdf

- Rodríguez, L. (2018). La proteína tau: qué es y cómo influye en la neurodegeneración. Titi. Recuperado en febrero de 2019. Disponible en: https://infotiti.com/2018/08/proteina-tau/ 
- Rodríguez, S. (2019). Teleasistencia avanzada: La comunicación inteligente entre el dispositivo y el usuario. Recuperado en julio de 2020. Disponible en: https://blogcorporation.televes.com/sociosanitario/teleasistencia-avanzada

- Rojas, M. (2019). Praxias, ¿Cómo el cerebro interviene en el movimiento?. Recuperado en noviembre de 2020. Disponible en: https://neuro-class.com/praxias-como-el-cerebro-interviene-en-el-movimiento/

- Romero, M. (2014). Importancia de la carga de enfermedad debida a factores ambientales. Revista Cubana de Higiene y Epidemiología, 52(2), 149-151. Recuperado en diciembre de 2020, de: http://scielo.sld.cu/scielo.php?script=sci_arttext\&pid=S1561-30032014000200001\&lng=es\&tlng=es

- Rovira, I. (s.f.). Acatisia: qué es, definición, síntomas, causas y tratamiento. Viviendo la salud. Recuperado en marzo de 2020. Disponible en: https://viviendolasalud.com/medicamentos/acatisia

- Rueda, F. (2009). ¿Qué es la computación en la nube?. Revista Sistemas, nro, 112, 72-80. Recuperado en abril de 2018. Disponible en: http://acistente.acis.org.co/typo43/fileadmin/Revista_112/tres.pdf

- Ruíz, I., Guillén, M. y Suárez, R. (2018). Manejo y control de los síntomas psicológicos y conductuales de las demencias [Material del curso]. Teleformación del Imserso. Gobierno de España. Recuperado en octubre de 2018. Disponible en: https://sede.imserso.gob.es/crealzheimer_01/formacion/tele_formacion/2018/index.htm

- Ryte (2020). Diseño de Experiencia de Usuario. Recuperado en diciembre de 2020. Disponible en: https://es.ryte.com/wiki/Dise\%C3\%B10_de_Experiencia_de_Usuario

- Salomon, J. A. (2010). Nuevos pesos de la discapacidad para la carga mundial de morbilidad. Boletín de la Organización Mundial de la Salud. Volumen 88, diciembre 2010, 877-953. Recuperado en marzo de 2019. Disponible en: https://www.who.int/bulletin/volumes/88/12/10-084301/es/

- Salazar, J. y Silvestre, S. (2016). Internet de las cosas. Techpedia. České vysoké učení technické v Praze Fakulta elektrotechnická. TechPedia. Recuperado en enero de 2019. Disponible en: https://core.ac.uk/download/pdf/81581111.pdf

- Sas (s.f.). Analítica predictiva: Qué es y por qué es importante. Recuperado en agosto de 2019. Disponible en: https://www.sas.com/es_mx/insights/analytics/predictive-analytics.html

- SAP (s.f.). ¿Qué es el Internet de las Cosas (IOT)? Recuperado en mayo de 2018. Disponible en: https://www.sap.com/latinamerica/trends/internet-of-things.html

- Schuller, G. (2007). Information design= complexity + interdisciplinarity + experiment. Aiga: the Professional association for design. Recuperado en marzo de 2020. Disponible en: https://theworldasflatland.net/wp-content/uploads/essay-aiga.pdf

- Secretaría de Salud (2017). Género y salud en cifras. Volumen 15 Núm. 3. Recuperado en agosto de 2017. Disponible en: https://www.gob.mx/cms/uploads/attachment/file/315224/revista_15-3-1.pdf 
- Seguí-Más E. y Server- R. (2010). El capital relacional de las cooperativas de crédito en España: Un estudio cualitativo de sus intangibles sociales mediante el análisis delphi. REVESCO, № 101.

Recuperado en marzo de 2020. Disponible en: https://www.researchgate.net/publication/ 46157180_EL_CAPITAL_RELACIONAL_DE_LAS_COOPERATIVAS_DE_CREDITO_EN_ESPANA_ UN_ESTUDIO_CUALITATIVO_DE_SUS_INTANGIBLES_SOCIALES_MEDIANTE_EL_ANALISIS_D ELPHI_THE_RELATIONAL_CAPITAL_OF_THE_CREDIT_COOPERATIVES_IN_SPAIN

- Suárez, R. (2019). El papel del deterioro cognitivo como antesala de la demencia. Teleformación del Imserso. Gobierno de España. Recuperado en septiembre de 2019. Disponible en: https://sede.imserso.gob.es/crealzheimer_01/formacion/tele_formacion/2019/index.htm

- Tecnología para los negocios (s.f.). Caminar con éxito hacia la Industria 4.0: Capítulo 14 Dispositivos (I) Internet de las cosas (IOT). Recuperado en julio de 2018. Disponible en: https://ticnegocios.camaravalencia.com/servicios/tendencias/caminar-con-exito-hacia-la-industria-4-0capitulo-14-dispositivos-i-internet-de-las-cosas-iot/

- TGS01 (s.f.). Teoría general de sistemas. Recuperado en septiembre de 2020. Disponible en: https://sites.google.com/site/ttggss001/

- Timeless (s.f.). Timeless / Care. Recuperado en noviembre de 2018. Disponible en: https://www.timeless.care/

- Tirado. G., López-Saez, A., Capilla, C., Correa, A. y Geidel, B. (2011). La valoración en el Síndrome del Cuidador. Desarrollo Científ Enferm. Vol. 19 № 3. pp 102- 106. Recuperado en mayo de 2019. Disponible en: http://www.index-f.com/dce/19pdf/19-102.pdf

- T. J., J. (2011). Estadios o etapas en el Alzheimer. Alzheimer Universal. Disponible en mayo de 2018. Disponible en: https://www.alzheimeruniversal.eu/2011/07/14/estadios-o-etapas-en-el-alzheimer/

- Terán, M. (2007). La Jornada: En México 2 millones de personas padecen Alzheimer, dice la UNAM. Recuperado en diciembre de 2017. Disponible en: http://jornada.com.mx/2007/06/26/ index.php?section $=$ ciencias \&article $=\mathrm{a} 02 \mathrm{n} 1 \mathrm{cie}$

- Tomé, G. (2019). Nuevas tecnologías TIC y enfermedad de Alzheimer. Know Alzheimer. Recuperado en diciembre de 2019. Disponible en: https://knowalzheimer.com/nuevas-tecnologias-tic-yenfermedad-de-alzheimer/

- Tovar, I. (2014). Análisis crítico para la elaboración de autoevaluaciones multimedia instruccionales. Tesis para la obtención del grado de Doctora en Diseño. No publicado. Universidad Autónoma Metropolitana. Unidad Azcapotzalco. México. 
- Villar, F. y Serrat, R. (2016). Hable con ellos: cuidados narrativos en el marco de una atención centrada en la persona. Revista Española de Geriatría y Gerontología. PubMed: 27461990 DOI: 10.1016/j.regg.2016.06.004. Recuperado en julio de 2018. Disponible en: https://www.sciencedirect.com/science/article/abs/pii/S0211139X16300762?via\%3Dihub

- Weber, R. (2010). Internet of Things - New Security and Privacy Challenges. Computer Law \& Security Review 26: 23-30.

- Yirda, A. (s.f.). Definición de Sistema. Recuperado en septiembre de 2020. Disponible en: https://conceptodefinicion.de/sistema/ 
ANEXOS 


\section{ANEXO I. INSTRUMENTOS DEL ESTUDIO EXPLORATORIO DE LA INVESTIGACIÓN}

\section{Al.1 Encuesta semiestructurada}

\section{Alzheimer \& Diseño}

¡Hola!

Como parte del desarrollo de un proyecto de investigación sobre pacientes con Alzheimer en etapa 1 -siendo esta etapa en la cual comienzan los primeros síntomas, causantes de olvidos, de la incapacidad para componer frases congruentes, además de diversos cambios de humor- requerimos de su apoyo para contestar esta encuesta, cuyo objetivo es obtener datos que contribuyan a la propuesta de un sistema de diseño que permita mejorar la calidad de vida de dichos pacientes así como de sus cuidadores cotidianos.

Agradecemos de antemano su participación.

*Obligatorio

Dirección de correo electrónico *

Tu dirección de correo electrónico

1- ¿Cuál es su se relación con el paciente de Alzheimer? *

Paciente

Familiar/Cuidador

Médico

Profesionista que trabaja con Alzheimer

2- ¿Qué actividades realiza usted para el cuidado del paciente con Alzheimer? *

Tu respuesta

3- ¿Cómo afecta el Alzheimer a la vida cotidiana del paciente y de sus familiares?

Tu respuesta 
4- ¿Qué es lo que más olvida el paciente con Alzheimer? *

Tu respuesta

5- ¿Cuáles son las actividades cotidianas que deja de hacer el paciente, en la primera etapa del desarrollo de la enfermedad? *

Tu respuesta

6- ¿Qué actividades realiza el paciente para evitar que la enfermedad progrese?

Tu respuesta

7- ¿Qué personas se involucran generalmente del cuidado diario del paciente con Alzheimer? *

Tu respuesta

8- ¿Qué aspectos deben tener presente los cuidadores para ayudar a mejorar la calidad de vida de los pacientes de Alzheimer en su primera etapa? *

Tu respuesta

9- ¿Considera que el paciente con Alzheimer en su primera etapa de desarrollo podria interactuar con dispositivos tecnológicos? ¿Por qué? *

Tu respuesta 
10- ¿Cómo podria impactar el uso de la tecnología en la mejora de calidad de vida del paciente con Alzheimer? *

Tu respuesta

11- Utópicamente, ¿qué invento considera que podria ayudar a mejorar la calidad de vida del paciente con Alzheimer en su primera etapa de desarrollo? *

Tu respuesta

¡GRACIAS!

Enviarme una copia de mis respuestas

\section{Enviar}

Figura Al.1 Encuesta semiestructurada.

\section{Al.2 Entrevista abierta no estructurada}

Las entrevistas partieron de una serie de cuestionamientos preestablecidos, los cuales dieron pauta a la generación de preguntas abiertas. Las preguntas base fueron:

- ¿Cómo definiría usted un episodio o crisis de EA?

- ¿Qué acciones realiza usted para sobrellevar un episodio de EA?

- ¿Usted cree que es posible evitar un episodio de EA?

- ¿Usted cree que es posible anticipar un episodio de EA?

- ¿Los síntomas que el paciente presenta, son constantes?

- ¿Cuáles son los síntomas más frecuentes antes de que un episodio se desencadene?

- ¿Usted piensa que los síntomas antes de que el episodio de la EA se desencadene podrían ser previsibles?

- ¿Qué acciones realiza para estabilizar al paciente después de un episodio de EA?

- ¿Usted considera que la tecnología digital podría ayudar en la EA? 


\section{ANEXO II. DISEÑO Y DESARROLLO DEL PROTOTIPO DE LA INTERFAZ GRÁFICA DE LA CENTINEL APP}

Para la creación del prototipo de la interfaz gráfica del sistema e-Health que serviría para validar las directrices de diseño y visualización propuestas en este proyecto de investigación, en primer lugar, era necesario desarrollar la imagen de la aplicación (App). Para ello, inicialmente debió definirse el nombre de la App, el cual se derivó de la palabra "centinela" -que significa "persona que está observando algo" (RAE, 2020)- dado que esta aplicación funciona como una extensión de los ojos del cuidador o, en otras palabras, se encarga de observar al paciente y notificar al cuidador cuando su situación de salud se encuentre fuera de los parámetros comunes, quedando como nombre definitivo CENTINEL App.

Además, debió diseñarse la imagen gráfica de la $A p p$, diseño realizado a partir de experimentación con diversas representaciones -con un alto nivel de iconicidad-, por un lado, de un ojo humano y, por otro, de una cámara (Ver: Figura All.1), conceptos relacionados directamente con el nombre y la función de la aplicación.

\section{0 \\ 000000}

Figura All.1 Experimentación con íconos.

De igual manera, el diseño de la imagen gráfica implicó la experimentación con diversas fuentes tipográficas, las cuales remitieran a la función de la App en concordancia con las necesidades de su usuario. (Ver: Figura All.2).



Figura All.2 Experimentación con fuentes e íconos. 
Así, la fuente tipográfica elegida fue la Century Gothic, al corresponder a un estilo geométrico que permite una adecuada legibilidad, modificando la interletra para que el peso de las contraformas resultara visualmente equilibrado.

Finalmente, se trabajó con una gradación monocromática, con contraste de luminosidad, de un matiz que hiciera referencia al propósito de la $A p p$, siendo elegido el color morado $(R=97, G=13$, $\mathrm{B}=143$ ) debido a que este describe habitualmente la lucha contra el Alzheimer (Mesa Editorial, 2016). Para compensar el matiz morado en el diseño de las pantallas que conformarían la interfaz gráfica, además se estableció el uso del matiz verde azulado ( $R=153, G=207, B=224)$, empleando ambos con sus variaciones lumínicas. (Ver: Figura All.3).

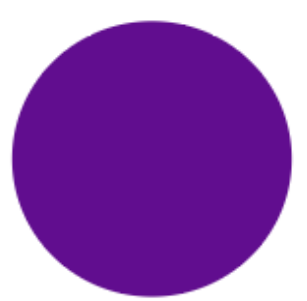

$R=97 \quad G=13 \quad B=143$

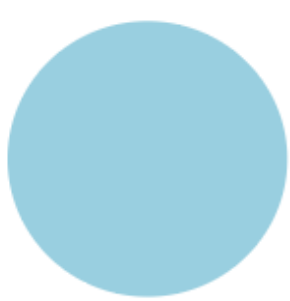

$R=153 \quad G=207 \quad B=224$
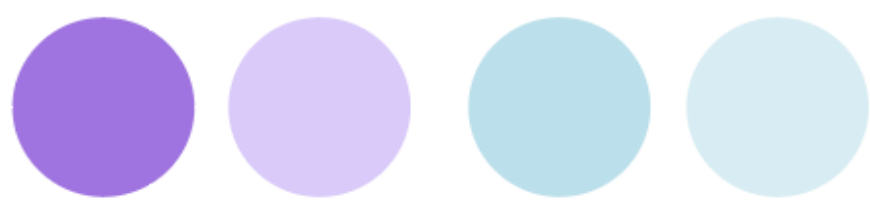

Figura All.3 Matices y variaciones lumínicas.

Así pudo establecerse la imagen gráfica que representará a la App. (Ver: Figura All.4).

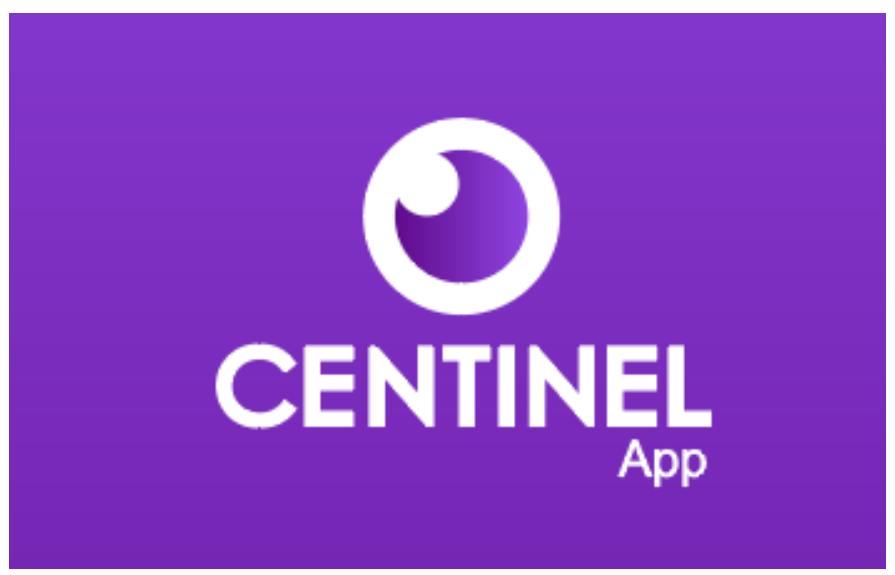

Figura All.4 Imagen final de la App. 
Establecida la imagen de la App, se procedió al desarrollo del prototipo de la interfaz gráfica correspondiente.

Para llevar a cabo dicha acción, en primer lugar, se realizaron los primeros bocetos digitales a partir de la implementación del software Balsamiq Wireframes ${ }^{104}$. (Ver: Figura All. 5).

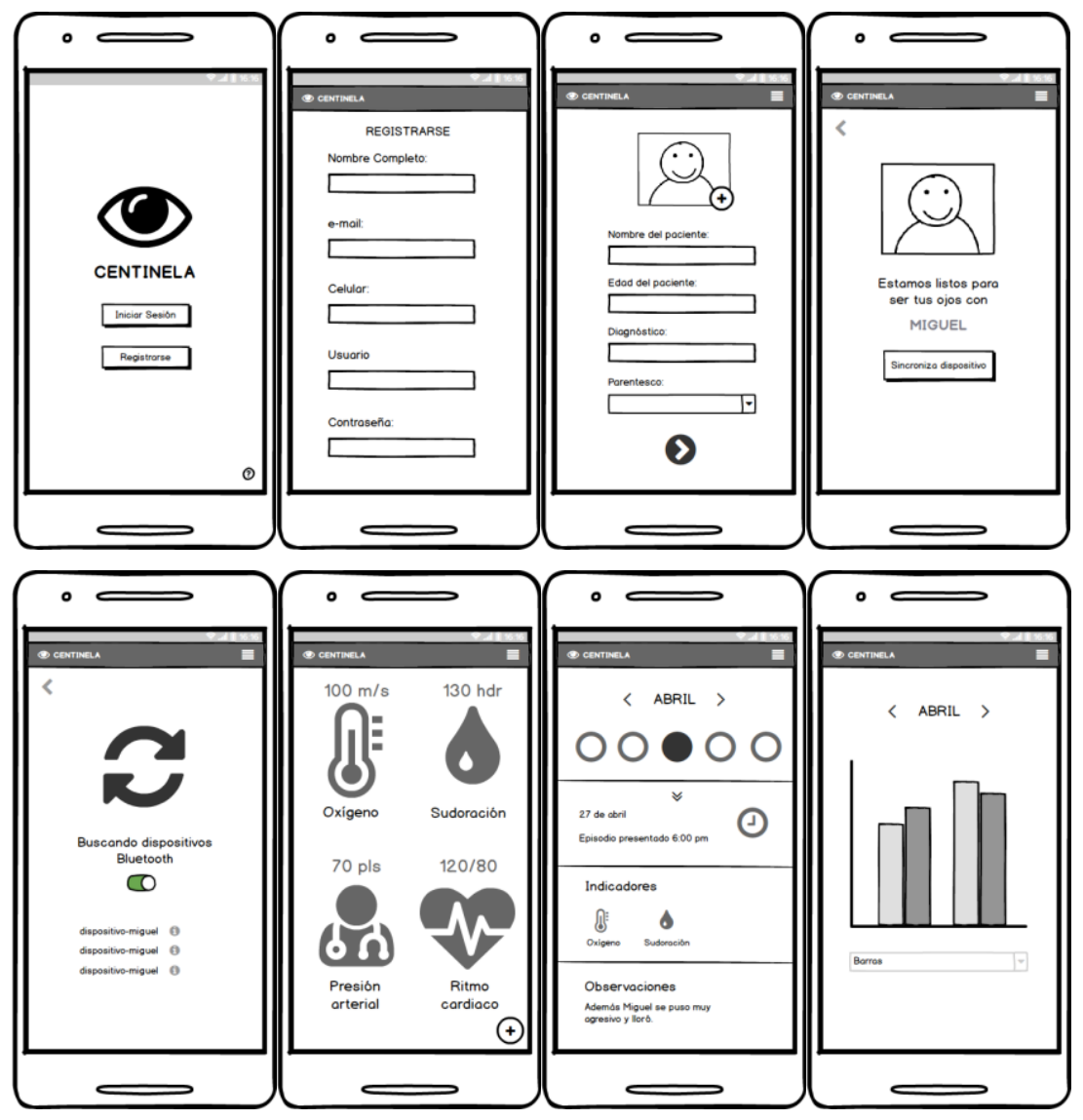

Figura All.5 Primeros bocetos digitales.

Posteriormente, a partir de la definición de la imagen gráfica, se desarrollaron digitalmente -en Adobe Illustrator@- cada una de las pantallas que conformarían la interfaz gráfica de la $A p p^{105}$. (Ver: Figura All. 6).

104 Herramienta de estructura de líneas de interfaz de usuario de baja fidelidad que reproduce la experiencia de dibujar en un bloc de notas o pizarra, a partir de una computadora. (Balsamiq, 2020).

105 Cabe mencionar que el desarrollo de la App se ha propuesto para dispositivos con sistema operativo Android, debido a que este permite el uso de software y hardware libre y su programación resulta relativamente más sencilla en comparación con el sistema IOS. 


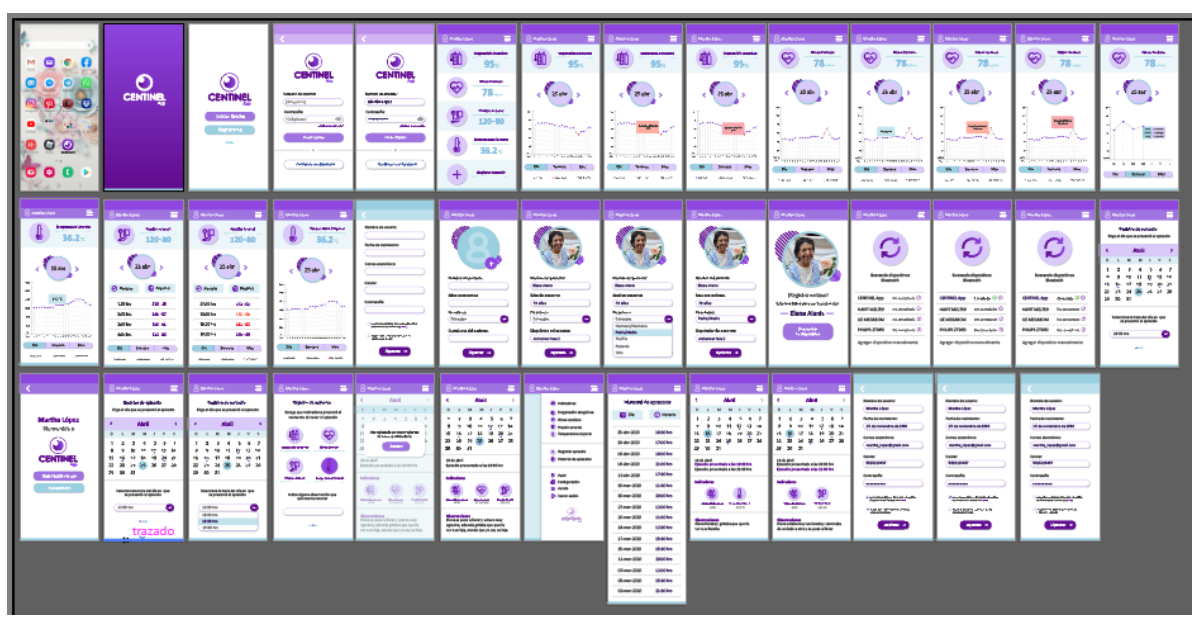

Figura All.6 Pantallas que conforman la interfaz gráfica de la App.

Finalmente, a partir de las pantallas desarrolladas, se utilizó la herramienta digital InVision ${ }^{106}$ la cual permitió establecer un prototipo de la interfaz gráfica de la CENTINEL App. (Ver: Figura All.7), cuyo funcionamiento se describe a continuación: (Ver: Tabla All.1).

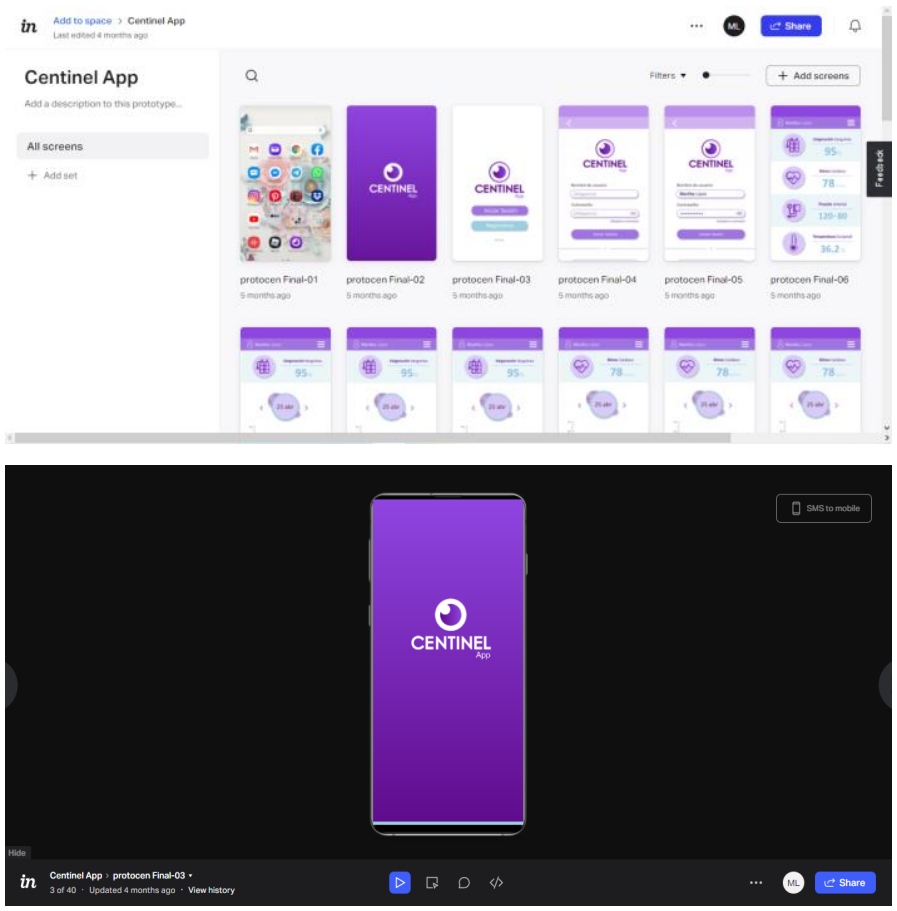

Figura All.7 Prototipo de CENTINEL App en InVision.

106 Plataforma de diseño de prototipos digitales que impulsa mejores experiencias de usuario. (Invision, 2020). 


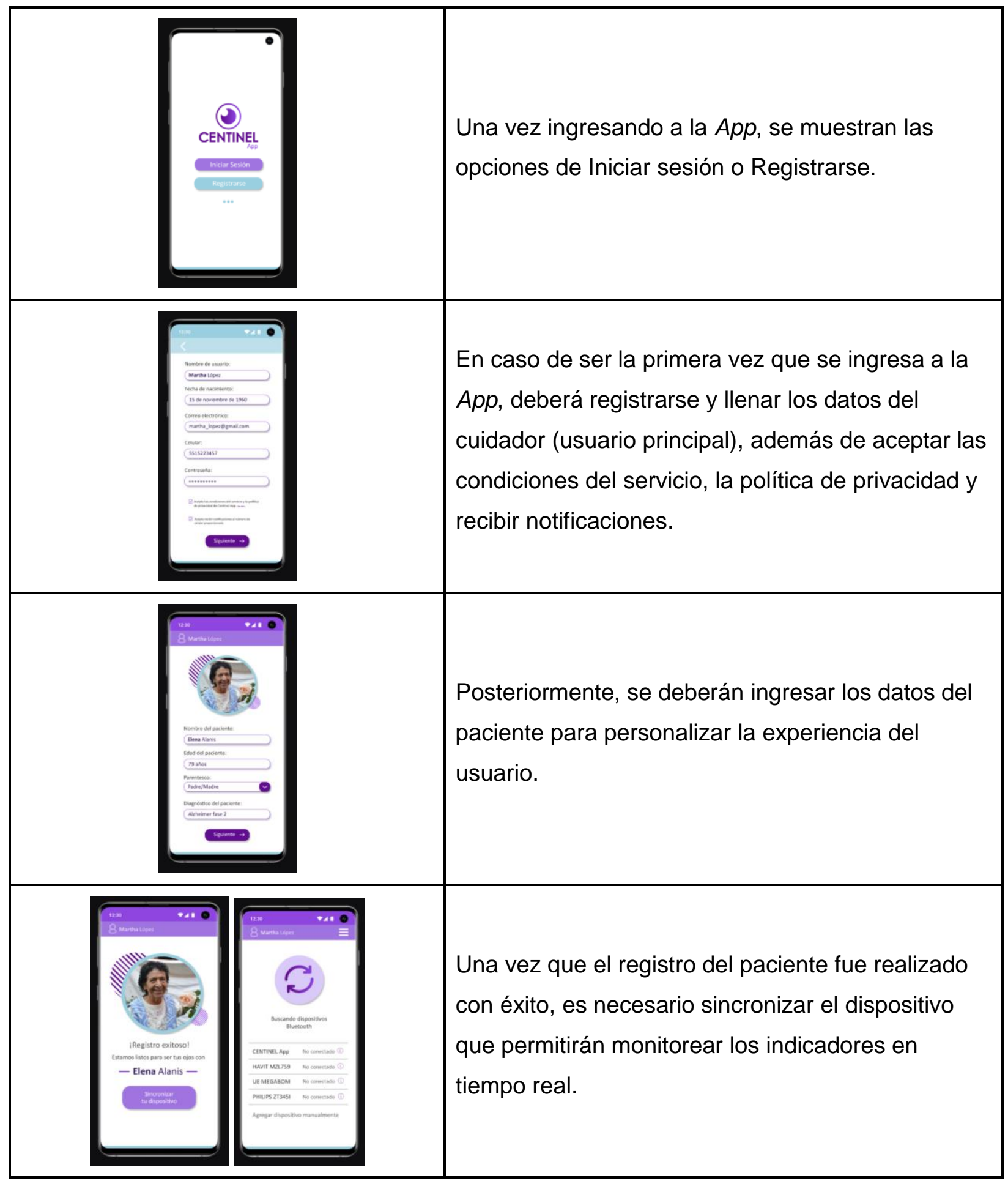




\begin{tabular}{|c|c|c|}
\hline Martha López & 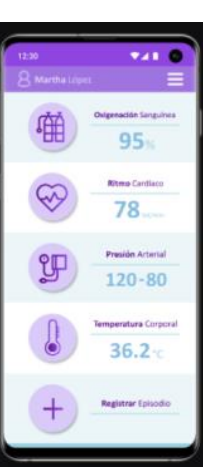 & $\begin{array}{l}\text { A continuación, el cuidador podrá elegir si desea } \\
\text { tener una guía rápida de uso o ingresar a la } \\
\text { pantalla de indicadores -oxigenación sanguínea, } \\
\text { ritmo cardíaco, presión arterial y temperatura } \\
\text { corporal- en tiempo real, los cuales en caso de salir } \\
\text { del valor promedio del paciente indicarían que } \\
\text { podría avecinarse un episodio de Alzheimer. }\end{array}$ \\
\hline 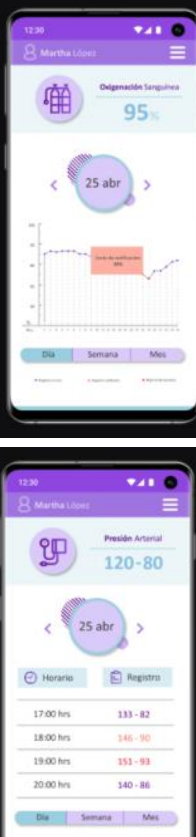 & 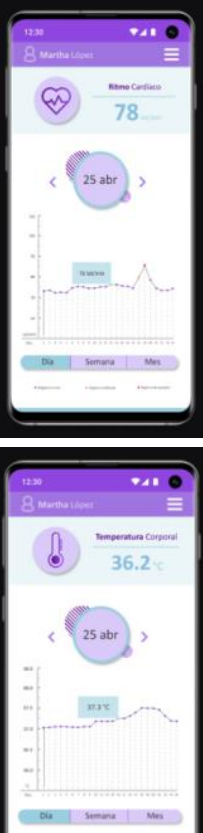 & $\begin{array}{l}\text { Al seleccionar cada indicador permitirá visualizar } \\
\text { una gráfica en la cual se podrá encontrar el valor } \\
\text { registrado en cada hora, además podrá } \\
\text { visualizarse una gráfica de líneas por semana y por } \\
\text { mes. Además, la App registra de manera } \\
\text { automática cuando existe un valor que se } \\
\text { encuentre fuera del promedio que el paciente } \\
\text { maneja, lo cual permite una visualización de } \\
\text { información más fácil. }\end{array}$ \\
\hline 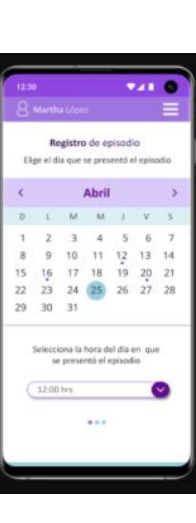 & 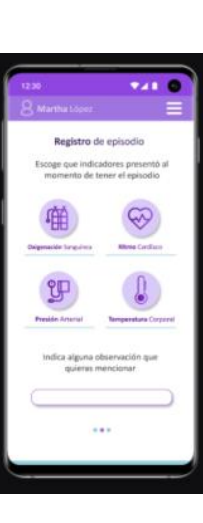 & $\begin{array}{l}\text { Además de los indicadores, es posible que el } \\
\text { cuidador lleve un registro de episodios, cada vez } \\
\text { que el cuidador registre un episodio, la App será } \\
\text { alimentada de datos proporcionados por el (día, } \\
\text { hora, indicador que presentó el paciente y } \\
\text { observación libre - todos relativos al episodio) los } \\
\text { cuales le servirán para brindar información } \\
\text { predictiva. }\end{array}$ \\
\hline
\end{tabular}




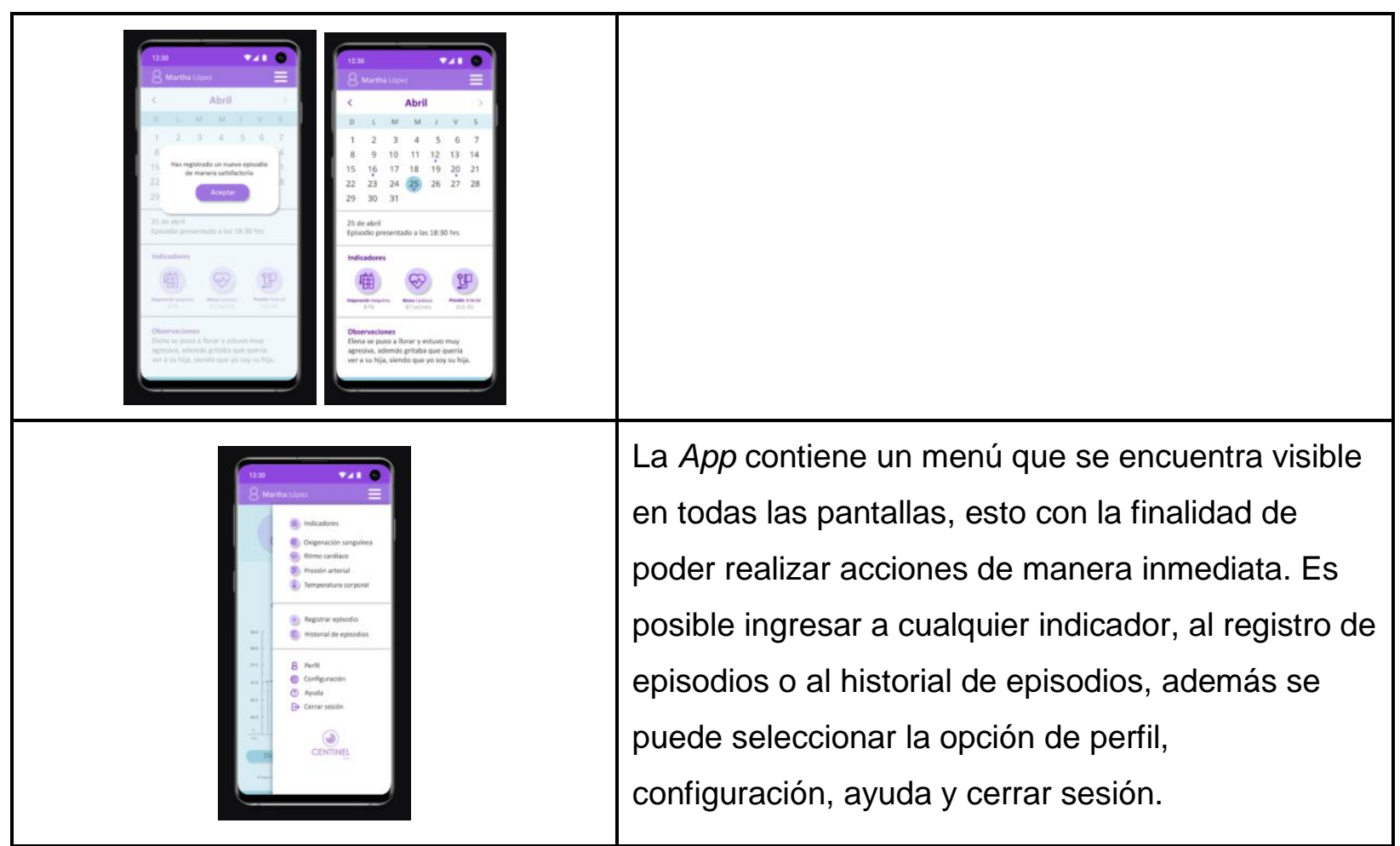

Tabla All.1 Funcionamiento de CENTINEL App. 


\section{ANEXO III. ANÁLISIS DE DATOS OBTENIDOS DE LA APLICACIÓN DE LOS INSTRUMENTOS DE VALIDACIÓN}

\section{Ronda 1}
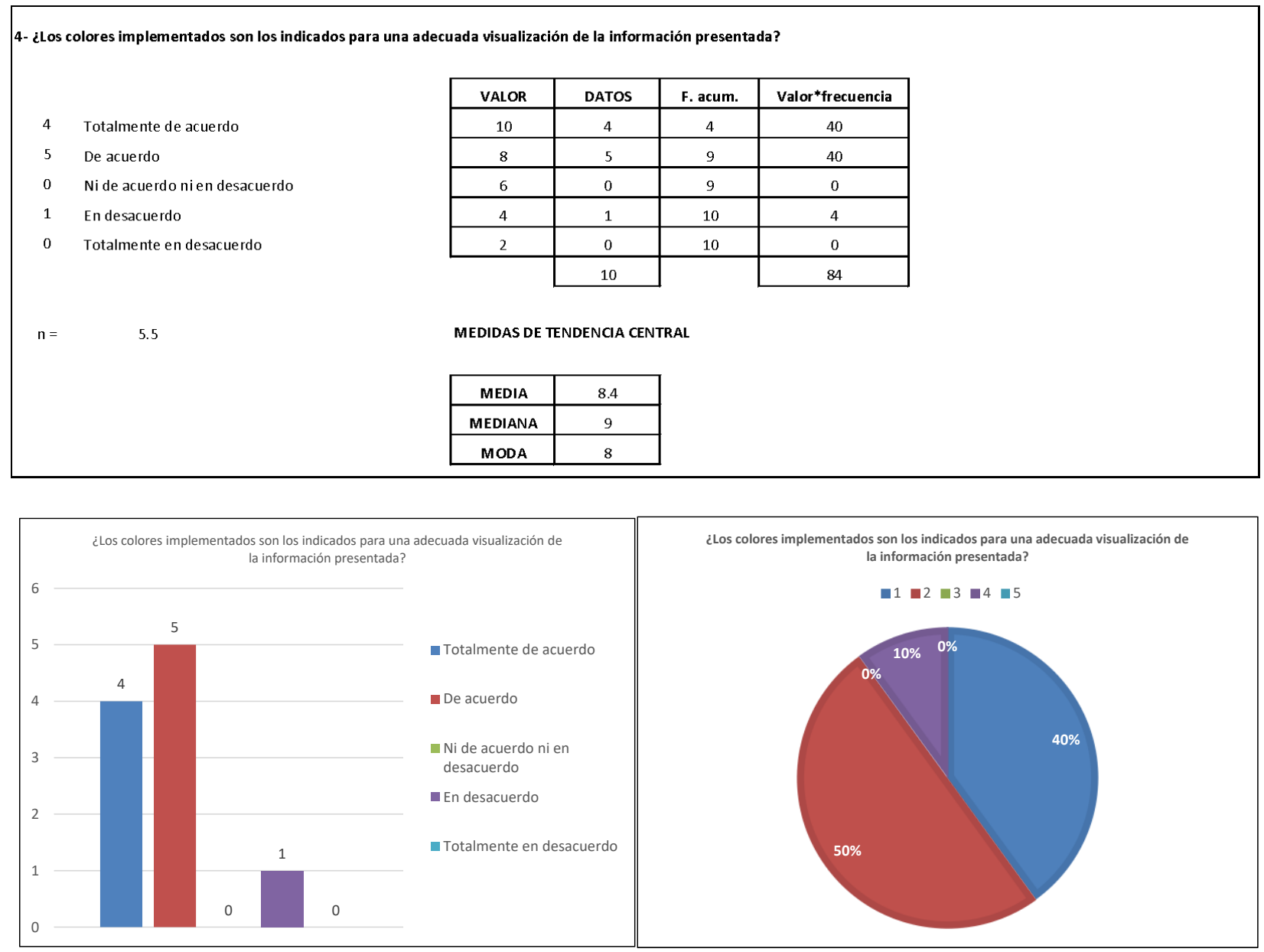

Los datos obtenidos a través del instrumento de validación por medio de las medidas de tendencia central permiten observar que la media a esta cuestión corresponde a un 8.4 lo cual entra en la tabla de valor: de acuerdo. Lo anterior indica que los colores implementados son los indicados para una adecuada visualización de la información. 

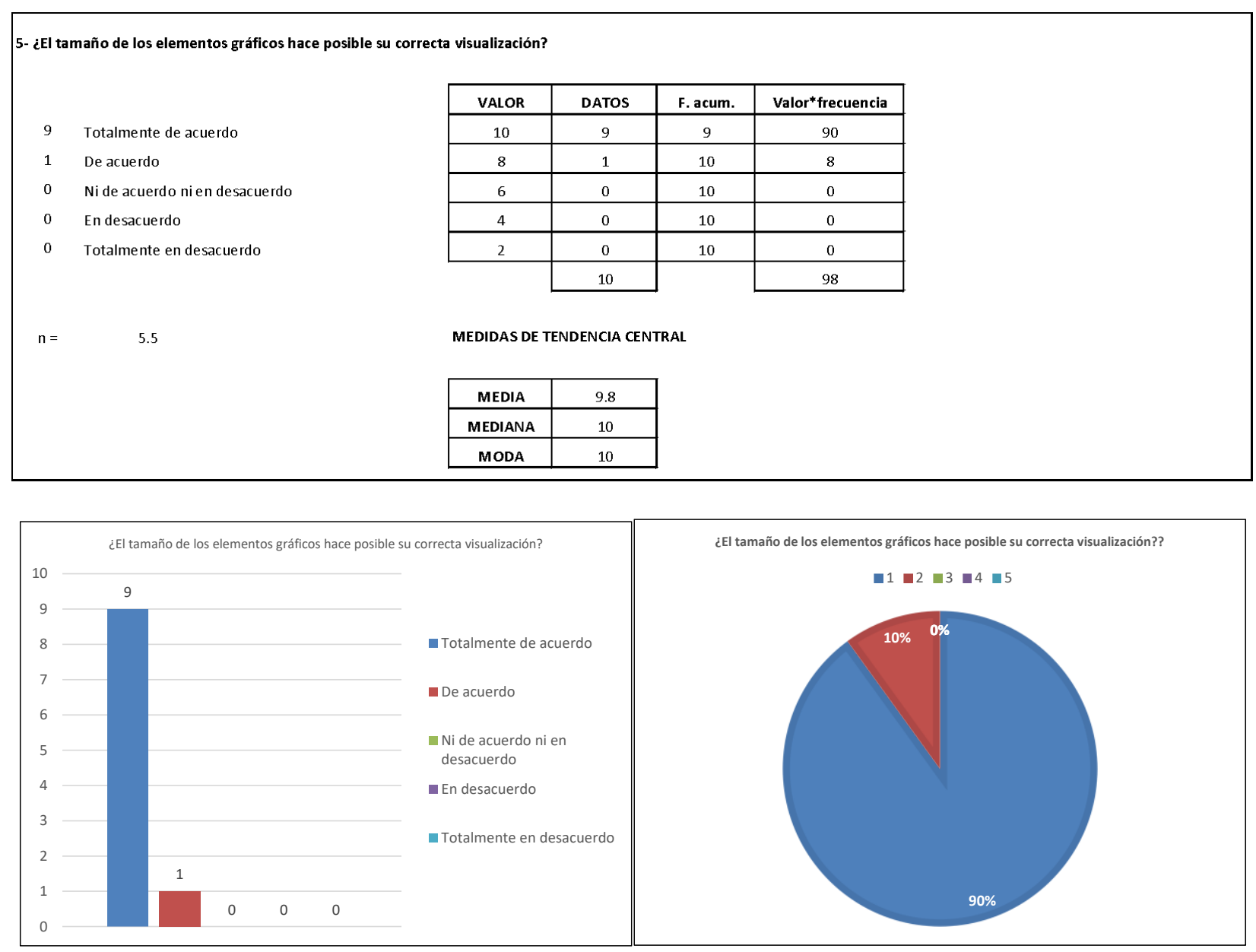

De acuerdo con la tabla y a las gráficas se puede observar que 9 de los 10 encuestados contestaron que estaban totalmente de acuerdo a la cuestión formulada, mientras que un encuestado contestó que estaba de acuerdo, lo que deja entrever que el tamaño de los elementos gráficos sí hace posible su correcta visualización. 

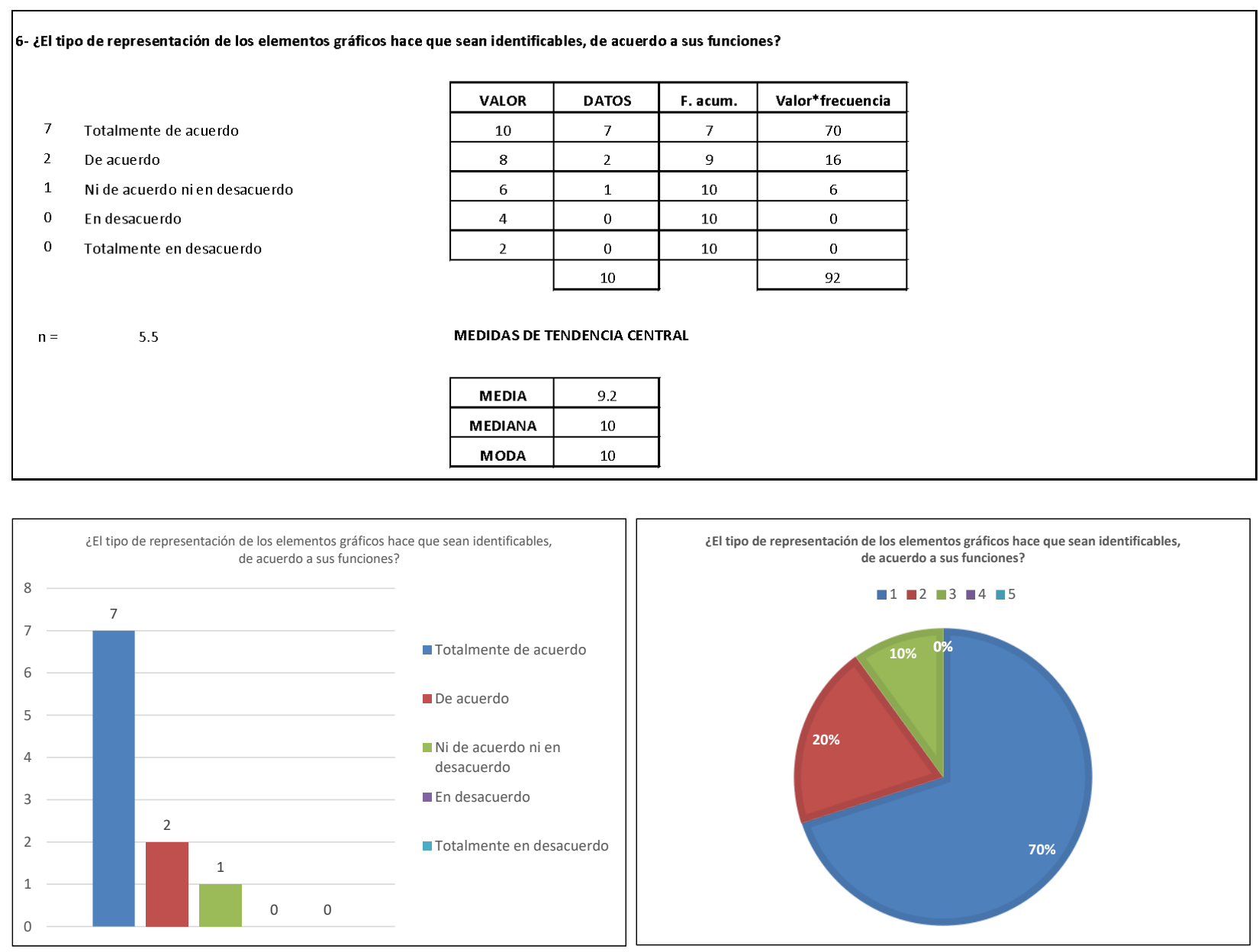

Con base en lo datos obtenidos en el instrumento de validación se muestra que 7 encuestados indicaron la respuesta totalmente de acuerdo, 2 de acuerdo y 1 ni de acuerdo ni desacuerdo, lo cual de acuerdo con las medidas de tendencia central se mantienen dentro del rango de $9.2-10$ equivalentes a totalmente de acuerdo, lo que indica que el tipo de representación de los elementos gráficos hace que sean identificables de acuerdo a su función. 

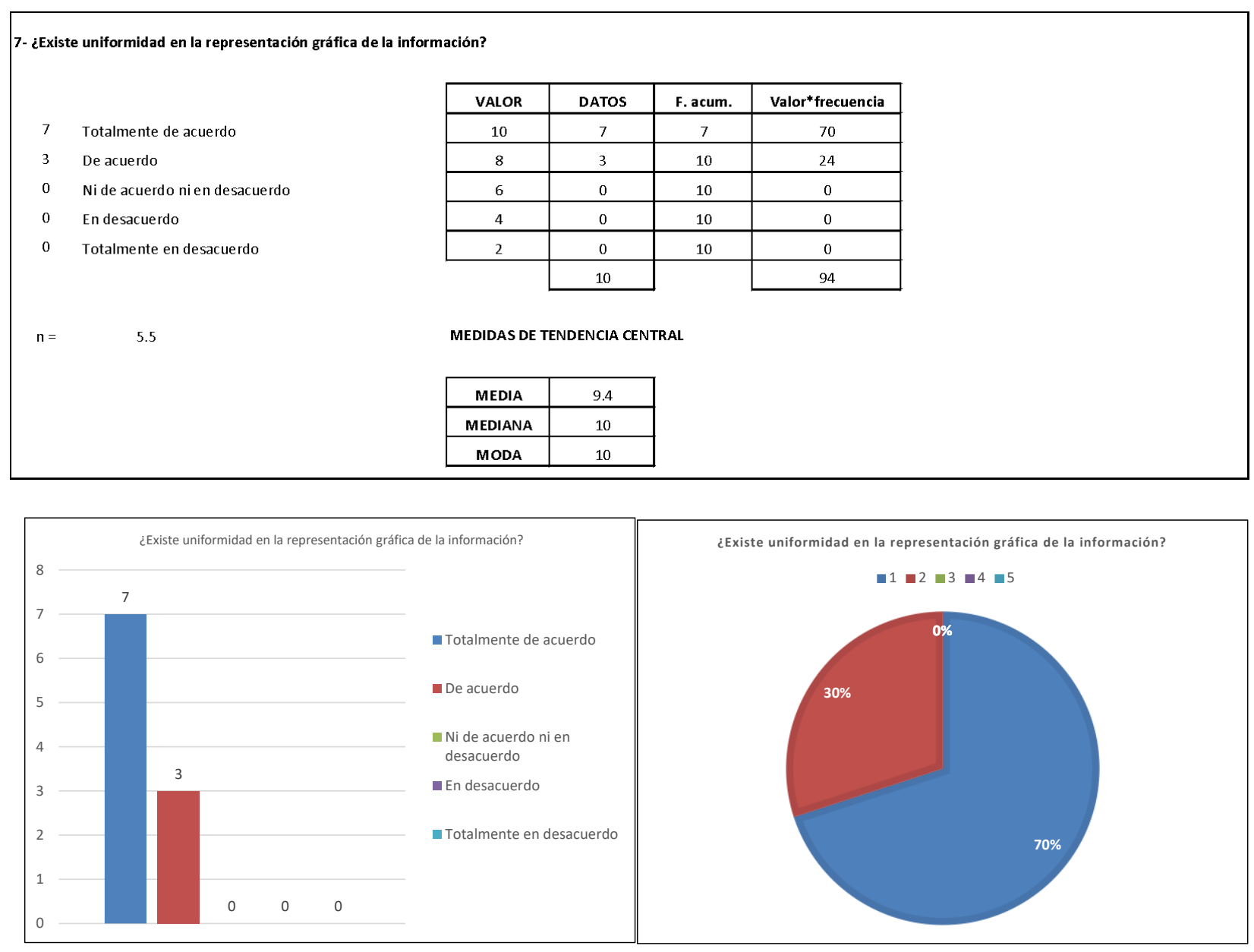

De acuerdo con la tabla y a las gráficas se puede notar que 7 de los 10 encuestados contestaron que estaban totalmente de acuerdo a la cuestión formulada, mientras que 3 encuestados contestaron que estaba de acuerdo, lo cual indica que existe uniformidad en la representación gráfica de la información. 

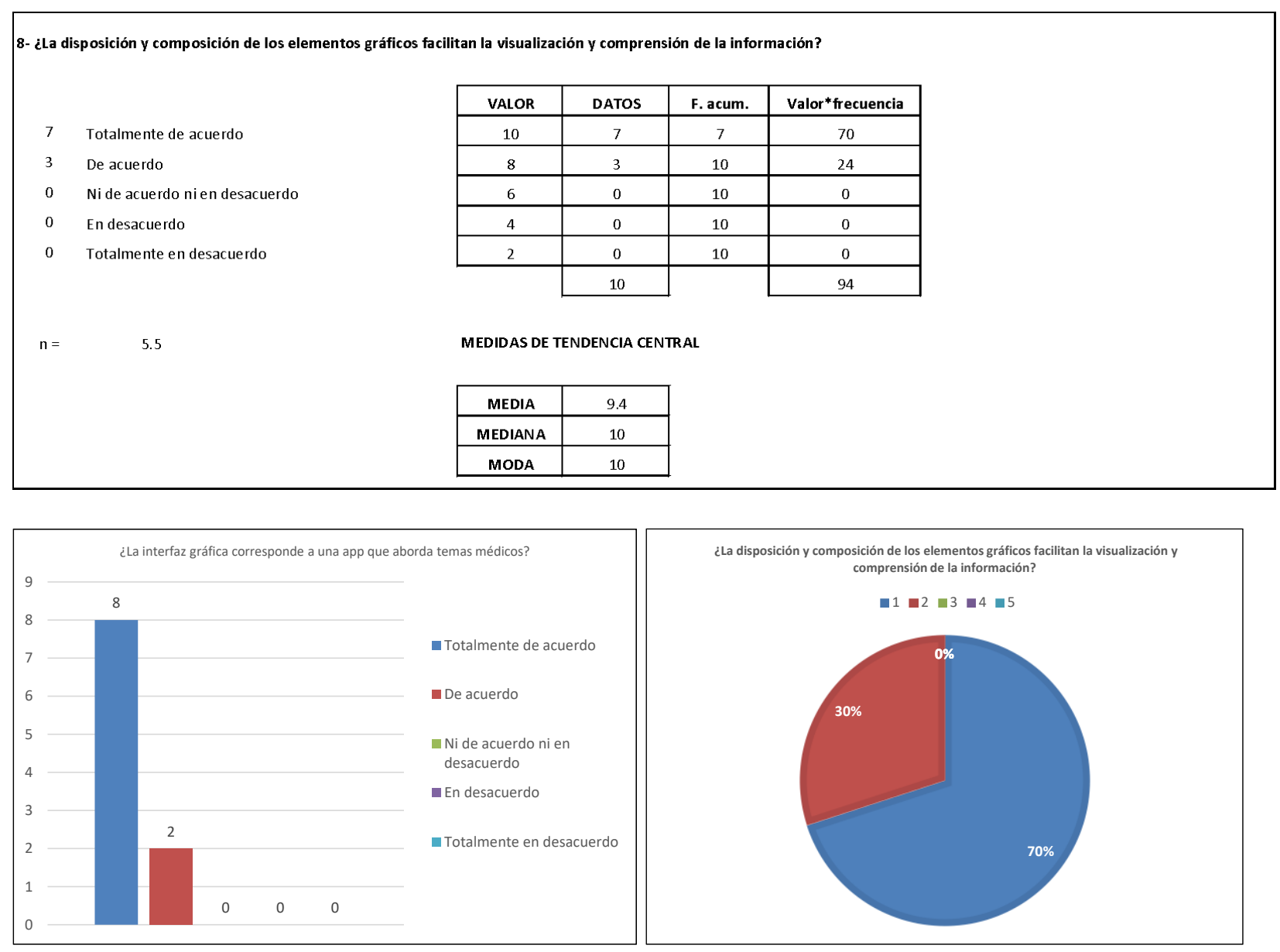

Con base en la tabla de las medidas de tendencia central, obtenidas de acuerdo con la información poseyente de los encuestados en el instrumento de validación se puede observar que la media a esta cuestión corresponde a un 9.4 lo cual entra en la tabla de valor: de acuerdo. Lo anterior permite comprobar que la disposición y la composición de los elementos gráficos facilitan la visualización y comprensión de la información. 

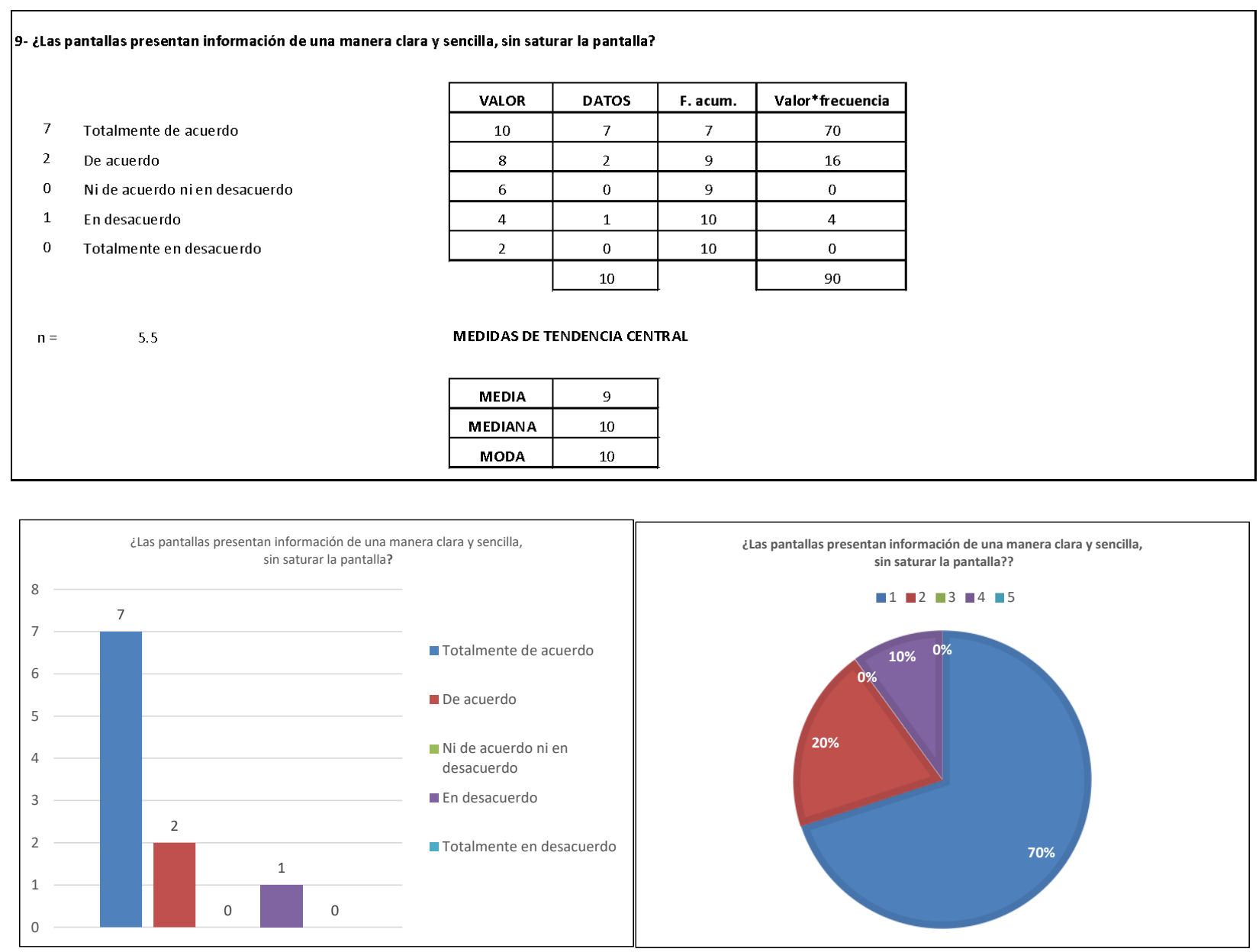

De acuerdo con las medidas de tendencia central obtenidas con base en las respuestas de los encuestados de esta cuestión se mantienen dentro del rango de 9 - 10 equivalentes a totalmente de acuerdo, lo cual permite corroborar que las pantallas presentan información de una manera clara y sencilla, sin saturar la pantalla. 

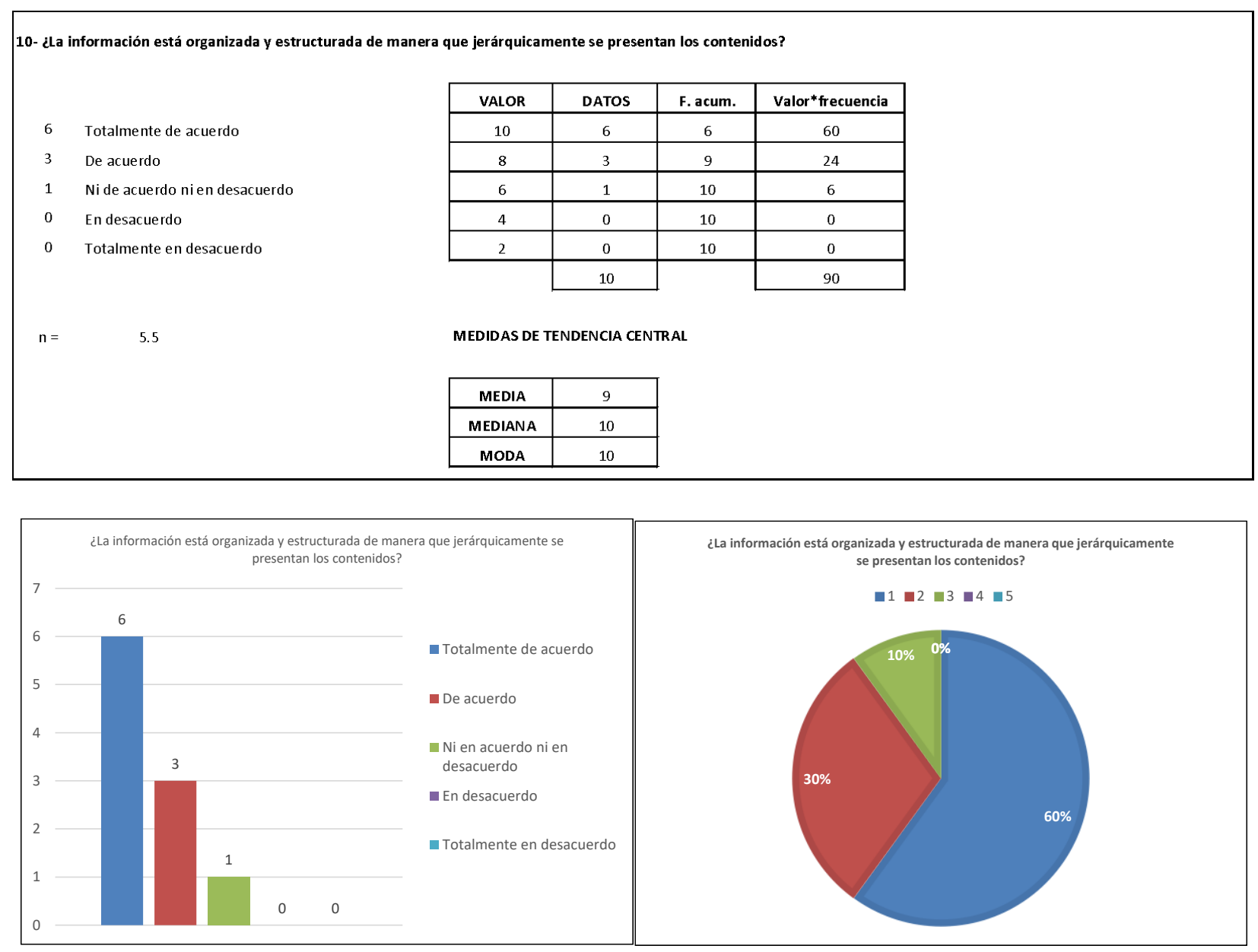

Con base en los datos obtenidos en el instrumento de validación se muestra que 6 encuestados indicaron la respuesta totalmente de acuerdo, 3 de acuerdo y 1 ni de acuerdo ni en desacuerdo, lo que permite corroborar que la información está organizada y estructurada de manera que jerárquicamente se presentan los contenidos. 

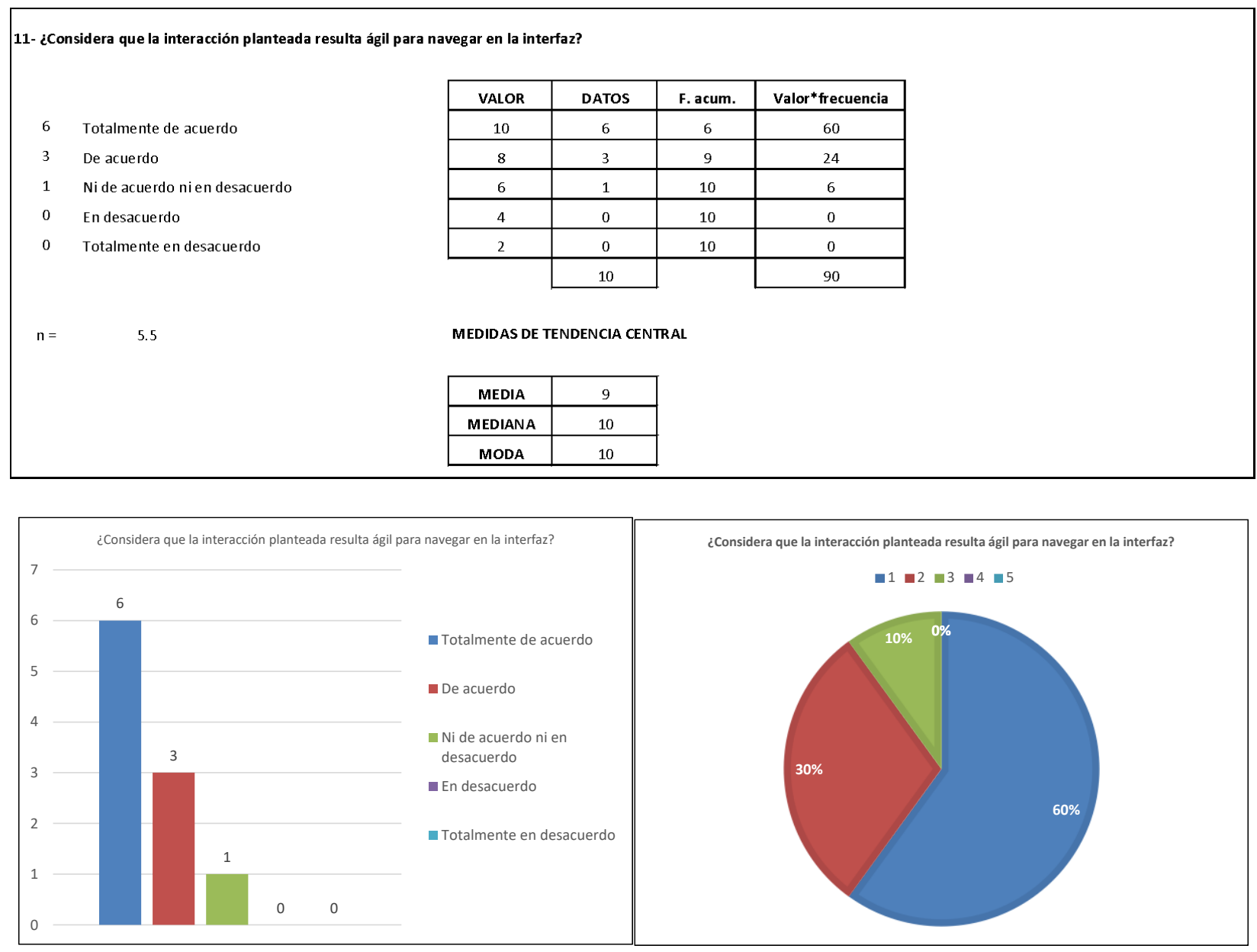

La tabla y las gráficas anteriores permiten observar que 6 de los 10 encuestados contestaron que estaban totalmente de acuerdo, 3 de acuerdo y 1 encuestado que no estaba ni de acuerdo ni en desacuerdo, lo que deja entrever de acuerdo con la mayoría de las respuestas por parte de los expertos que la interacción planteada resulta ágil para navegar en la interfaz. 

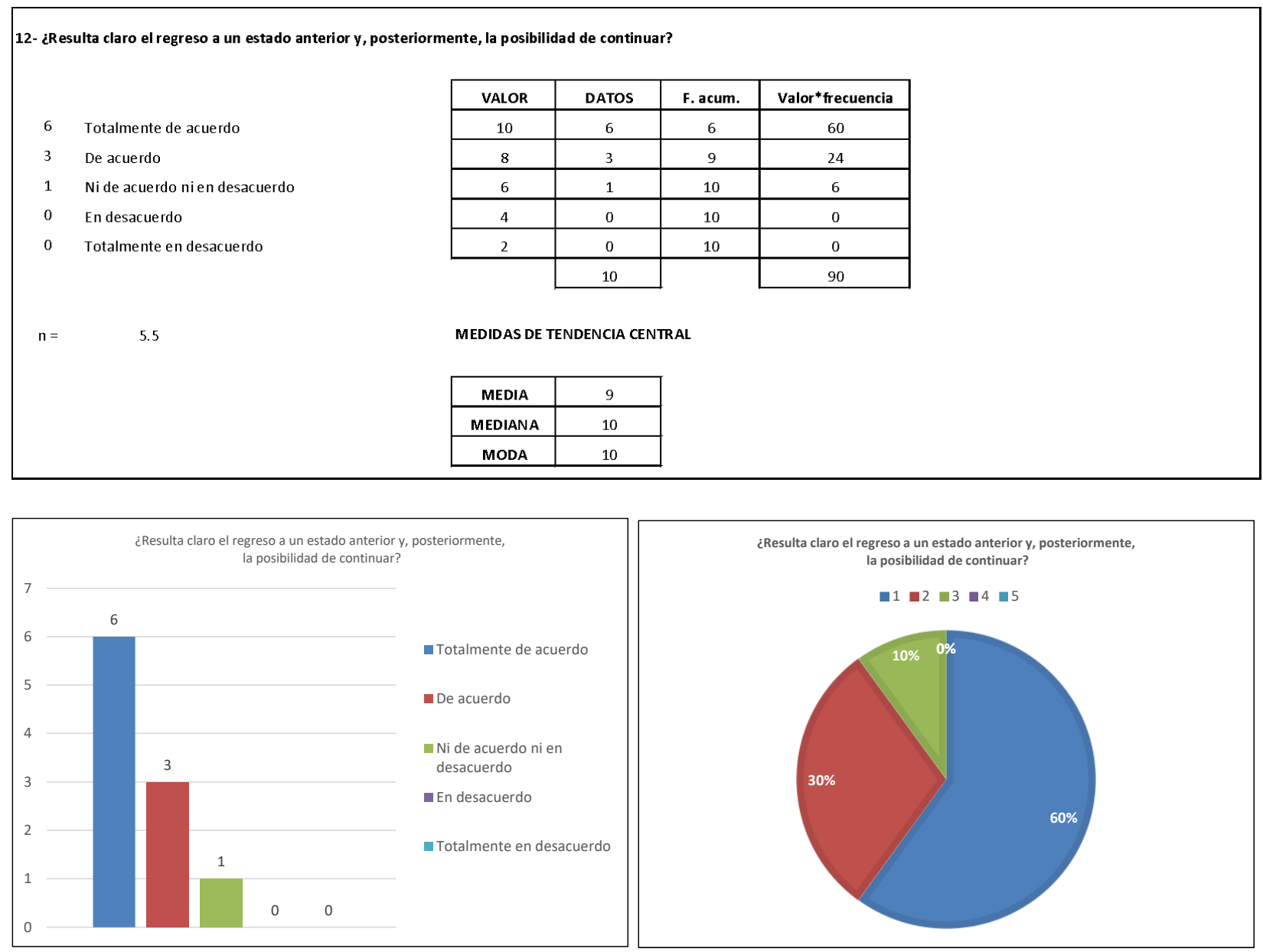

Con base en los resultados obtenidos por los encuestados, se obtuvo que 6 de estos contestaron totalmente de acuerdo, 3 de acuerdo y 1 ni de acuerdo ni en desacuerdo. Lo cual permite obtener una media de 9.0, por ende, se puede decir que los expertos consideran que el regreso a un estado anterior y, posteriormente, la posibilidad de continuar resultó claro. 

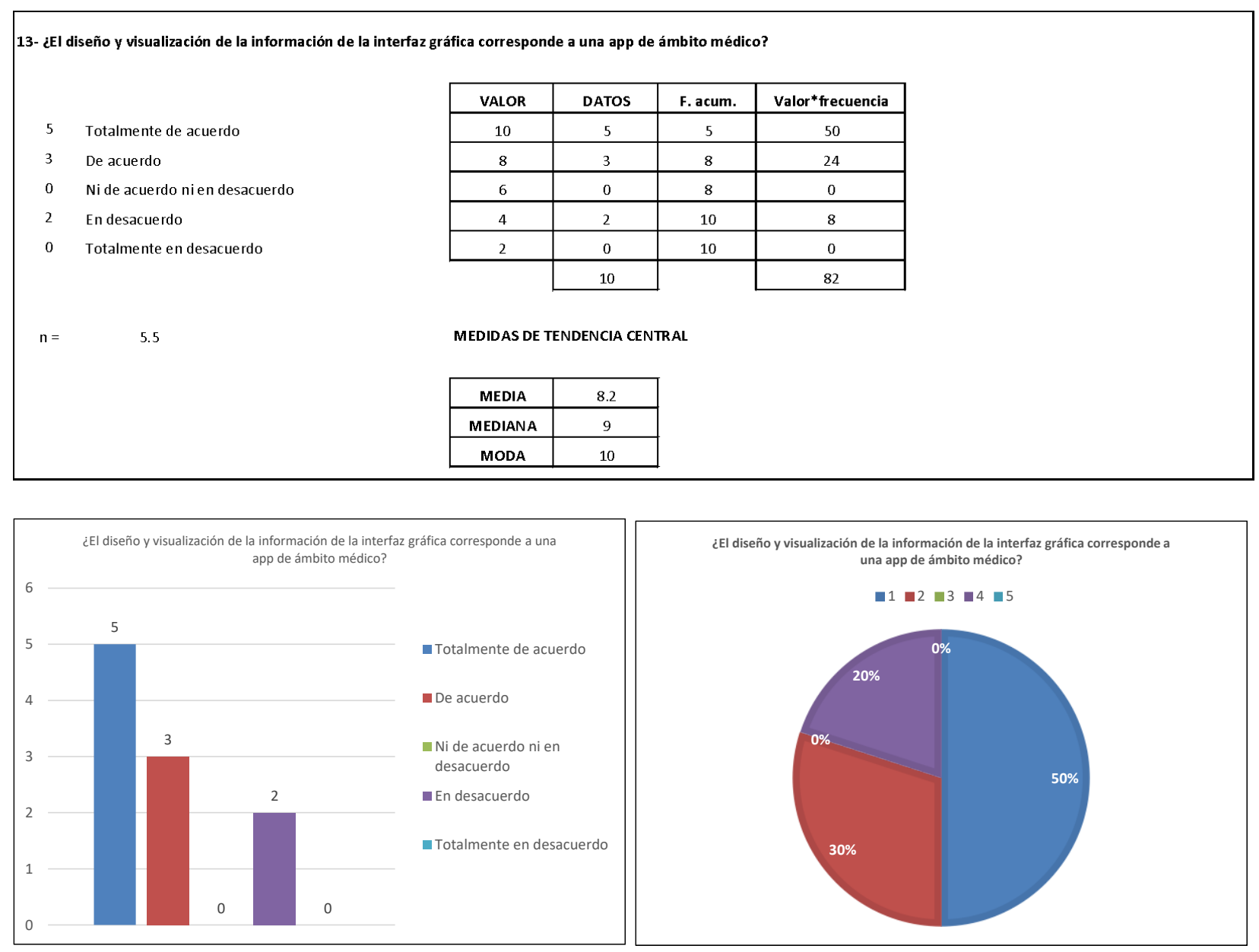

En cuanto a la información obtenida por parte de los encuestados se puede notar que el diseño y visualización de la información de la interfaz gráfica no corresponde del todo a una App de ámbito médico, es verdad que, 5 encuestados contestaron totalmente de acuerdo y 3 que estaban de acuerdo, sin embargo, dicha aseveración surge con base en que 2 encuestados contestaron que estaban en desacuerdo. Lo cual se convierte en un punto a mejorar en los posteriores diseños de interfaz gráfica correspondientes al ámbito médico. 

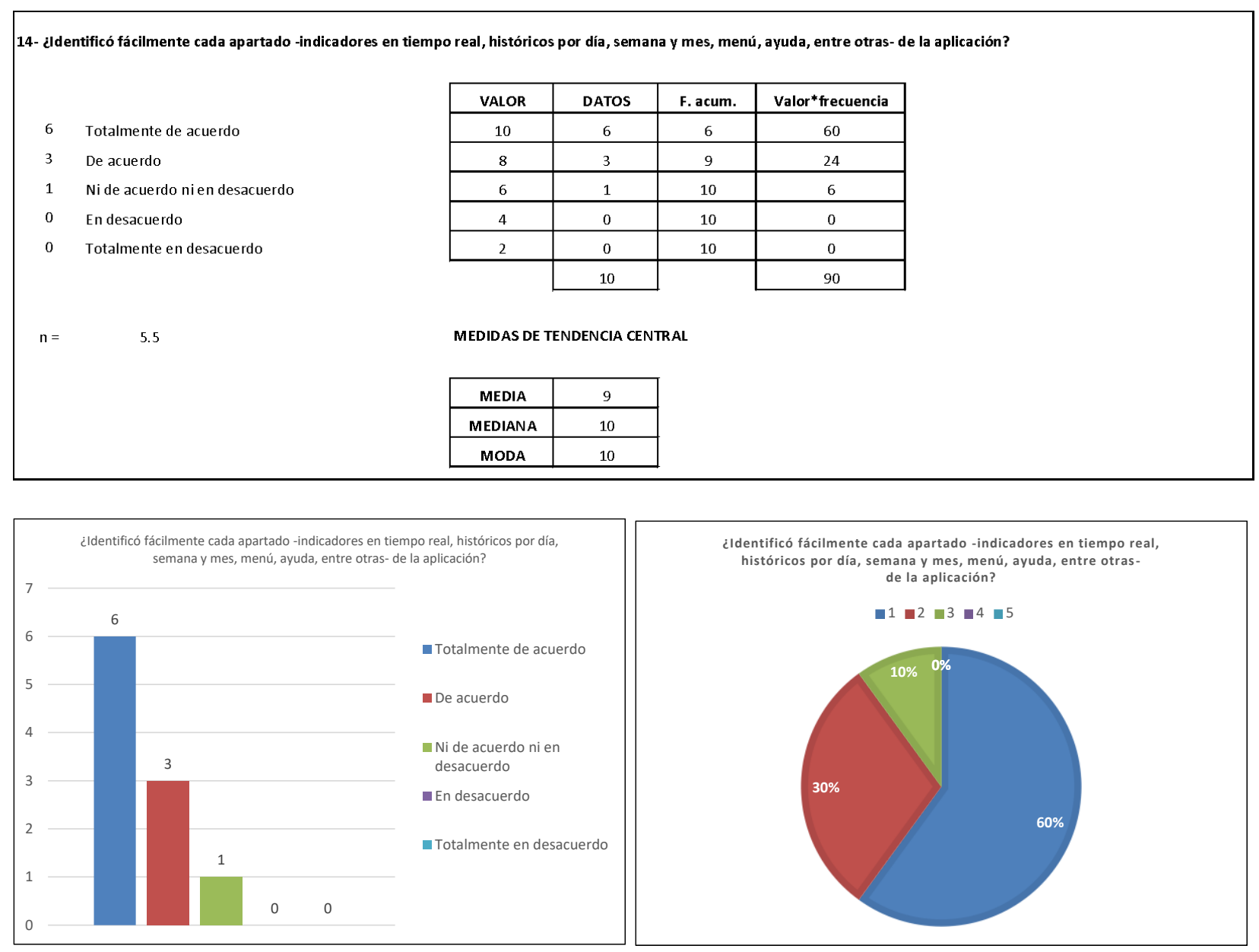

Con base en lo datos obtenidos en el instrumento de validación se muestra que 6 encuestados indicaron la respuesta totalmente de acuerdo, 3 de acuerdo y 1 ni de acuerdo ni en desacuerdo, lo cual de acuerdo a las medidas de tendencia central se mantienen dentro del rango de 9 - 10 equivalentes a totalmente de acuerdo, lo que permite corroborar que fue posible la identificación de cada apartado -indicadores en tiempo real, históricos, por día por semana y mes, menú, ayuda, entre otras- de la aplicación de una manera fácil. 

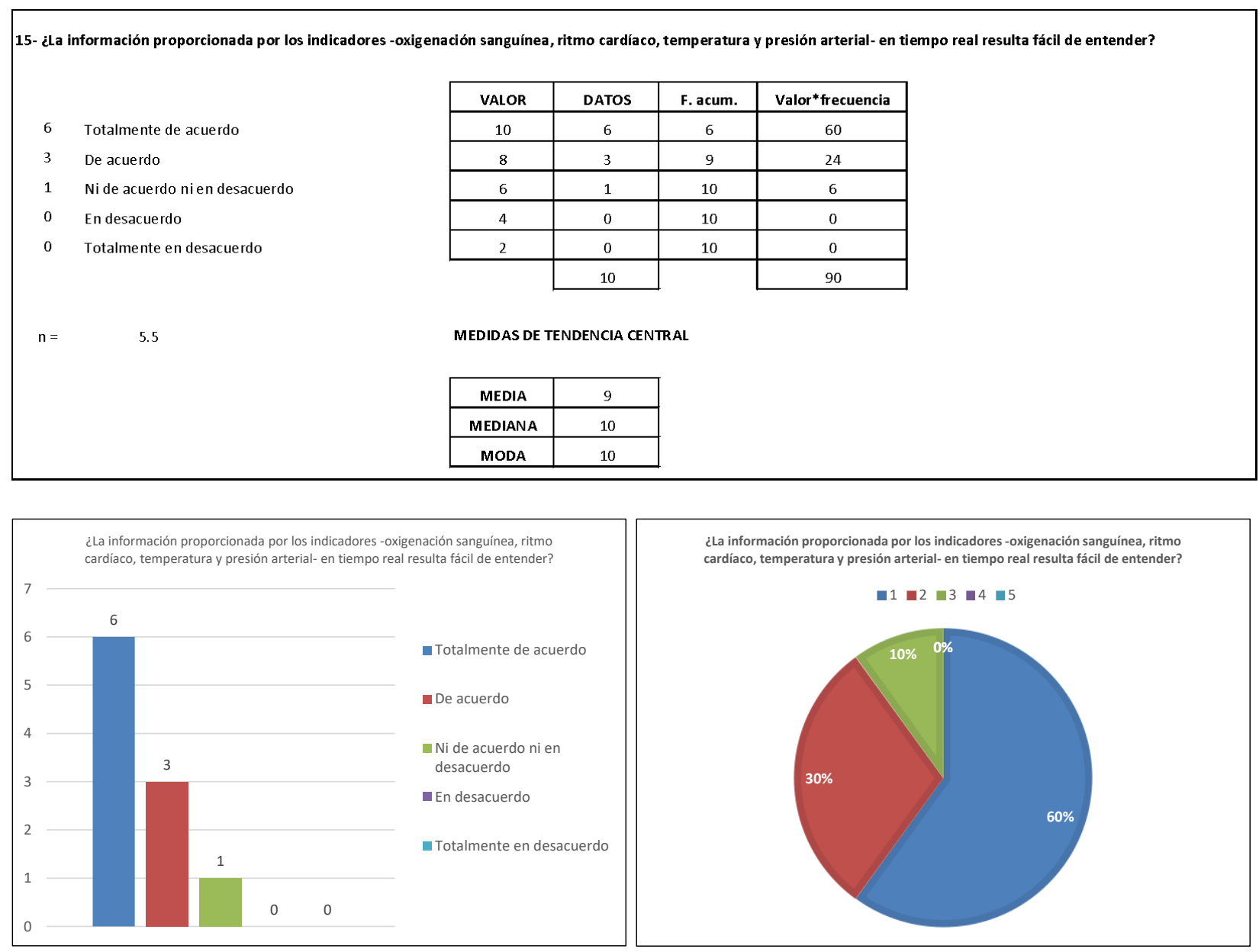

Con base en la tabla de las medidas de tendencia central, obtenidas de acuerdo con la información poseyente de los encuestados en el instrumento de validación se puede observar que la media a esta cuestión corresponde a 9, valor que entra en la tabla: totalmente de acuerdo. Lo anterior permite comprobar que la información proporcionada por los indicadores -oxigenación sanguínea, ritmo cardíaco, temperatura y presión arterial- en tiempo real resultó fácil de entender. 



De acuerdo con la tabla y a las gráficas se puede notar que 5 de los 10 encuestados contestaron que estaban totalmente de acuerdo a la cuestión formulada, mientras que 5 encuestados contestaron que estaba de acuerdo, lo cual indica que la información proporcionada por los indicadores de oxigenación sanguínea, ritmo cardíaco y temperatura en histórico, a través de gráficas de línea resultó fácil de entender. 

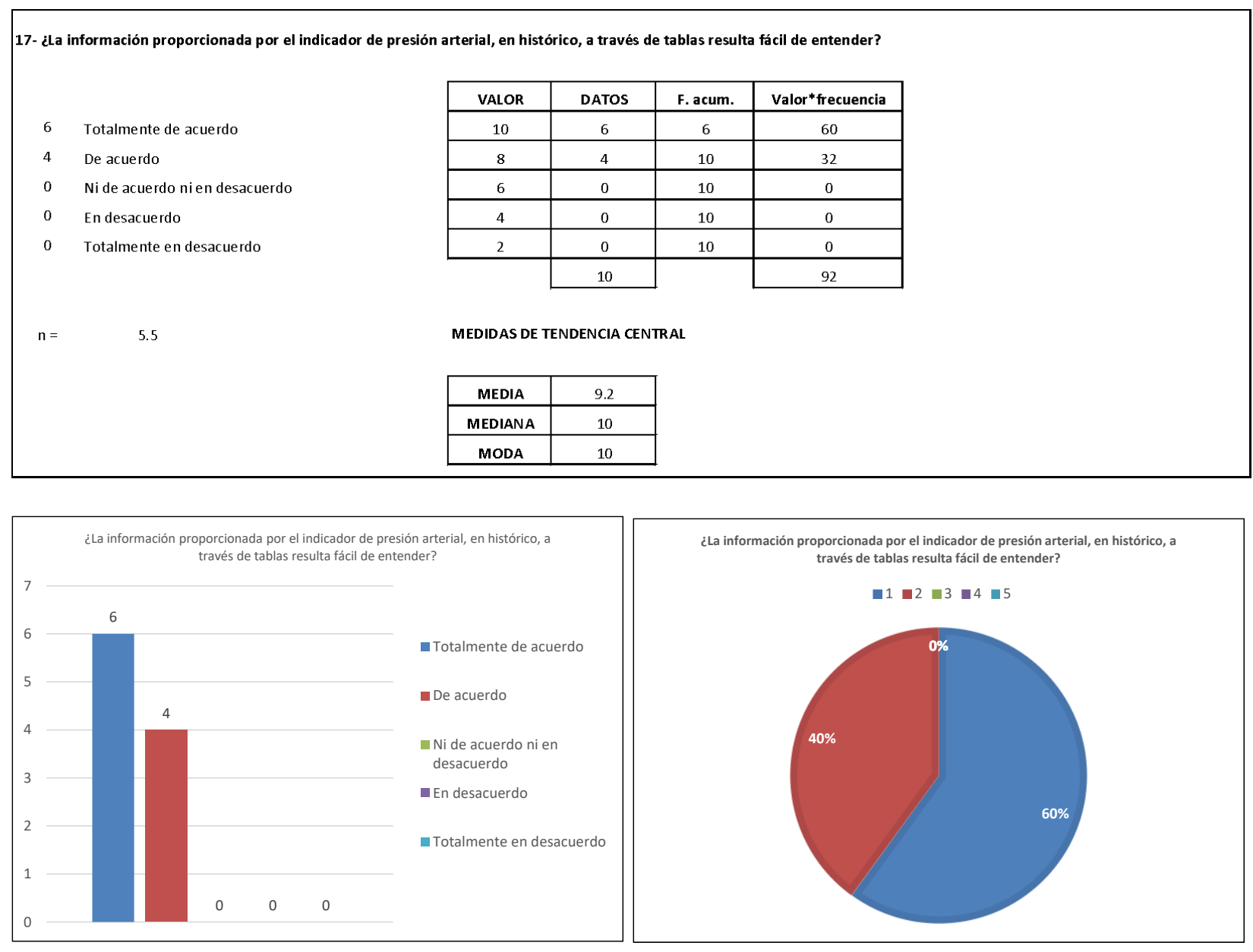

Partiendo de los resultados obtenidos por los 10 encuestados, se obtuvo que 6 de estos contestaron totalmente de acuerdo y 4 de acuerdo. Lo cual permite obtener una media de 9.2 lo que equivale al valor: totalmente de acuerdo, por ende, se puede decir que la información proporcionada por el indicador de presión arterial, en histórico, a través de tablas resultó fácil de entender. 

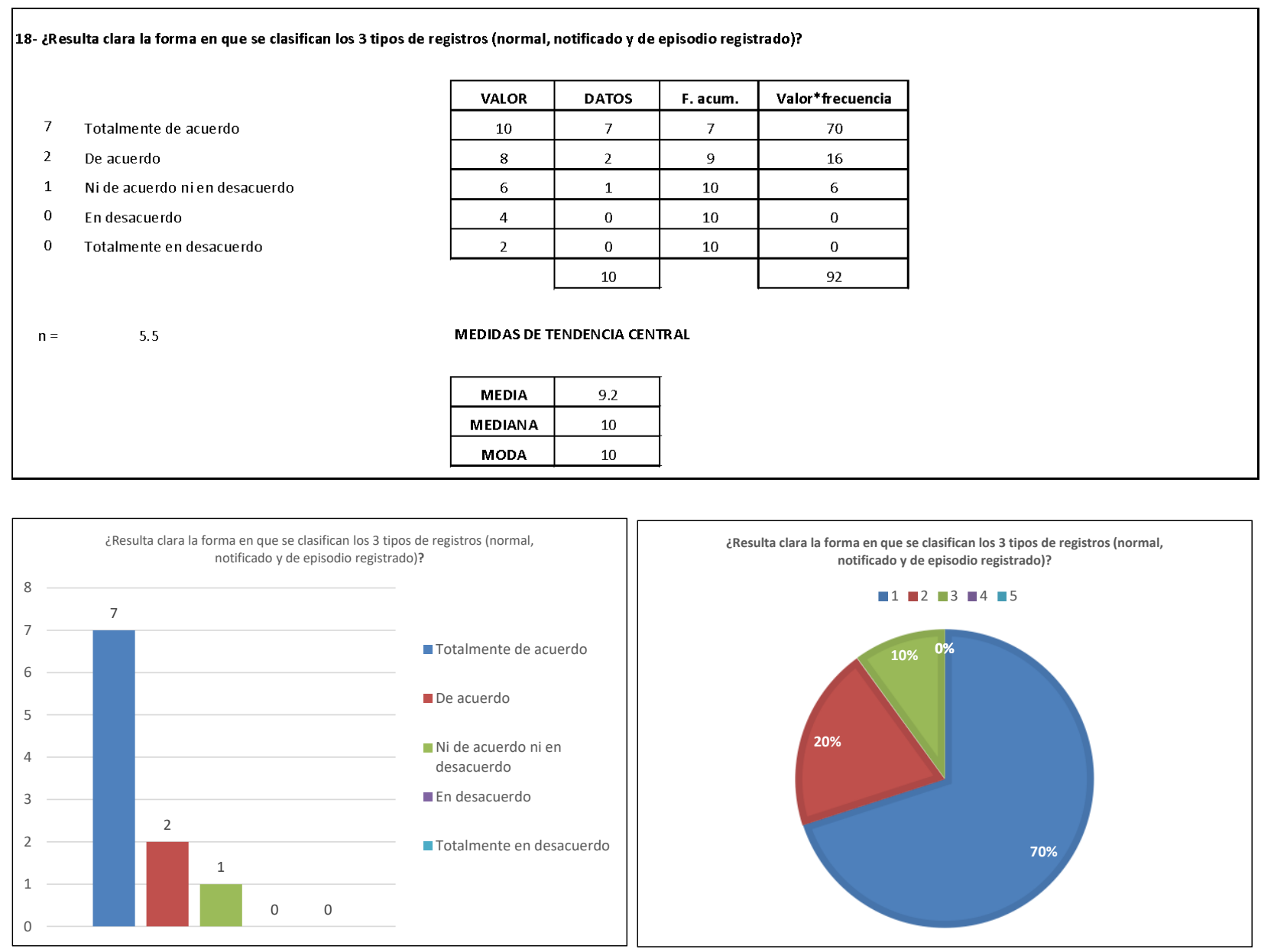

La tabla y las gráficas anteriores permiten observar que 7 de los 10 encuestados contestaron que estaban totalmente de acuerdo, 2 de acuerdo y 1 encuestado que no estaba ni de acuerdo ni en desacuerdo, lo que deja entrever que la forma en la que se clasifican los 3 tipos de registros (normal, notificación enviada y de episodio registrado) resultó clara. 

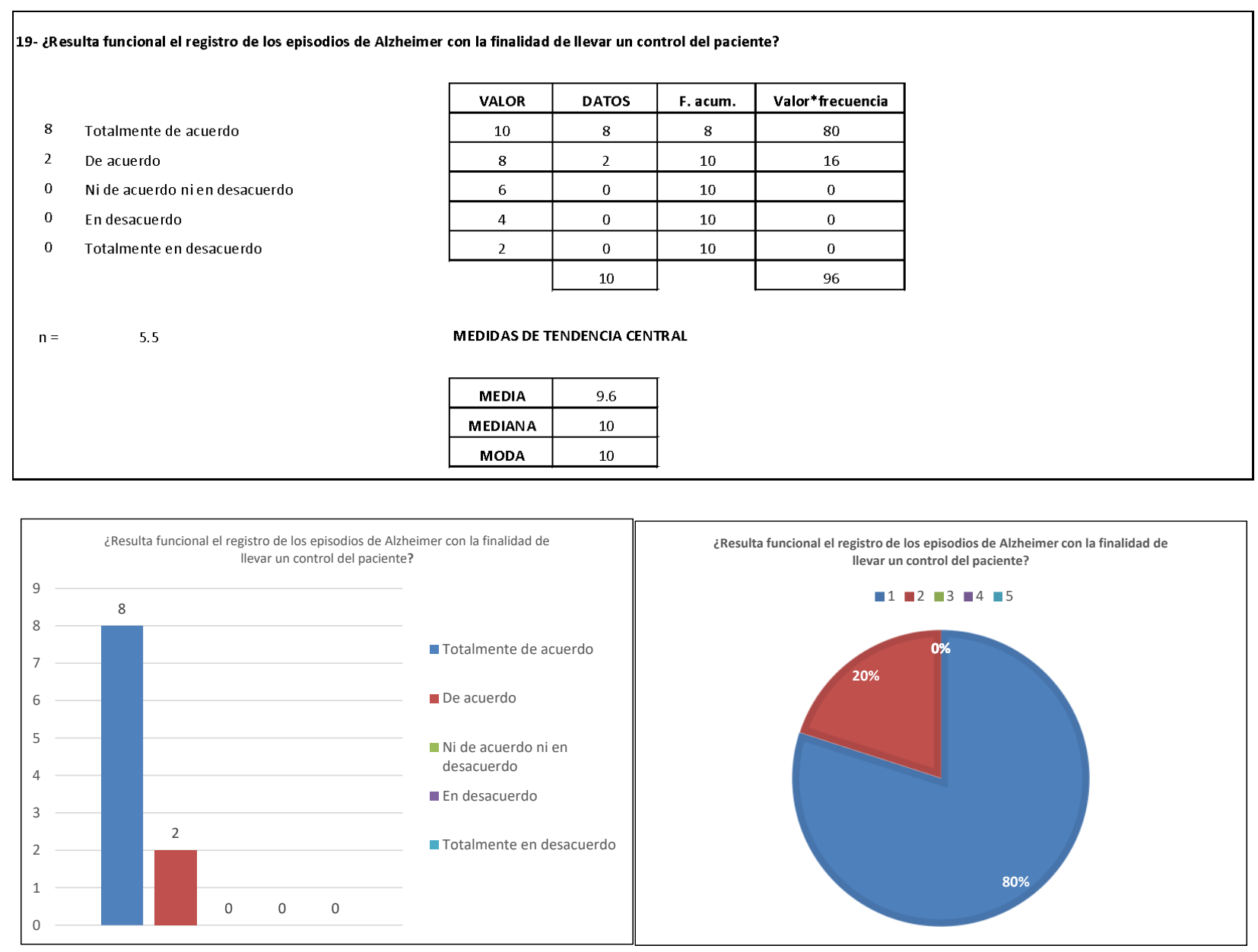

Partiendo de los datos obtenidos del instrumento de validación se muestra que 8 encuestados de los 10, indicaron que estaban totalmente de acuerdo, mientras que 2 indicaron de acuerdo, como consecuencia, las medidas de tendencia central se mantienen dentro del rango de 9.6 - 10 equivalentes a totalmente de acuerdo, lo que permite corroborar que el registro de los episodios de Alzheimer resulta funcional, con la finalidad de llevar un control del paciente. 

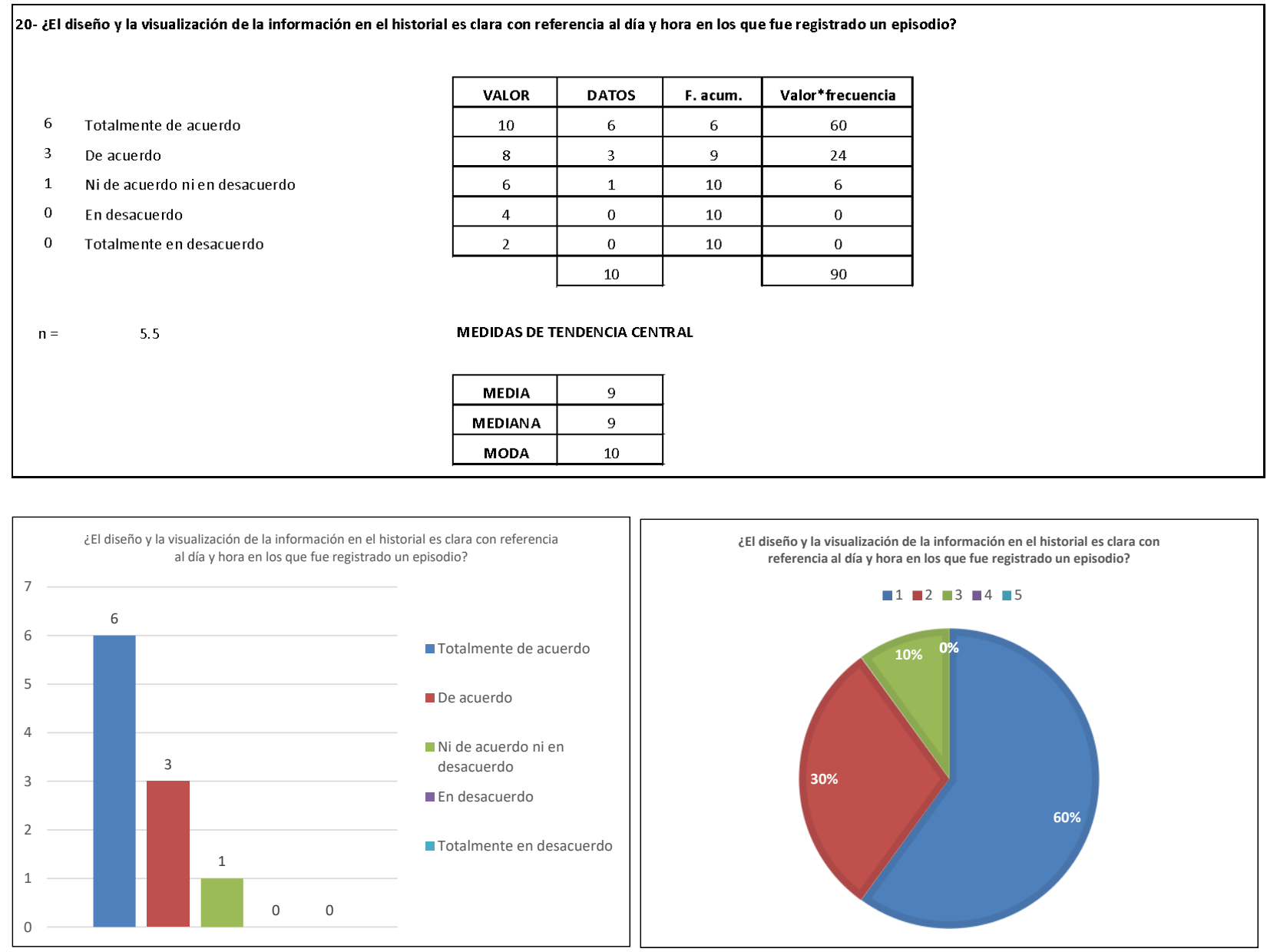

Haciendo referencia a la tabla de las medidas de tendencia central, obtenidas de acuerdo con la información poseyente de los encuestados en el instrumento de validación se puede observar que la media a esta cuestión corresponde al valor de 9.0. Lo anterior permite entrever que el diseño y la visualización de la información en el historial con referencia al día y hora en los que fue registrado un episodio resultaron claros. 

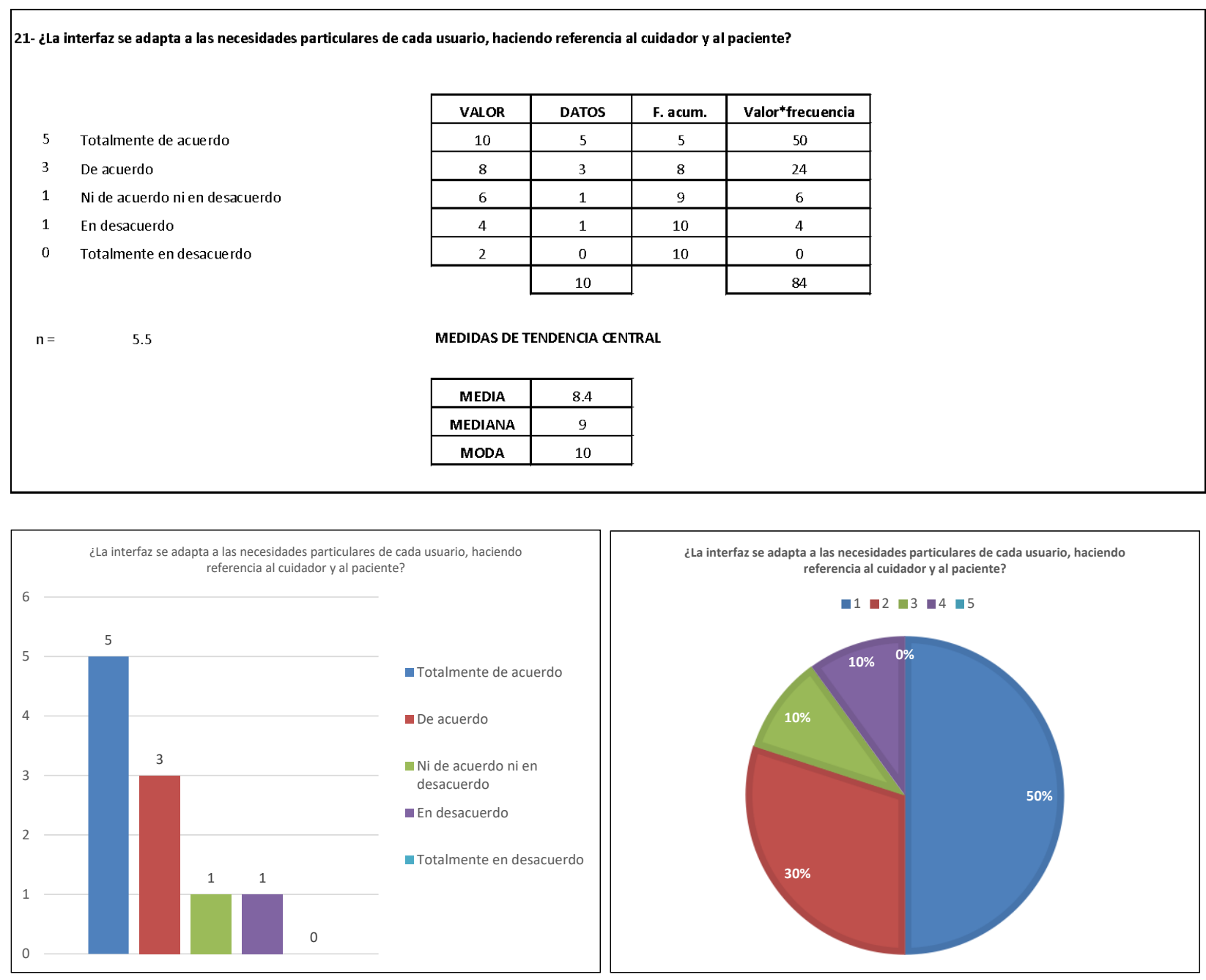

Con respecto a los datos obtenidos por parte de los encuestados se puede notar que la interfaz se adapta a las necesidades particulares de cada usuario, haciendo referencia al cuidador y al paciente, sin embargo, vale la pena mencionar que no se cubrió totalmente con este punto, debido a que, 5 encuestados contestaron totalmente de acuerdo, 3 que estaban de acuerdo, 1 estuvo $\mathrm{ni}$ de acuerdo ni en desacuerdo y finalmente 1 contestó que estaba en desacuerdo. Lo cual se convierte en un punto a mejorar en los posteriores diseños de interfaz gráfica. 

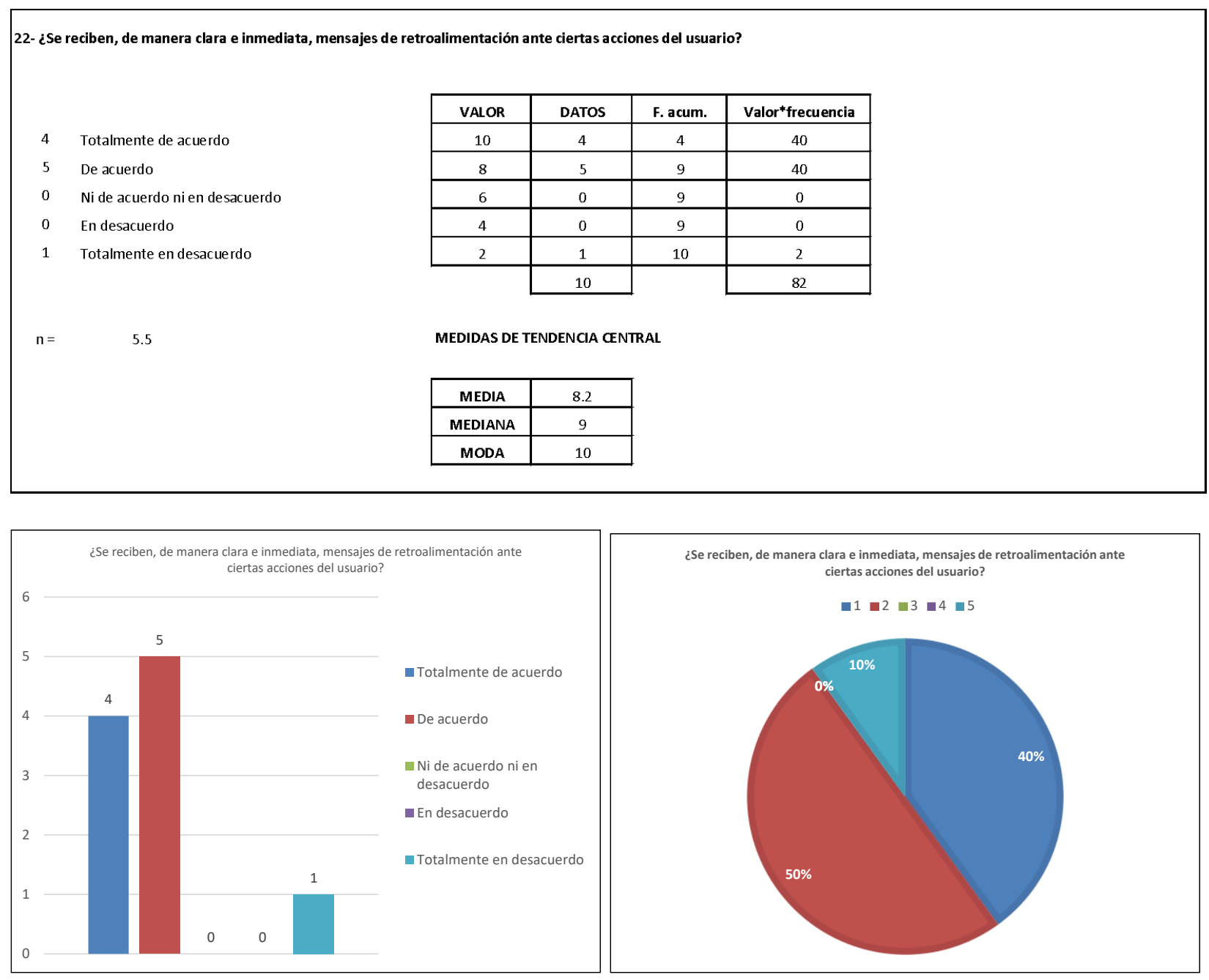

En cuanto a la última cuestión de la ronda 1, se puede aseverar que se obtuvieron respuestas parcialmente favorables con respecto a que se reciben de manera inmediata, mensajes de retroalimentación ante ciertas acciones del usuario, debido a que 4 de los 10 encuestados contestaron que estaban totalmente de acuerdo, 5 contestaron que estaban de acuerdo y 1 contestó que estaba totalmente en desacuerdo. Cabe mencionar que posiblemente las respuestas se vieron afectadas debido a que la muestra de la interfaz gráfica correspondió a un prototipo. 


\section{Ronda 2}




De acuerdo con la tabla y a las gráficas se puede verificar que 8 de los 10 expertos contestaron que estaban totalmente de acuerdo con la cuestión formulada, mientras que 2 encuestados contestaron que estaban de acuerdo, lo que confirma que la interfaz gráfica corresponde a una App que aborda temas médicos. 


\begin{tabular}{|c|c|c|c|c|c|}
\hline \multicolumn{6}{|c|}{ 5- ¿La interfaz gráfica está dirigida principalmente a cuidadores de pacientes con Alzheimer? } \\
\hline & \multirow{6}{*}{$\begin{array}{l}\text { Totalmente de acuerdo } \\
\text { De acuerdo } \\
\text { Ni de acuerdo ni en desacuerdo } \\
\text { En desacuerdo } \\
\text { Totalmente en desacuerdo }\end{array}$} & \multirow{2}{*}{\begin{tabular}{|c|} 
VALOR \\
10 \\
\end{tabular}} & \multirow{2}{*}{$\begin{array}{c}\text { DATOS } \\
10 \\
\end{array}$} & \multirow{2}{*}{$\begin{array}{c}\text { F. acum. } \\
10 \\
\end{array}$} & \multirow{2}{*}{$\begin{array}{c}\text { Valor*frecuencia } \\
100 \\
\end{array}$} \\
\hline & & & & & \\
\hline & & 8 & 0 & 10 & 0 \\
\hline & & 6 & 0 & 10 & 0 \\
\hline & & 4 & 0 & 10 & 0 \\
\hline & & 2 & 0 & 10 & 0 \\
\hline & & & 10 & & 100 \\
\hline \multirow[t]{4}{*}{$\mathrm{n}=$} & \multirow[t]{4}{*}{5.5} & \multicolumn{4}{|c|}{ MEDIDAS DE TENDENCIA CENTRAL } \\
\hline & & MEDIA & 10 & & \\
\hline & & MEDIANA & 10 & & \\
\hline & & MODA & 10 & & \\
\hline
\end{tabular}


Haciendo referencia a la tabla de las medidas de tendencia central, obtenidas de acuerdo con la información poseyente de los encuestados en el instrumento de validación se puede observar que la media a esta cuestión corresponde a un valor de 10. Lo anterior permite corroborar que los expertos están totalmente de acuerdo en que la interfaz gráfica está dirigida principalmente a cuidadores de pacientes con Alzheimer. 

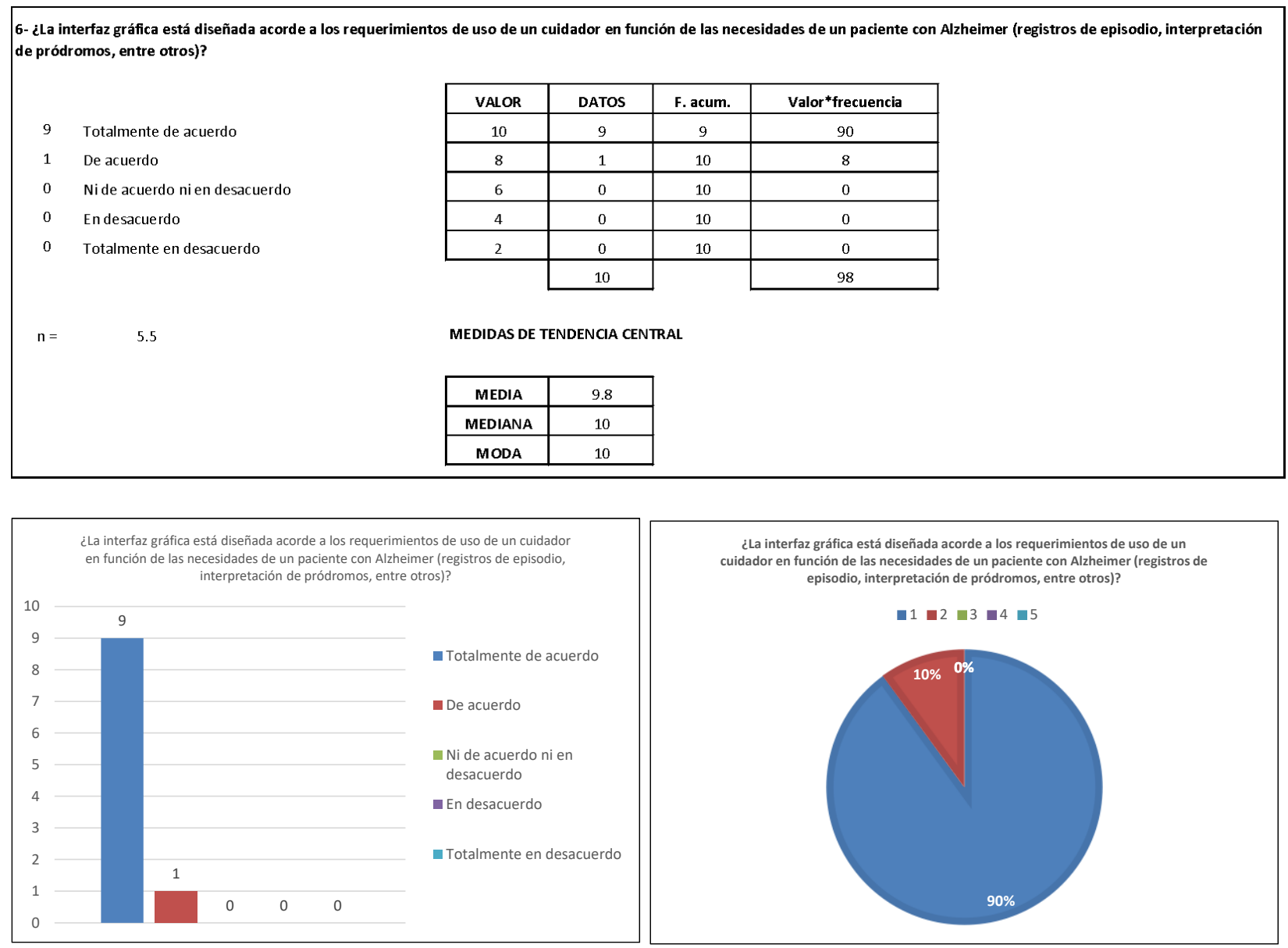

Partiendo de los resultados obtenidos por los 10 encuestados, se obtuvo que 9 de estos contestaron totalmente de acuerdo y 1 de acuerdo. Lo cual permite obtener una media de 9.8 lo que equivale a un valor que entra en: totalmente de acuerdo, por ende, se puede decir que la interfaz gráfica está diseñada acorde a los requerimientos de uso de un cuidador en función de las necesidades de un paciente con Alzheimer -registros de episodios, interpretación de pródromos, entre otros-. 


\begin{tabular}{|c|c|c|c|c|c|}
\hline \multicolumn{6}{|c|}{ 7- ¿La app podria ser funcional para el médico tratante del paciente con Alzheimer? } \\
\hline \multirow{6}{*}{$\begin{array}{l}9 \\
1 \\
0 \\
0 \\
0\end{array}$} & \multirow{6}{*}{$\begin{array}{l}\text { Totalmente de acuerdo } \\
\text { De acuerdo } \\
\text { Ni de acuerdo ni en desacuerdo } \\
\text { En desacuerdo } \\
\text { Totalmente en desacuerdo }\end{array}$} & \multirow{2}{*}{\begin{tabular}{|c|} 
VALOR \\
10 \\
\end{tabular}} & \multirow{2}{*}{$\begin{array}{c}\text { DATOS } \\
9 \\
\end{array}$} & \multirow{2}{*}{$\begin{array}{c}\text { F. acum. } \\
9 \\
\end{array}$} & \multirow{2}{*}{$\begin{array}{c}\text { Valor }{ }^{*} \text { frecuencia } \\
90 \\
\end{array}$} \\
\hline & & & & & \\
\hline & & 8 & 1 & 10 & 8 \\
\hline & & 6 & 0 & 10 & 0 \\
\hline & & 4 & 0 & 10 & 0 \\
\hline & & 2 & 0 & 10 & 0 \\
\hline & & & 10 & & 98 \\
\hline \multirow[t]{4}{*}{$n=$} & \multirow[t]{4}{*}{5.5} & \multicolumn{4}{|c|}{ MEDIDAS DE TENDENCIA CENTRAL } \\
\hline & & MEDIA & 9.8 & & \\
\hline & & MEDIANA & 10 & & \\
\hline & & MODA & 10 & & \\
\hline
\end{tabular}
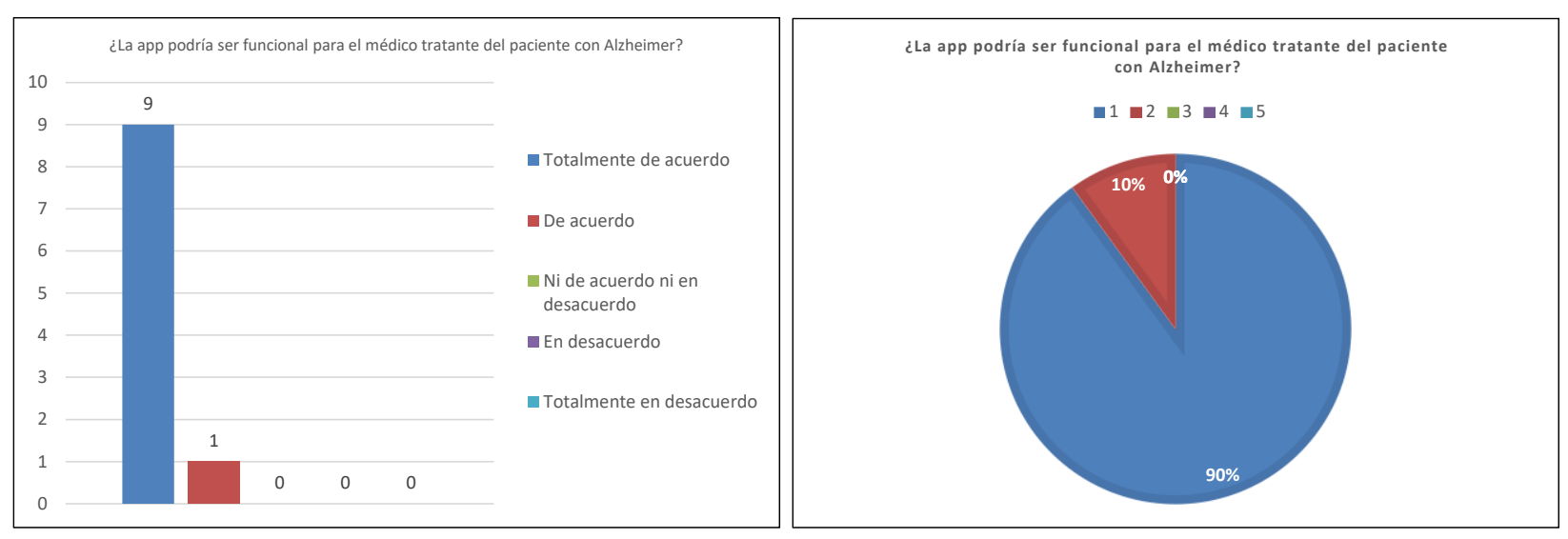

Se puede aseverar que se obtuvieron respuestas favorables con respecto a que la App podría ser funcional para el médico tratante del paciente con Alzheimer, debido a que 9 de los 10 encuestados contestaron que estaban totalmente de acuerdo, mientras que 1 contestó que estaba de acuerdo. 


\begin{tabular}{|c|c|c|c|c|c|}
\hline \multicolumn{6}{|c|}{$\begin{array}{l}\text { 8- ¿Cuándo el usuario selecciona un indicador (oxigenaciór } \\
\text { proporciona la información inmediata referente a este? }\end{array}$} \\
\hline \multirow[b]{2}{*}{10} & \multirow[b]{2}{*}{ Totalmente de acuerdo } & VALOR & DATOS & F. acum. & Valor*frecuencia \\
\hline & & 10 & 10 & 10 & 100 \\
\hline 0 & De acuerdo & 8 & 0 & 10 & 0 \\
\hline 0 & Ni de acuerdo ni en desacuerdo & 6 & 0 & 10 & 0 \\
\hline 0 & En desacuerdo & 4 & 0 & 10 & 0 \\
\hline 0 & Totalmente en desacuerdo & 2 & 0 & 10 & 0 \\
\hline & & & 10 & & 100 \\
\hline \multirow[t]{4}{*}{$\mathrm{n}=$} & \multirow[t]{4}{*}{5.5} & \multicolumn{4}{|c|}{ MEDIDAS DE TENDENCIA CENTRAL } \\
\hline & & MEDIA & 10 & & \\
\hline & & MEDIANA & 10 & & \\
\hline & & MODA & 10 & & \\
\hline
\end{tabular}
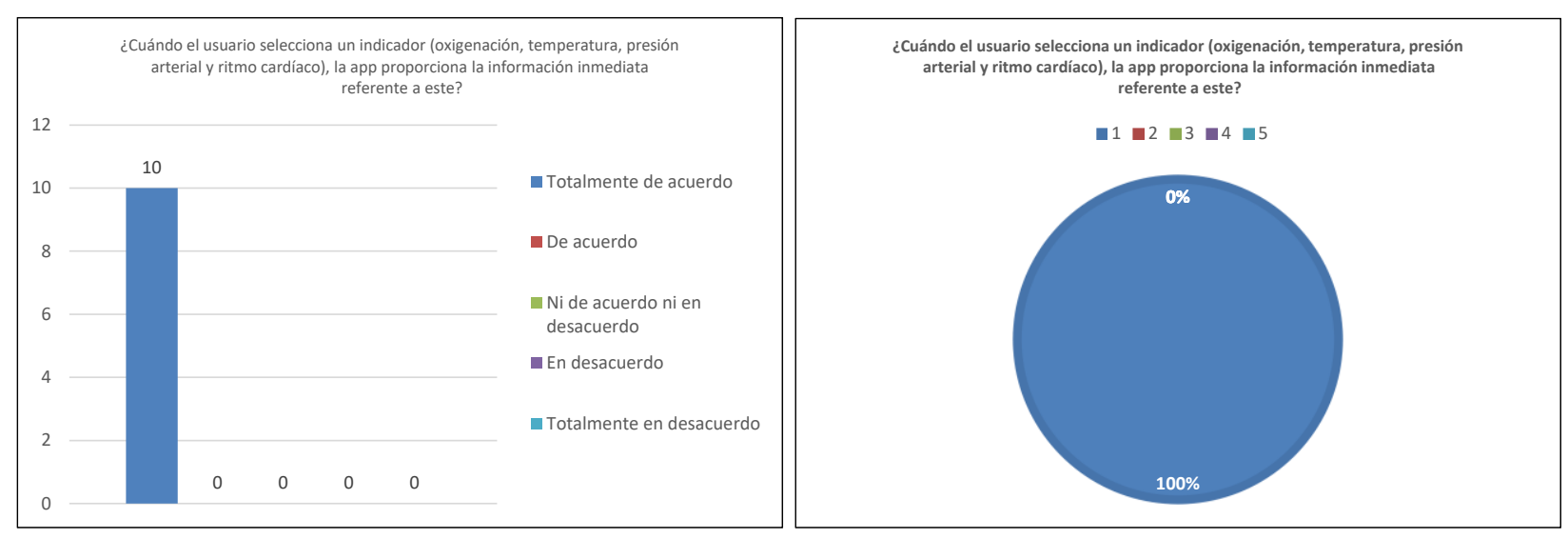

De acuerdo con las medidas de tendencia central obtenidas de esta cuestión, todas las respuestas de los encuestados se encuentran dentro del valor 10 , equivalente a totalmente de acuerdo, lo cual permite corroborar que cuando el usuario selecciona un indicador -oxigenación, temperatura, presión arterial y ritmo cardíaco- la App proporciona la información inmediata referente a este. 



Con base en la tabla de las medidas de tendencia central, obtenidas de acuerdo a la información poseyente de los encuestados en el instrumento de validación se puede observar que la media a esta cuestión corresponde a 10 lo cual entra en la tabla de valor: totalmente de acuerdo. Lo anterior permite comprobar que la información que proporciona cada apartado resulta acorde a la información esperada. 


\section{CURRICULUM VITAE}

\section{Mónica Yazmín López López}

Diseñadora de la Comunicación Gráfica, egresada de la Universidad Autónoma Metropolitana Unidad Azcapotzalco generación 2011-2016. Profesora del Departamento de Procesos y Técnicas de Realización, en la Licenciatura de Diseño de la Comunicación Gráfica y en el Tronco General de Asignaturas de la División de Ciencias y Artes para el Diseño. Miembro del Área de Investigación de Nuevas Tecnologías, perteneciente a la misma Institución. Ha participado en diversos congresos nacionales e internacionales dictando conferencias, así mismo, ha publicado en memorias de eventos y en revistas en torno al diseño, la educación, el diseño inclusivo y la gamificación.

Además, ha realizado diversos proyectos profesionales en la empresa AVF y de manera freelance, realizando actividades tales como lo son el diseño de interfaces gráficas y el desarrollo de serious games y App multiplataforma, sitios Web, diseño corporativo, diseño de señalética, entre otras actividades relacionadas con el diseño de la comunicación gráfica, para marcas reconocidas. 


\section{Prototipo CENTINEL App}

https://germonkeys.invisionapp.com/console/share/2H272UNIPQ/479111631

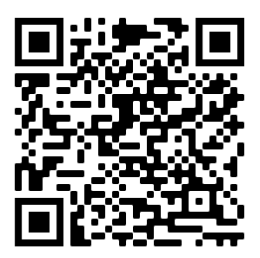

Video explicativo de CENTINEL App https://youtu.be/q7J4JKXA7WY

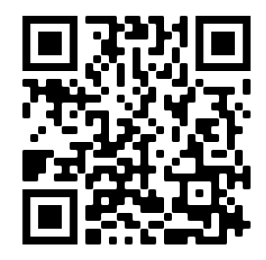

